\title{
Palladium-Catalyzed Aryl-Furanylation of Alkenes: Synthesis of Benzofuran-Containing 3,3-Disubstituted Oxindoles
}

\author{
Hongbo Qi, Kaiming Han, Shufeng Chen* \\ Inner Mongolia Key Laboratory of Fine Organic Synthesis, Department of Chemistry \\ and Chemical Engineering, Inner Mongolia University, Hohhot 010021, China \\ E-mail: shufengchen@imu.edu.cn
}

\section{CONTENTS}

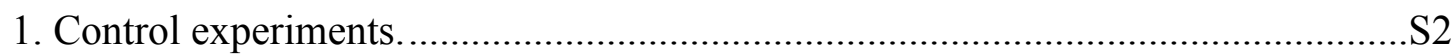

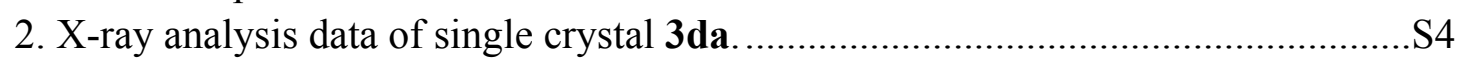

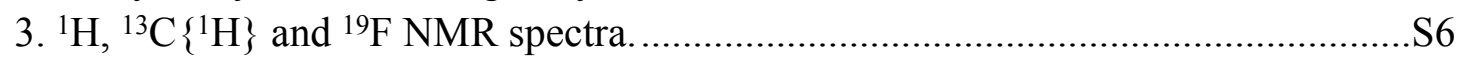




\section{Control Experiments.}

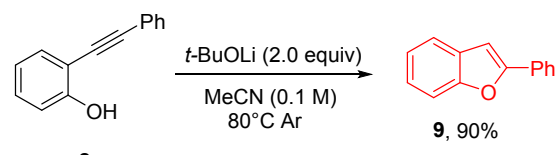

\section{Scheme S1}

A sealed tube was charged with $o$-alkynylphenol 2 a $(0.24 \mathrm{mmol}, 46.8 \mathrm{mg}), t$ BuOLi $(0.48 \mathrm{mmol}, 76.8 \mathrm{mg})$ in $\mathrm{MeCN}(2.4 \mathrm{~mL})$. Under an argon atmosphere, the reaction mixture was stirred at $80{ }^{\circ} \mathrm{C}$ for $8 \mathrm{~h}$. After cooling to room temperature, the reaction mixture was concentrated. The residue was purified by flash chromatography on silica gel to afford the corresponding product 9 in $90 \%$ yield $(42.2 \mathrm{mg})$ (Scheme S1).

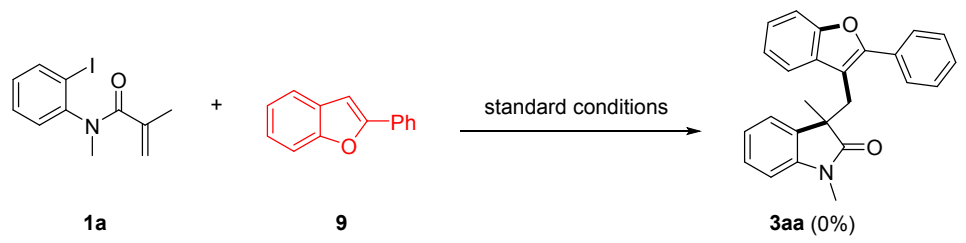

Scheme S2

A sealed tube was charged with 1 a $(0.1 \mathrm{mmol}, 1.0$ equiv. $)$, furan $9(0.15 \mathrm{mmol}$, 1.5 equiv.), $\mathrm{Pd}\left(\mathrm{PPh}_{3}\right)_{4}(5.78 \mathrm{mg}, 5.0 \mathrm{~mol} \%), t$-BuOLi (16.0 mg, $\left.0.2 \mathrm{mmol}\right)$ in $\mathrm{MeCN}$ $(1.0 \mathrm{~mL})$. Under an argon atmosphere, the reaction mixture was stirred at $80{ }^{\circ} \mathrm{C}$ for 10 h. After cooling to room temperature, the reaction mixture was monitored, and no corresponding product 3aa was obtained (Scheme S2).

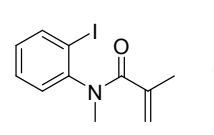

1a

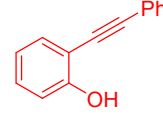

2a
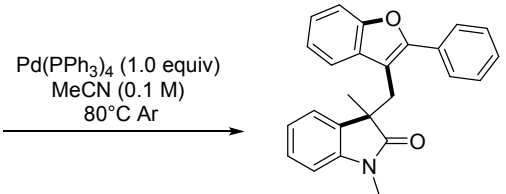

3aa $(83 \%)$

Scheme S3

A sealed tube was charged with $\mathbf{1 a}(0.1 \mathrm{mmol}, 1.0$ equiv. $), o$-alkynylphenols $\mathbf{2 a}$ (0.15 mmol, 1.5 equiv.), $\mathrm{Pd}\left(\mathrm{PPh}_{3}\right)_{4}(115.5 \mathrm{mg}, 1$ equiv.) in $\mathrm{MeCN}(1.0 \mathrm{~mL})$. Under an argon atmosphere, the reaction mixture was stirred at $80{ }^{\circ} \mathrm{C}$ in an oil bath for $10 \mathrm{~h}$. After cooling at room temperature, the mixture was concentrated under reduced pressure. The residue was purified by silica gel chromatography to afford the product $\mathbf{3 a a}$ in $83 \%$ 
yield (30.5 mg) (Scheme S3).

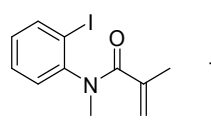

$1 \mathrm{a}$

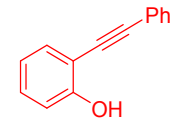

2a standard conditions TEMPO (1.0 equiv.)
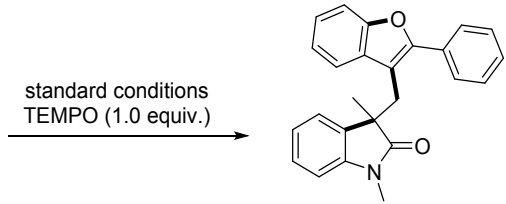

3aa (93\%)

\section{Scheme S4}

A sealed tube was charged with 19 ( $0.1 \mathrm{mmol}, 1.0$ equiv. $), o$-alkynylphenols $\mathbf{2 a}$ (0.15 mmol, 1.5 equiv.), $\mathrm{Pd}\left(\mathrm{PPh}_{3}\right)_{4}(115.5 \mathrm{mg}, 1.0$ equiv.), $t$-BuOLi (16.0 mg, 0.2 mmol), TEMPO(15.6 mg, 1 equiv.) in MeCN (1.0 mL). Under an argon atmosphere, the reaction mixture was stirred at $80{ }^{\circ} \mathrm{C}$ for $10 \mathrm{~h}$. After cooling at room temperature, the mixture was concentrated under reduced pressure. The residue was purified by silica gel chromatography to afford the product $3 \mathbf{a a}$ in $93 \%$ yield $(341 \mathrm{mg})$ (Scheme S4).

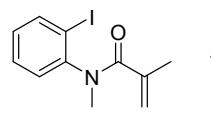

$1 a$

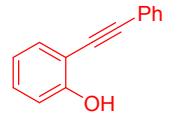

2a

\section{standard conditions BHT (1.0 equiv.)}
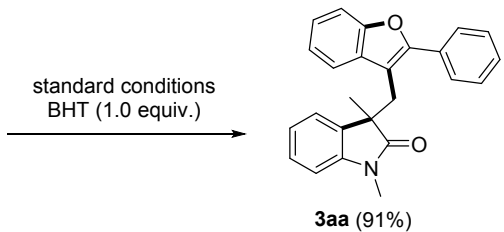

Scheme S5

A sealed tube was charged with $\mathbf{1 a}(0.1 \mathrm{mmol}, 1.0$ equiv. $), o$-alkynylphenol $\mathbf{2 a}$ (0.15 mmol, 1.5 equiv.), $\mathrm{Pd}\left(\mathrm{PPh}_{3}\right)_{4}(115.5 \mathrm{mg}, 1$ equiv.), $t$-BuOLi (16.0 mg, $0.2 \mathrm{mmol})$, BHT(15.6 mg, 1 equiv.) in $\mathrm{MeCN}(1.0 \mathrm{~mL})$. Under an argon atmosphere, the reaction mixture was stirred at $80{ }^{\circ} \mathrm{C}$ for $10 \mathrm{~h}$. After cooling at room temperature, the mixture was concentrated under reduced pressure. The residue was purified by silica gel chromatography to afford the product 3aa in 91\% yield (33 mg) (Scheme S5). 


\section{X-ray analysis data of single crystal 3da.}

The crystal of product 3da was obtained by slow evaporation in $n$-hexane and dichloromethane. The single crystal X-ray analysis determined the structure of product 3da as expected (Figure S1).
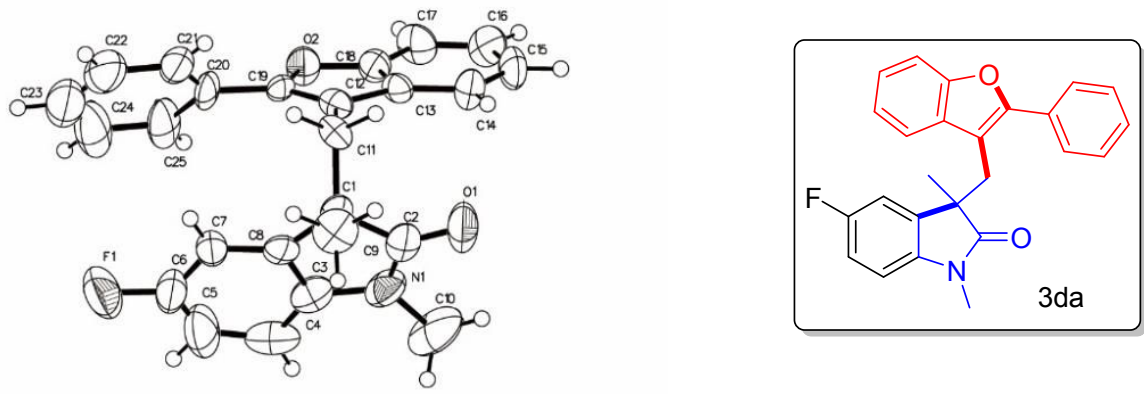

Figure S1. X-ray structure of product 3da

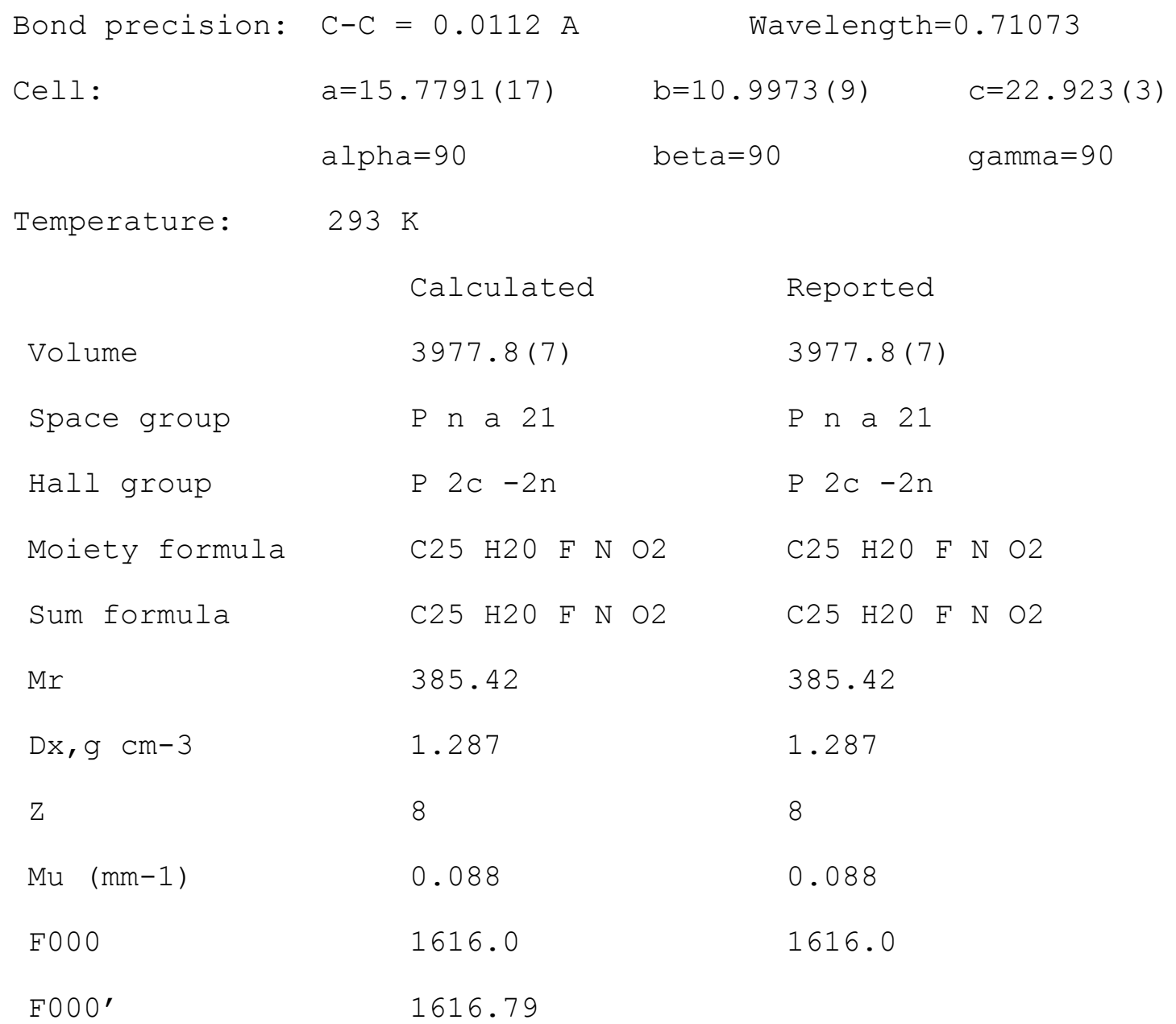




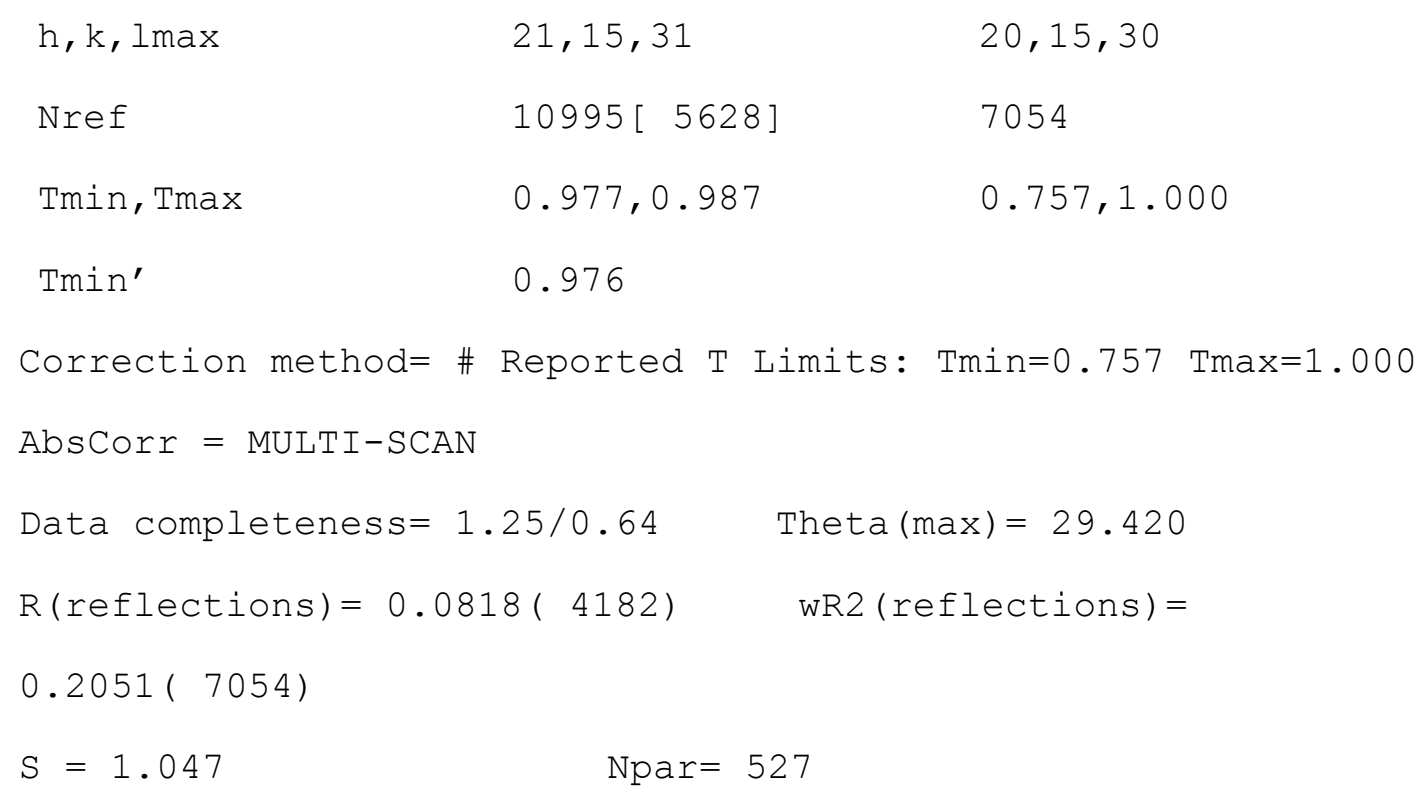




\section{3. ${ }^{1} \mathrm{H},{ }^{13} \mathrm{C}\left\{{ }^{1} \mathrm{H}\right\}$ and ${ }^{19} \mathrm{~F}$ NMR spectra.}

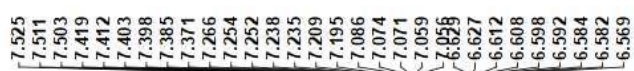

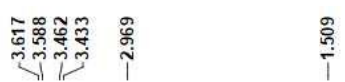
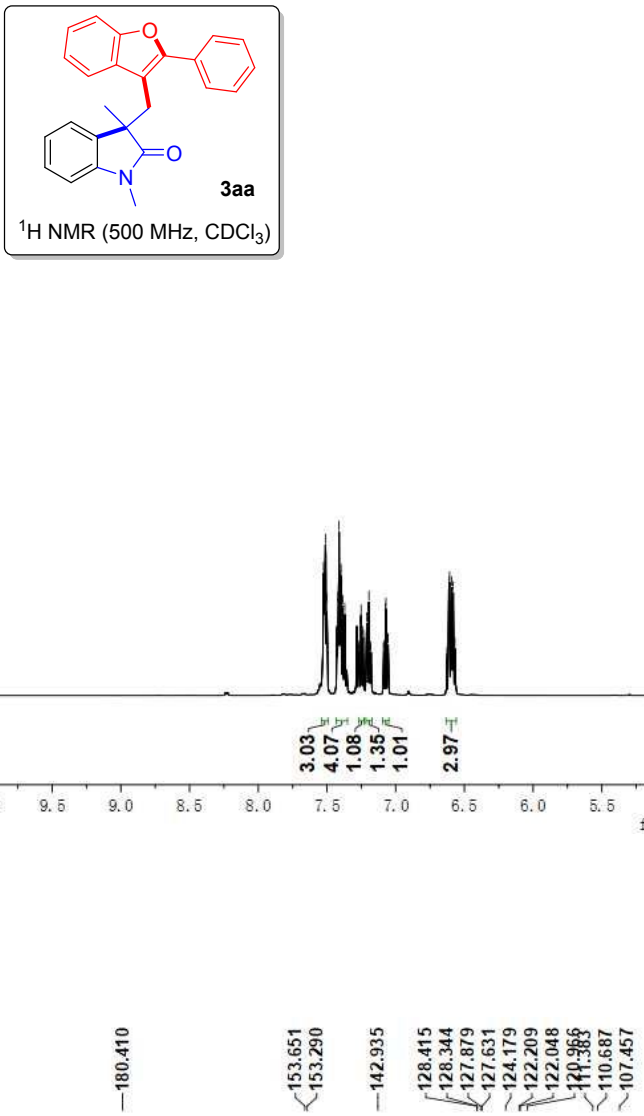

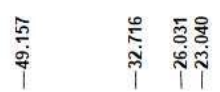
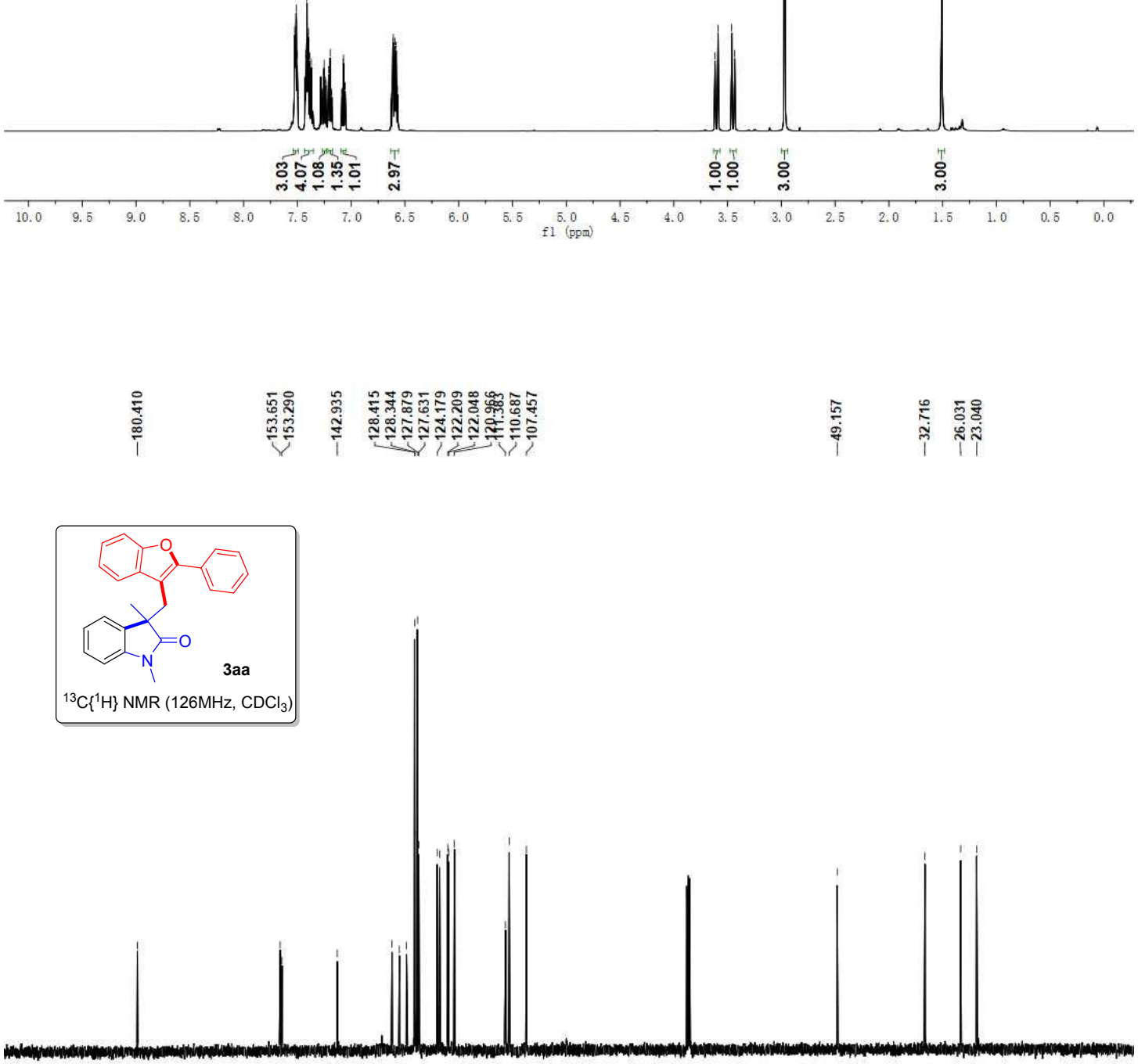

${ }_{200}^{1} \quad 190 \quad 180 \quad 170$ $10 \stackrel{100}{f 1}(\mathrm{pgm})$ 


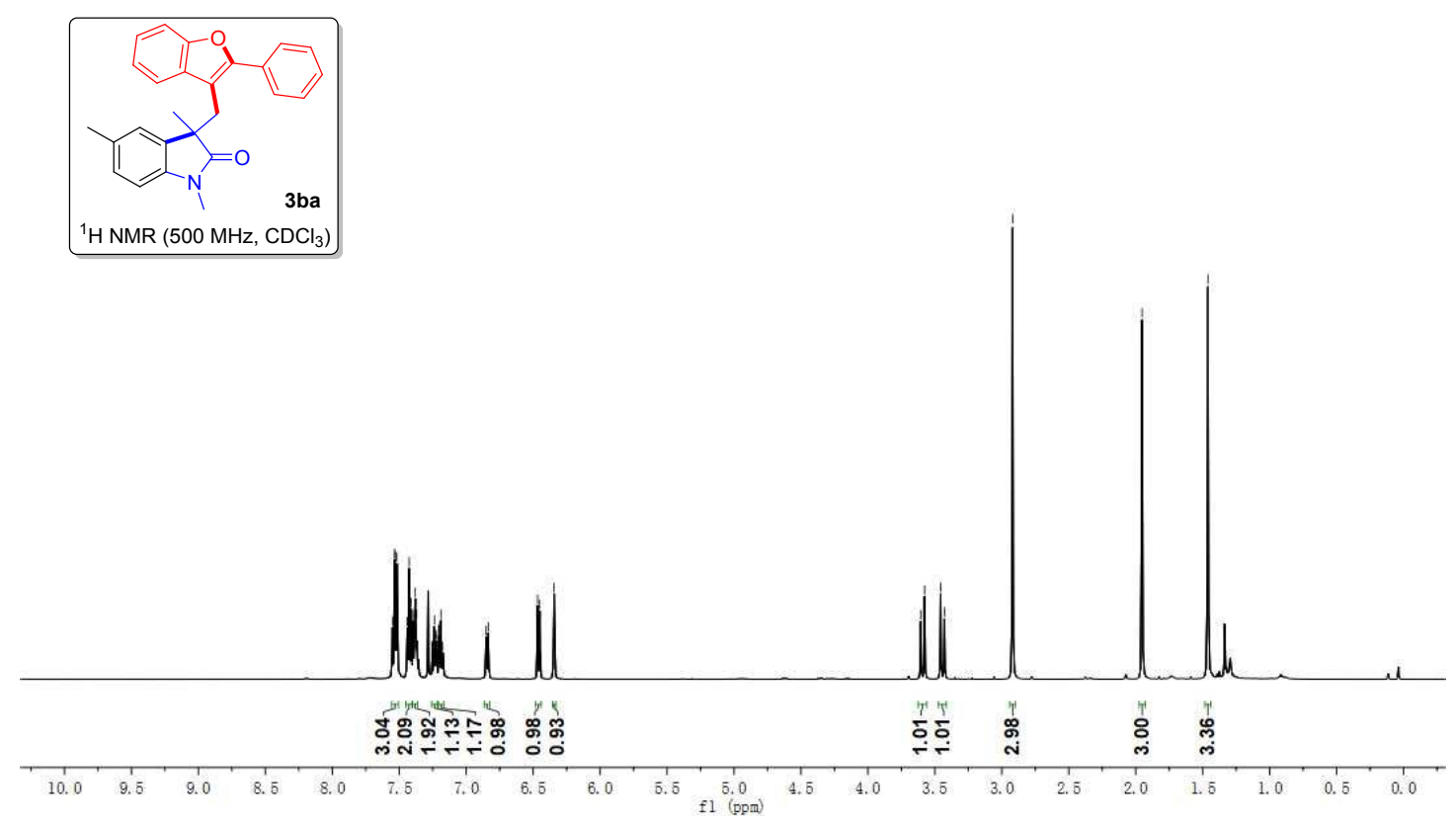

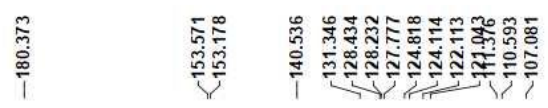

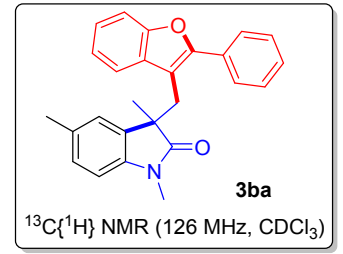

${ }^{13} \mathrm{C}\left\{{ }^{1} \mathrm{H}\right\} \mathrm{NMR}\left(126 \mathrm{MHz}, \mathrm{CDCl}_{3}\right)$

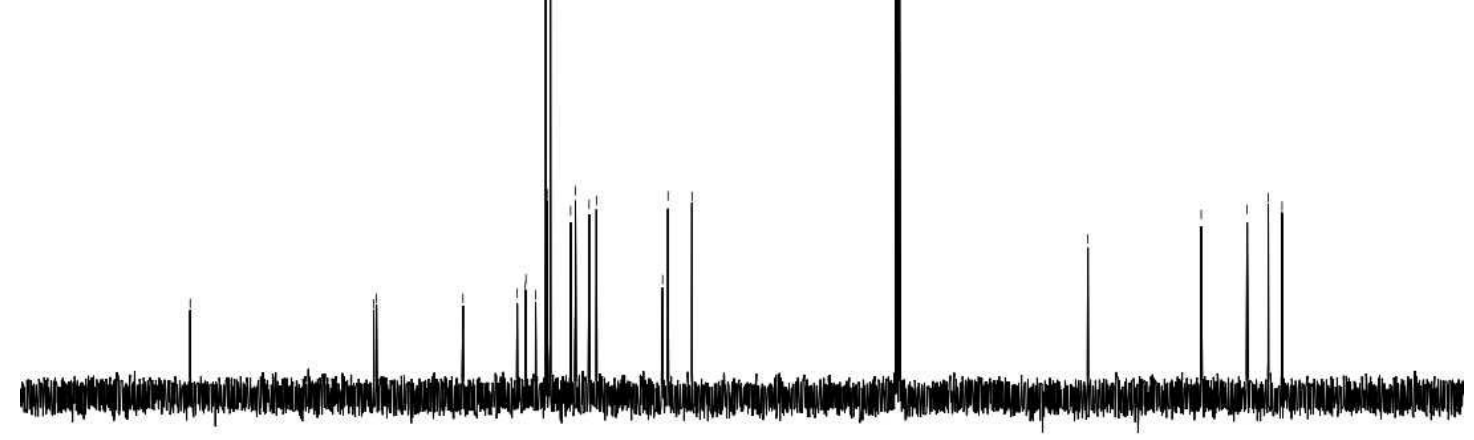

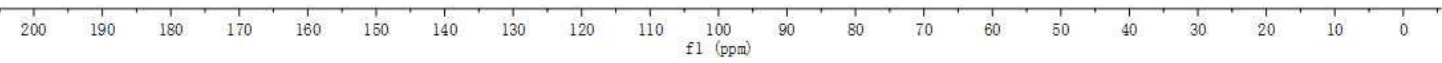



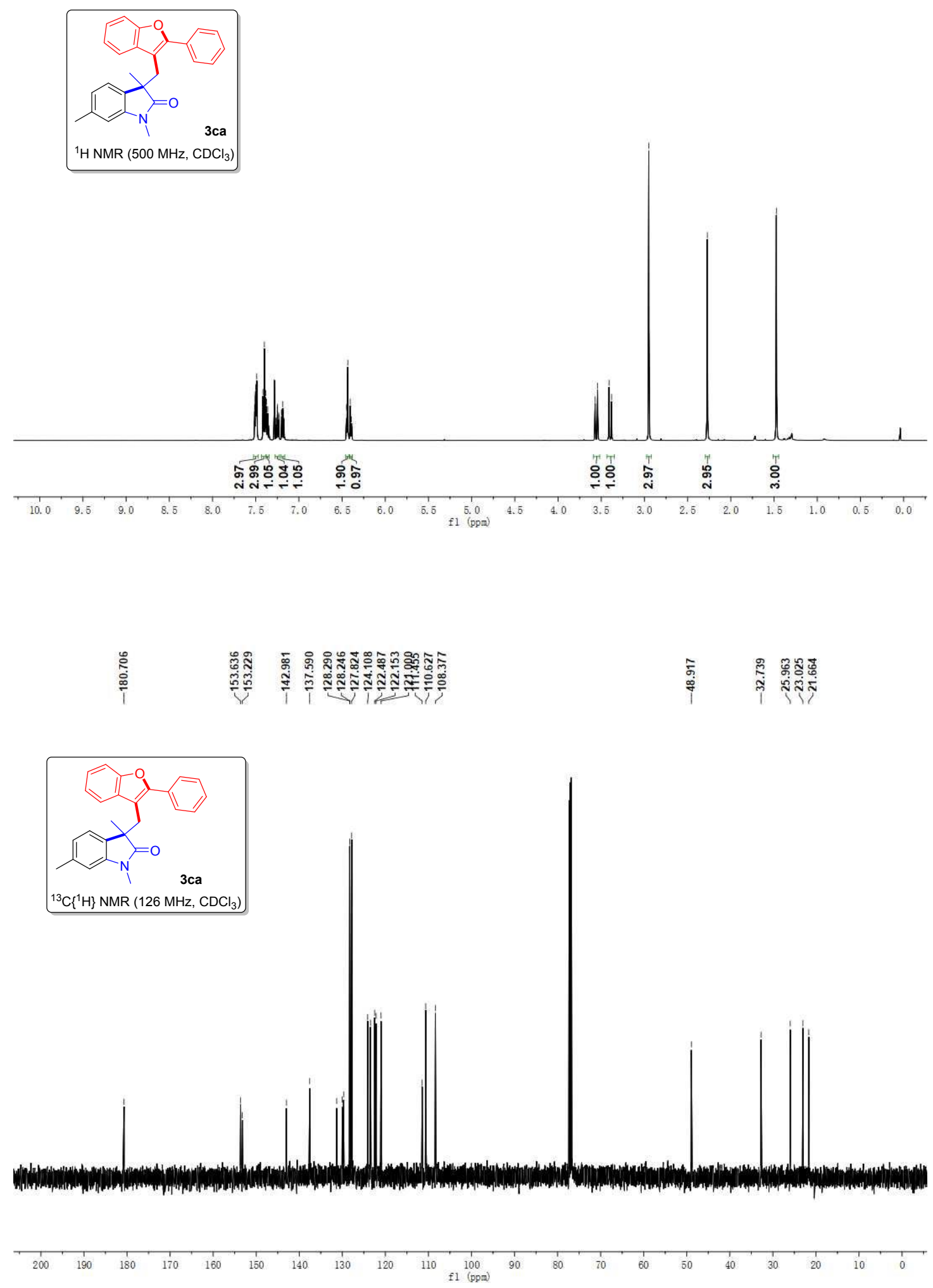

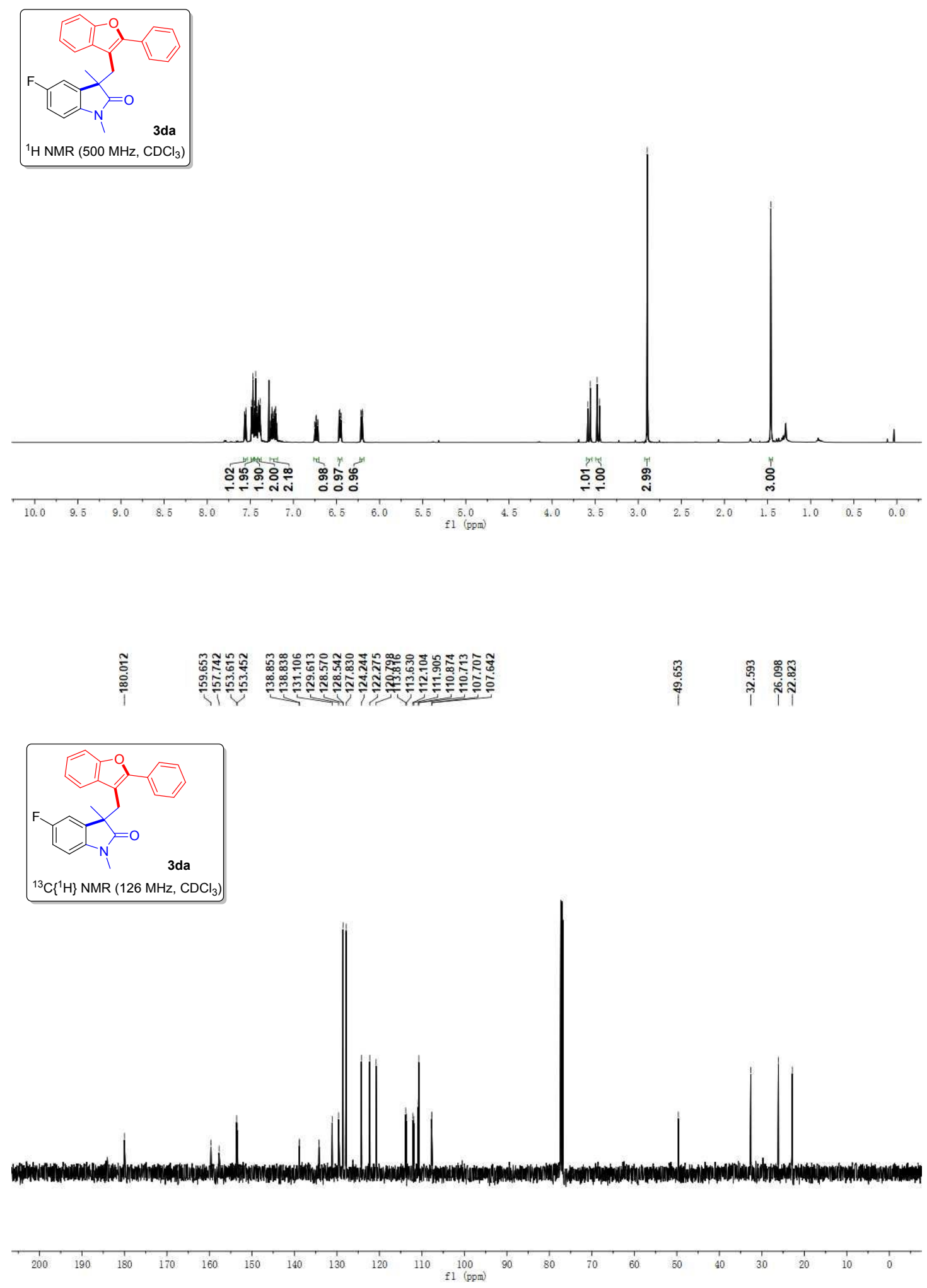

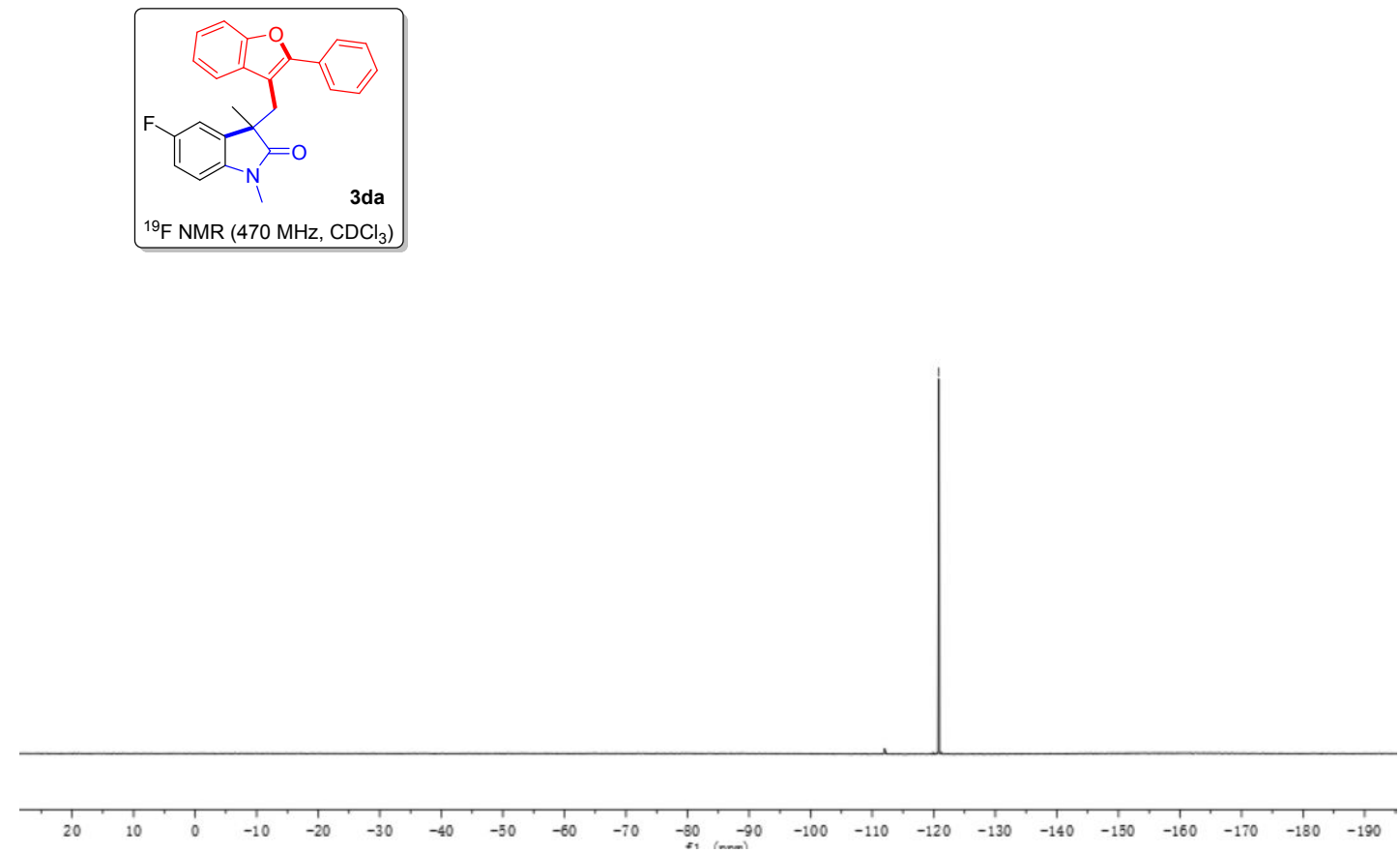

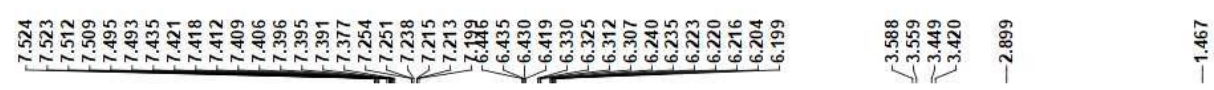
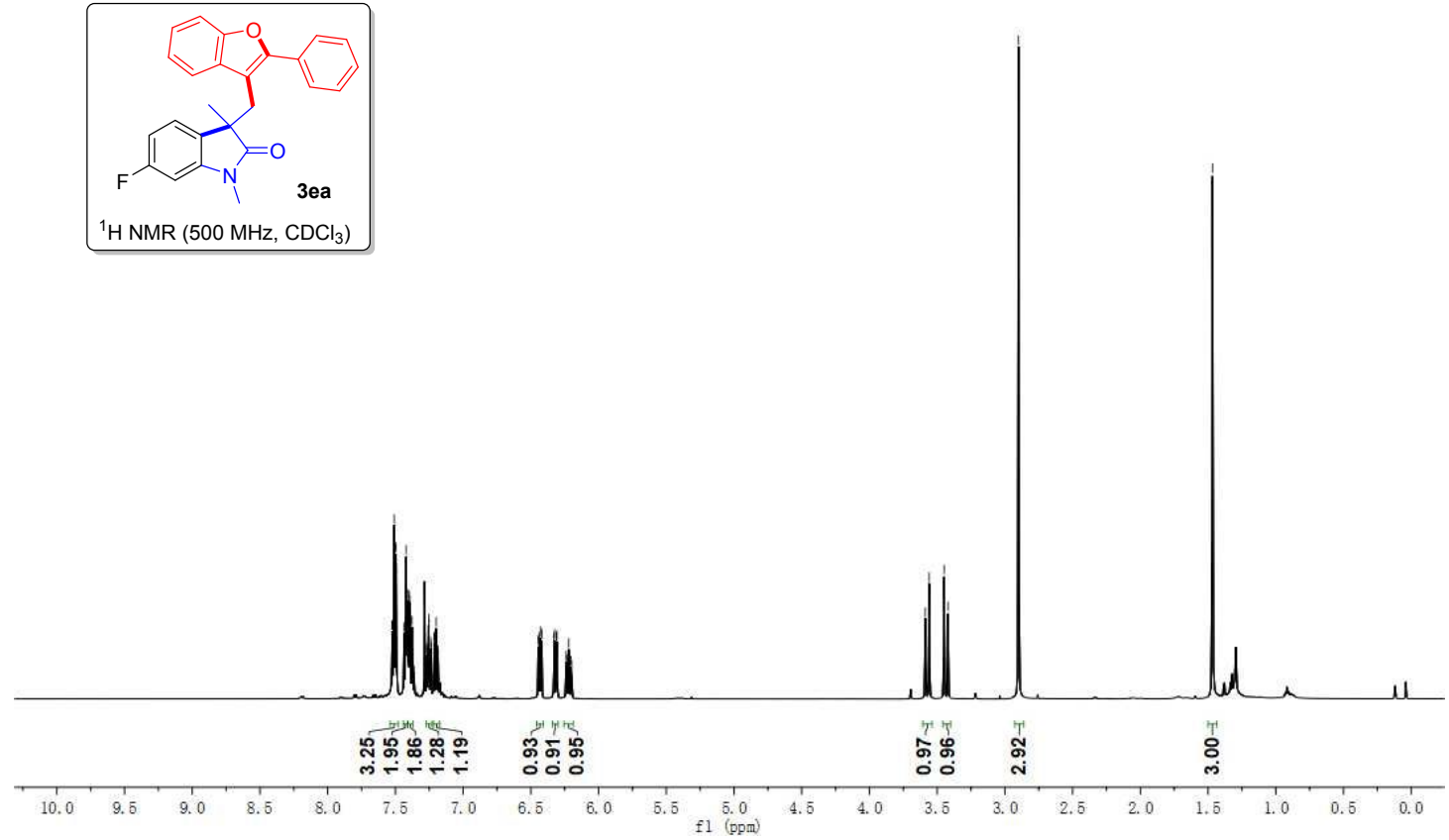

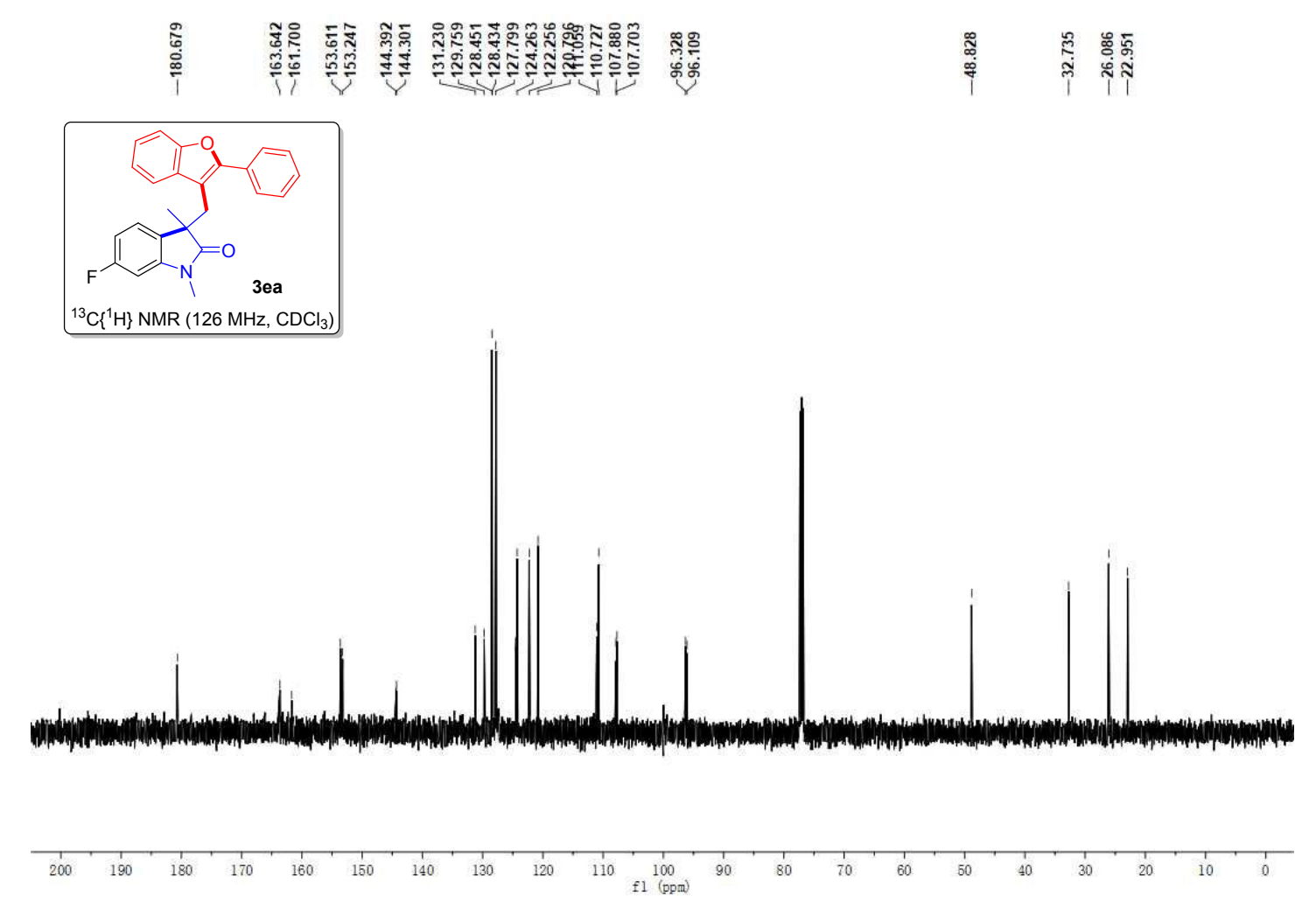

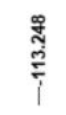
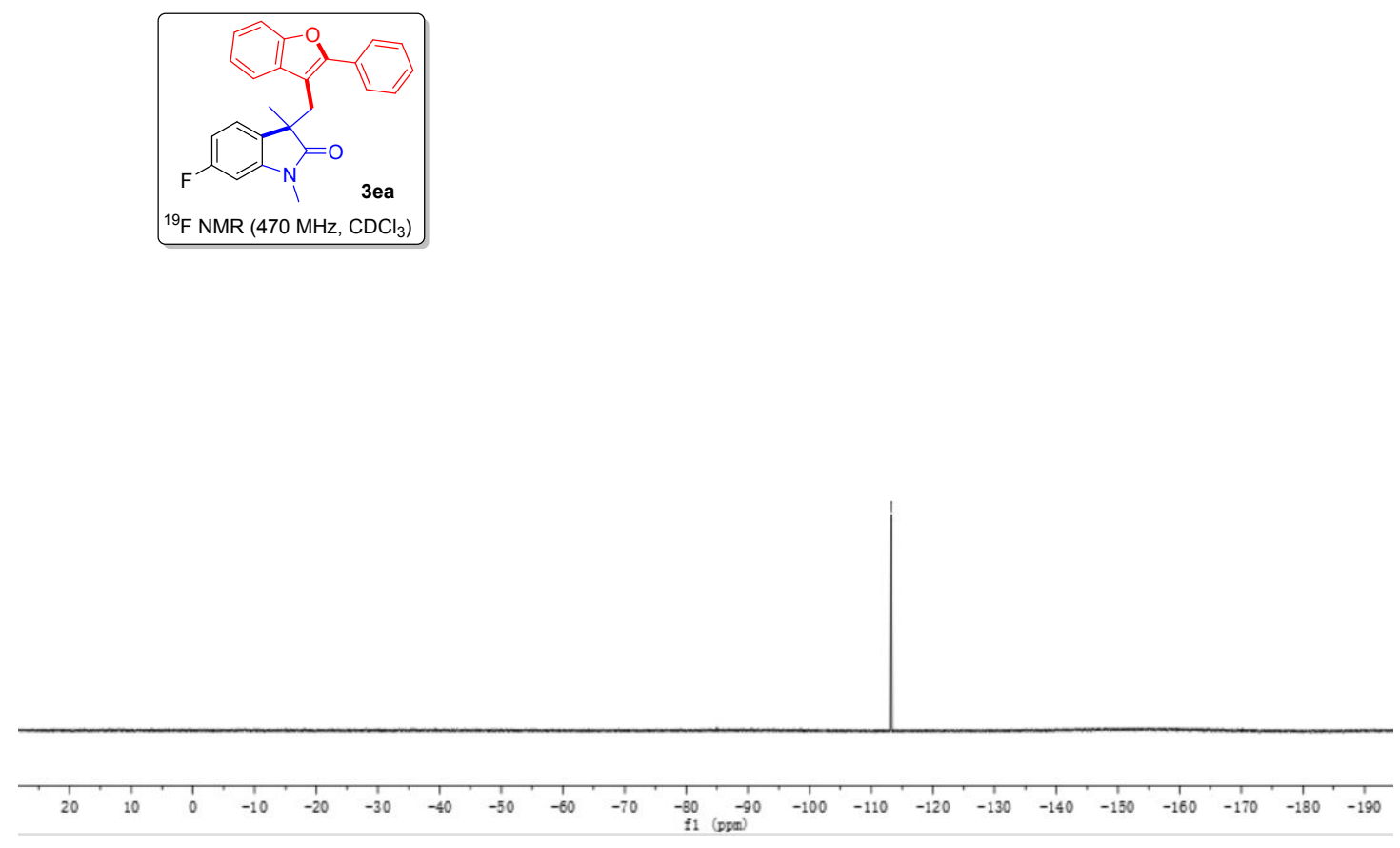


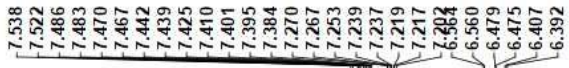

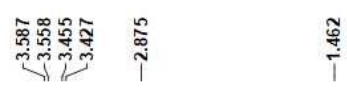
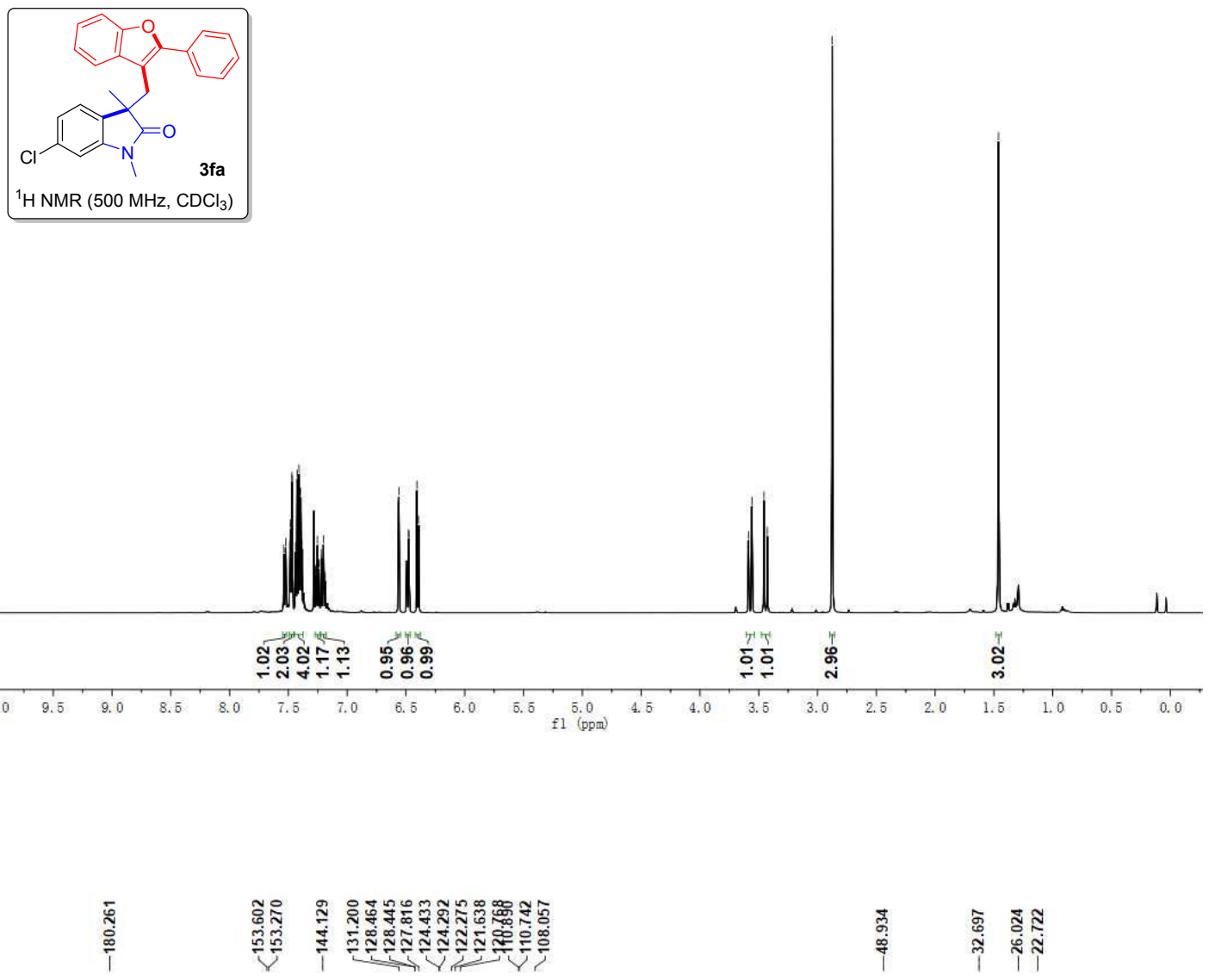

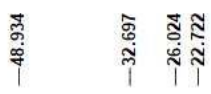
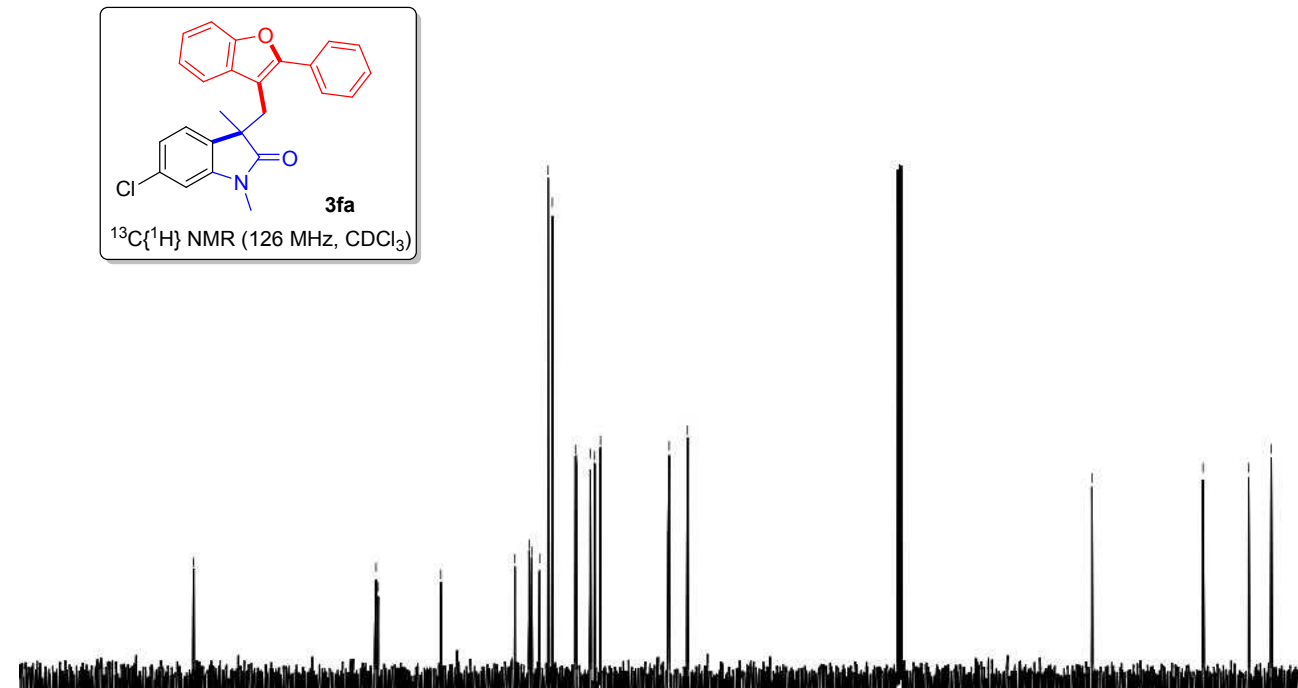

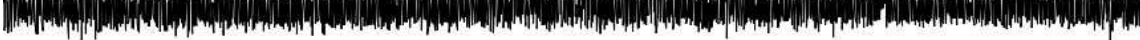

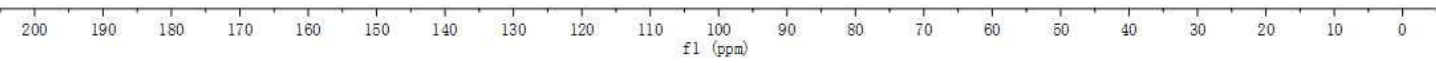



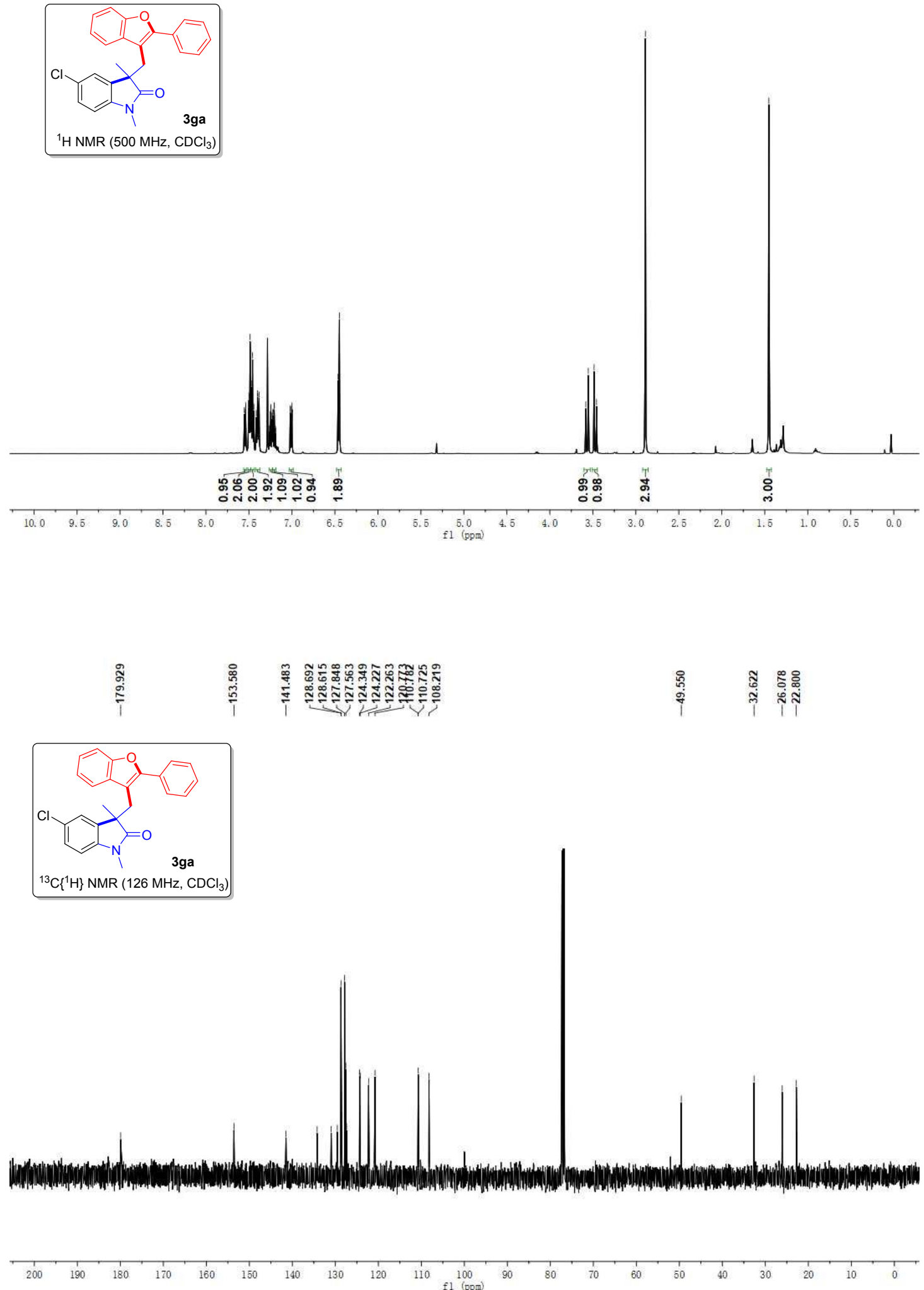

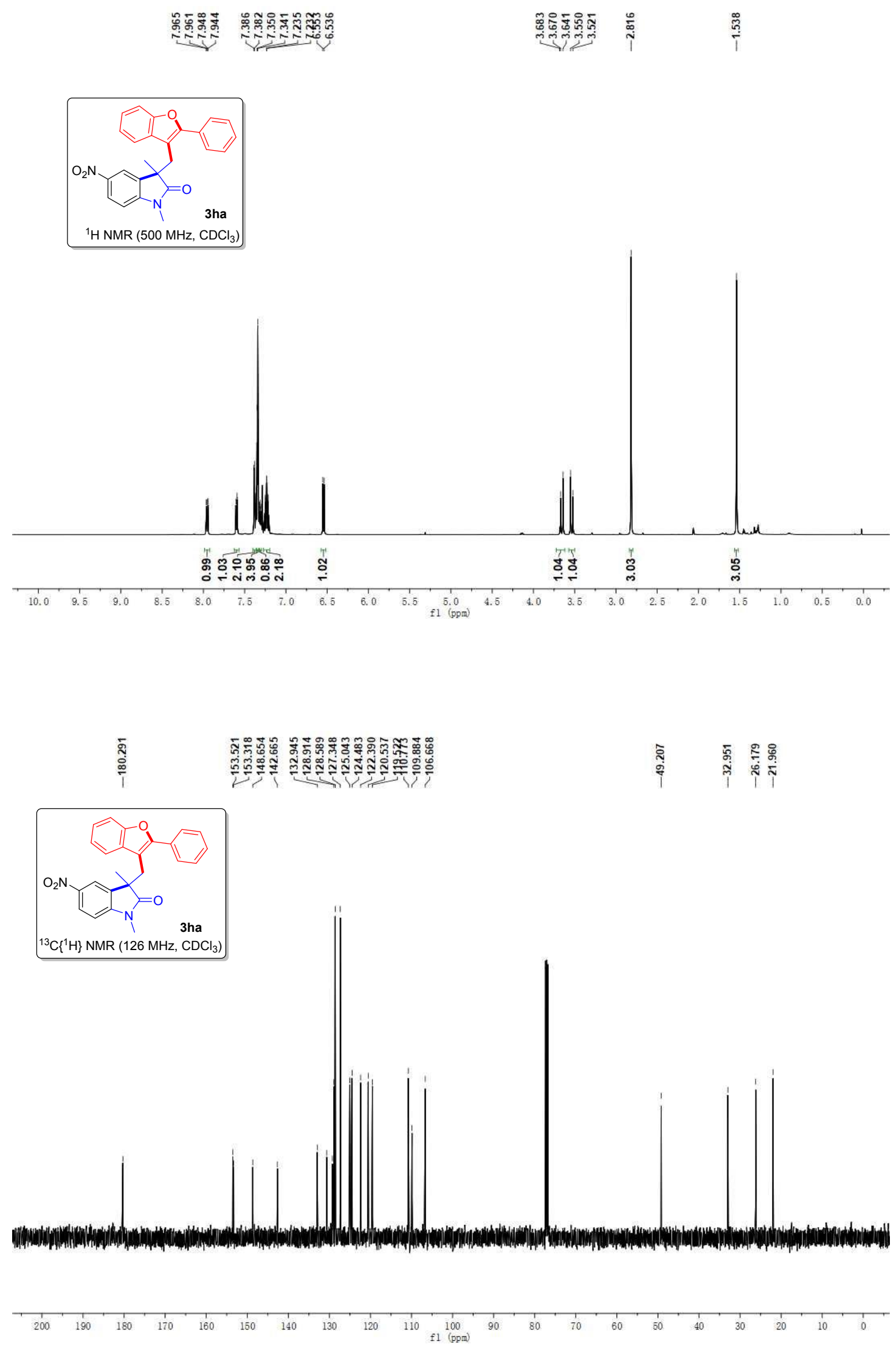

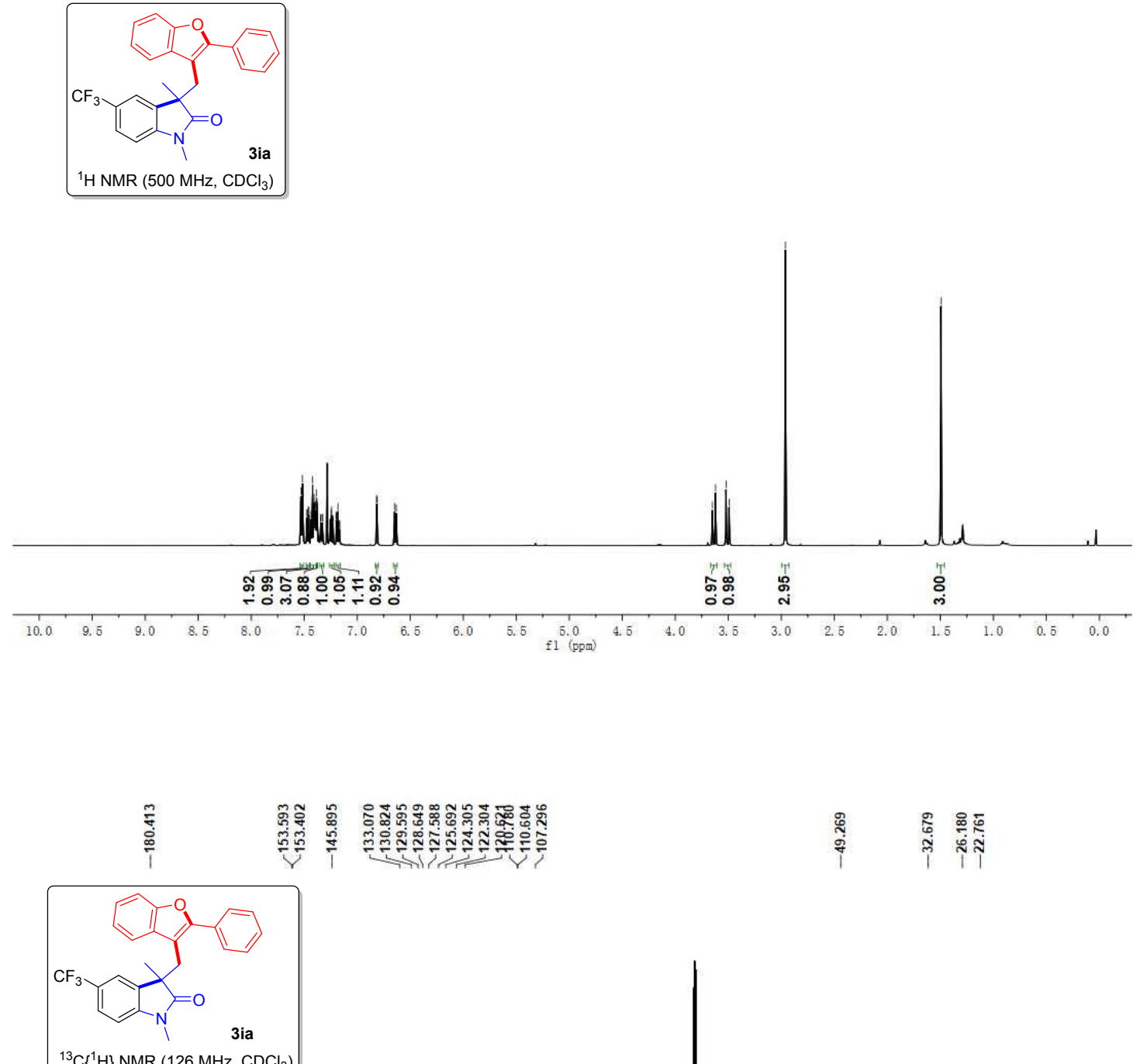

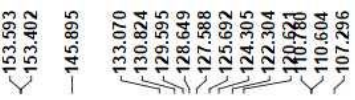

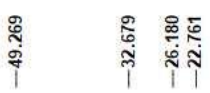

${ }^{13} \mathrm{C}\left\{{ }^{1} \mathrm{H}\right\}$ NMR $\left(126 \mathrm{MHz}, \mathrm{CDCl}_{3}\right)$
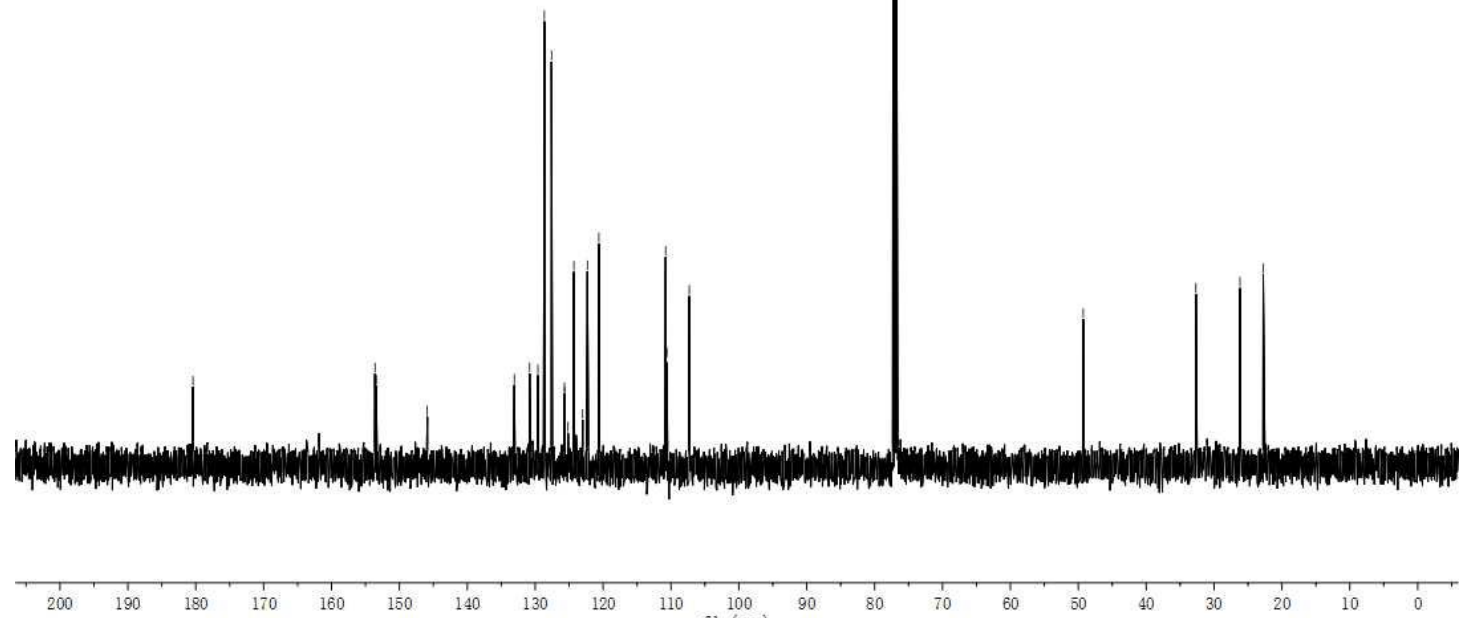

$110 \quad \begin{aligned} & 100 \\ & \mathrm{f} 1\end{aligned}$ 

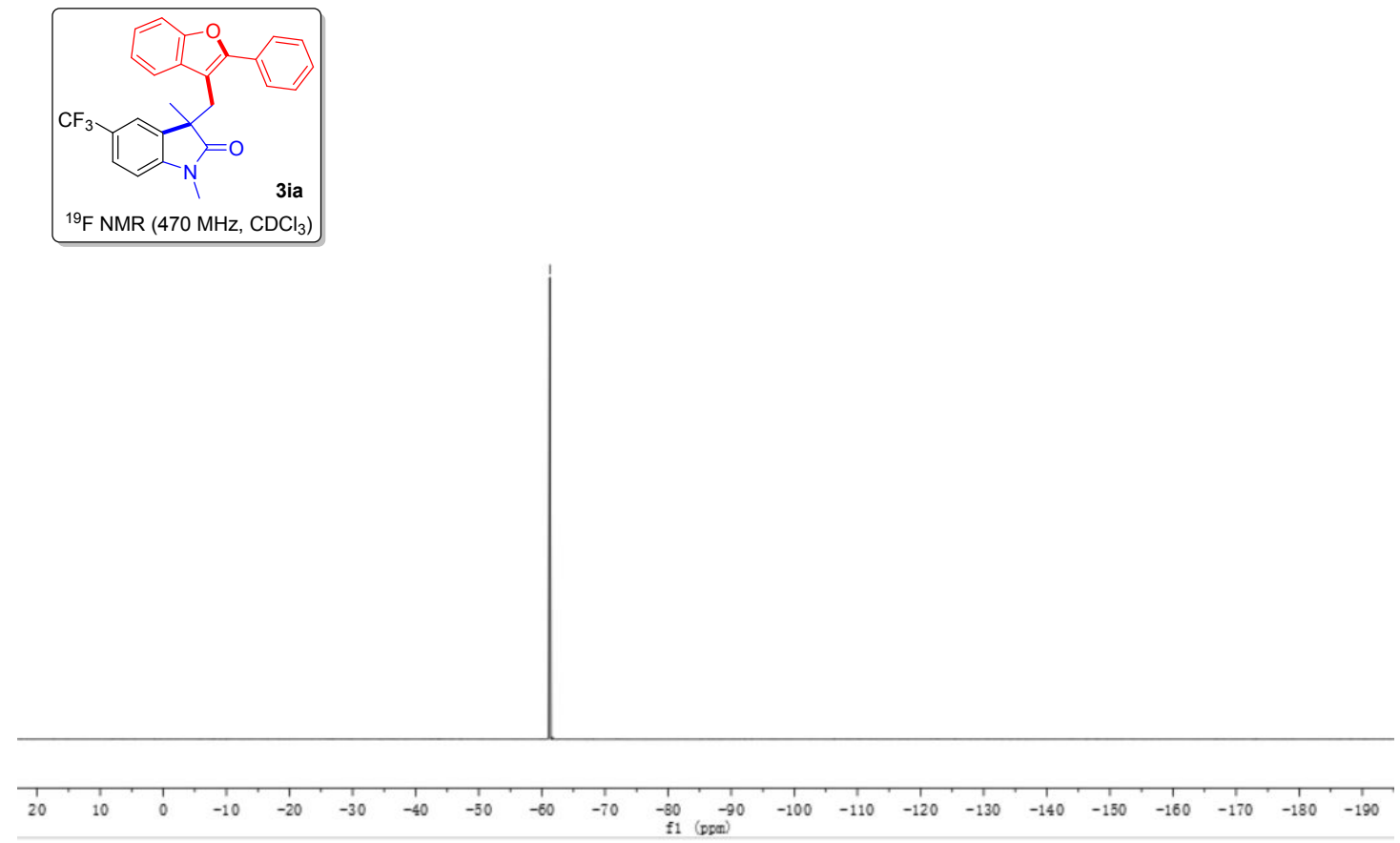

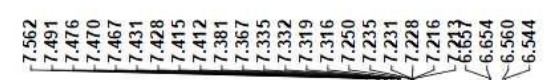

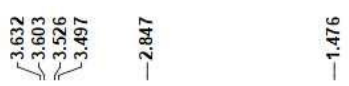
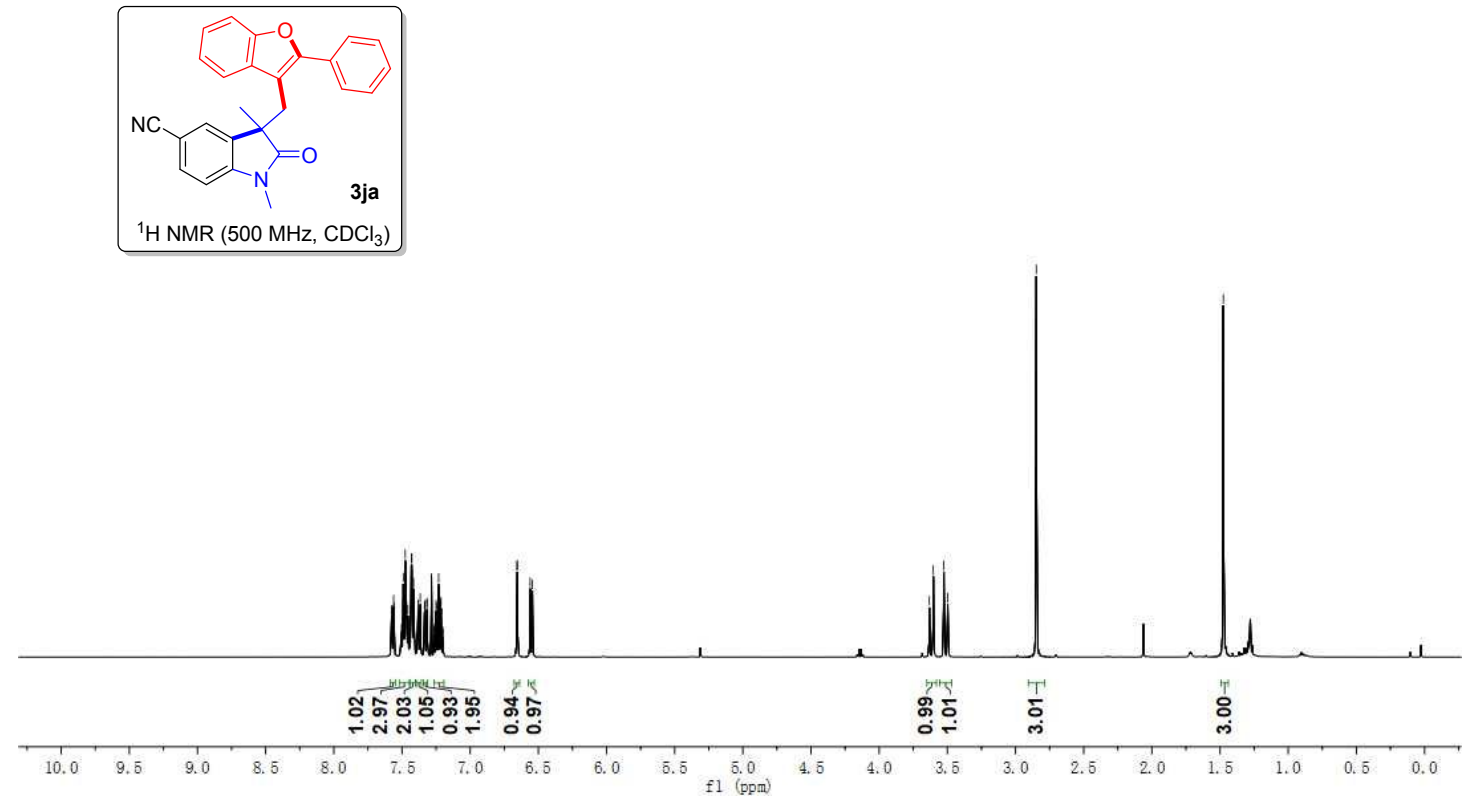

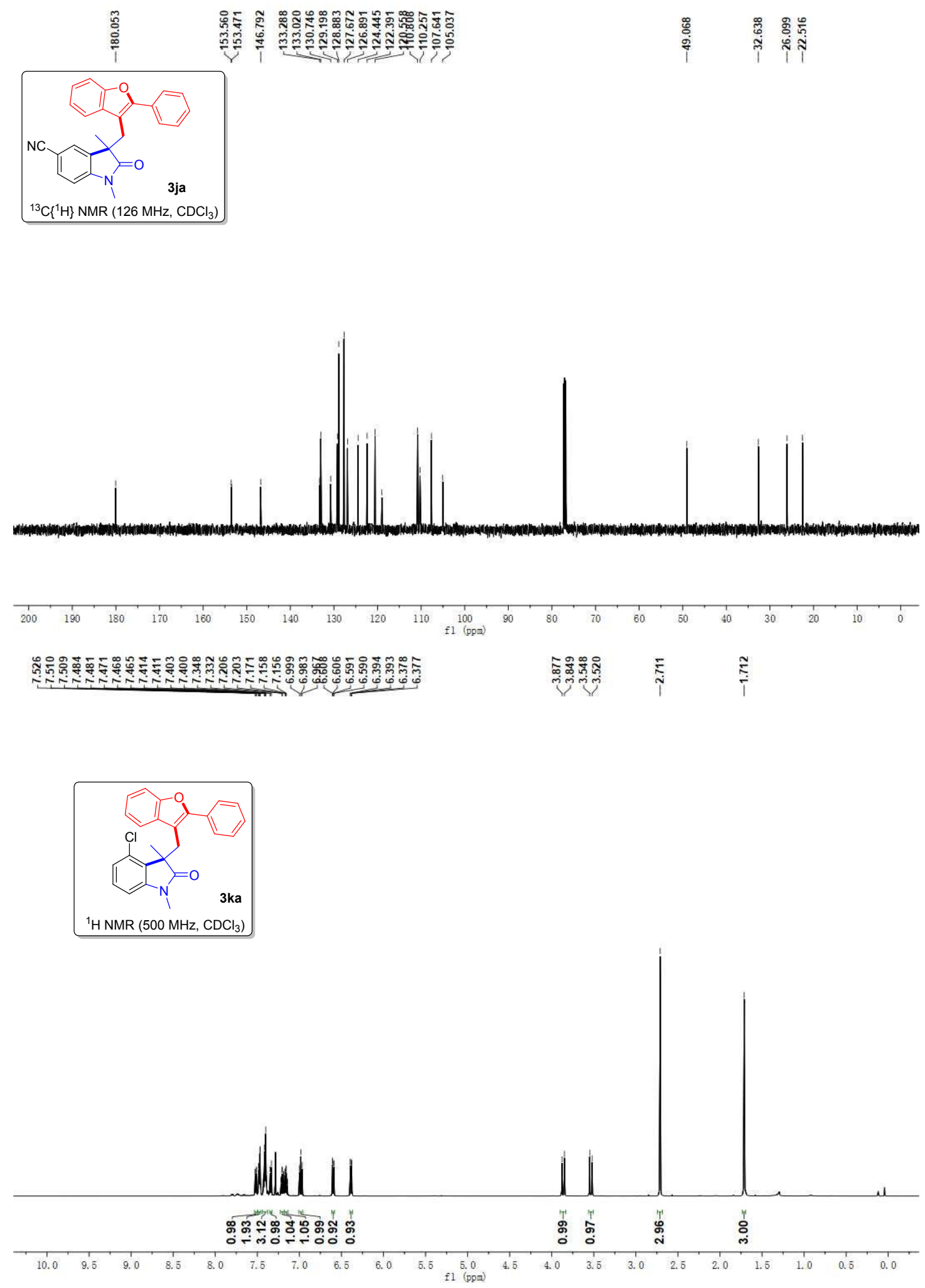


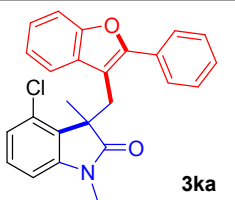

${ }^{13} \mathrm{C}\left\{{ }^{1} \mathrm{H}\right\}$ NMR $\left(126 \mathrm{MHz}, \mathrm{CDCl}_{3}\right)$
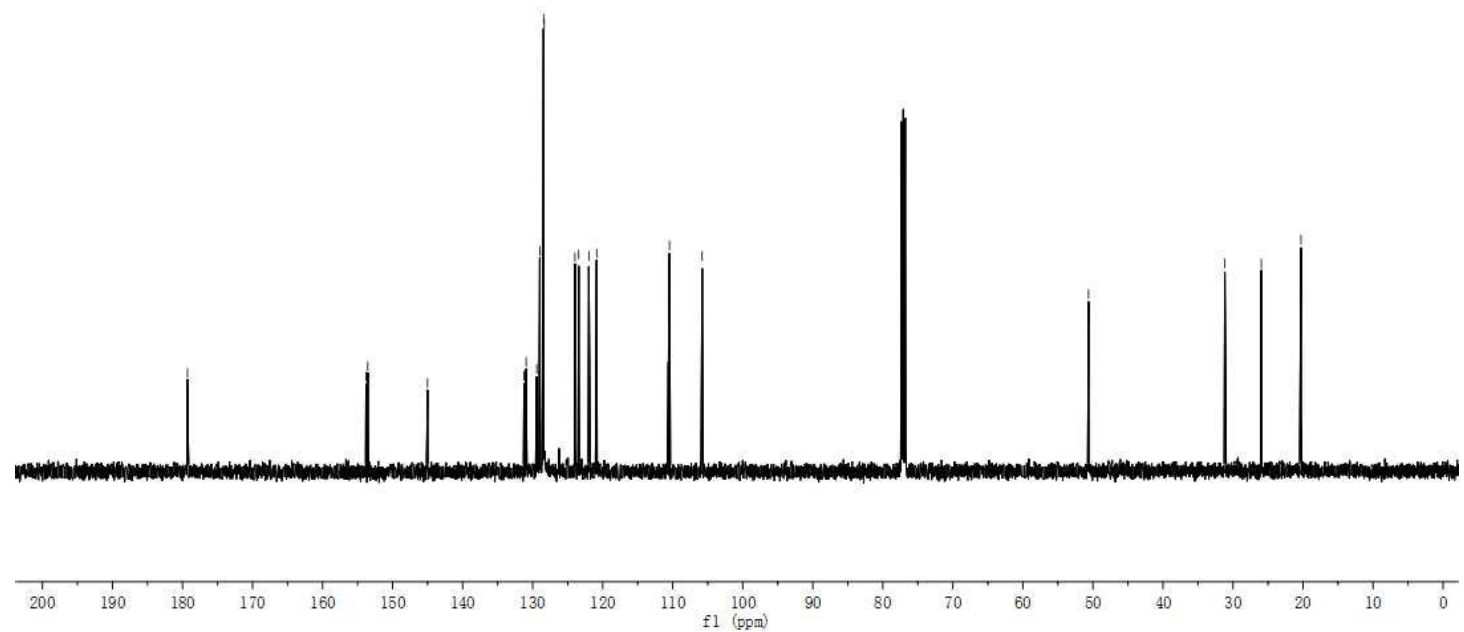

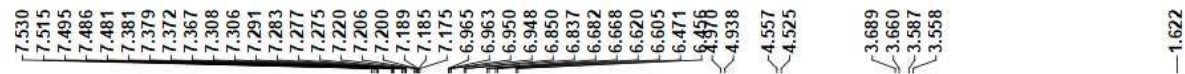

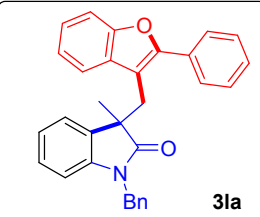

${ }^{1} \mathrm{H}$ NMR $\left(500 \mathrm{MHz}, \mathrm{CDCl}_{3}\right)$

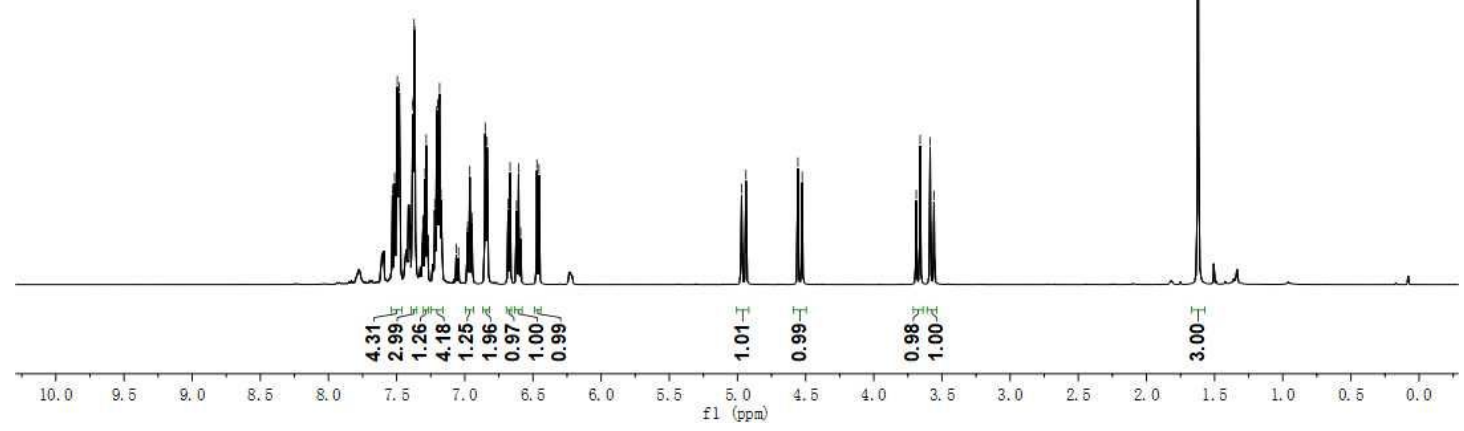



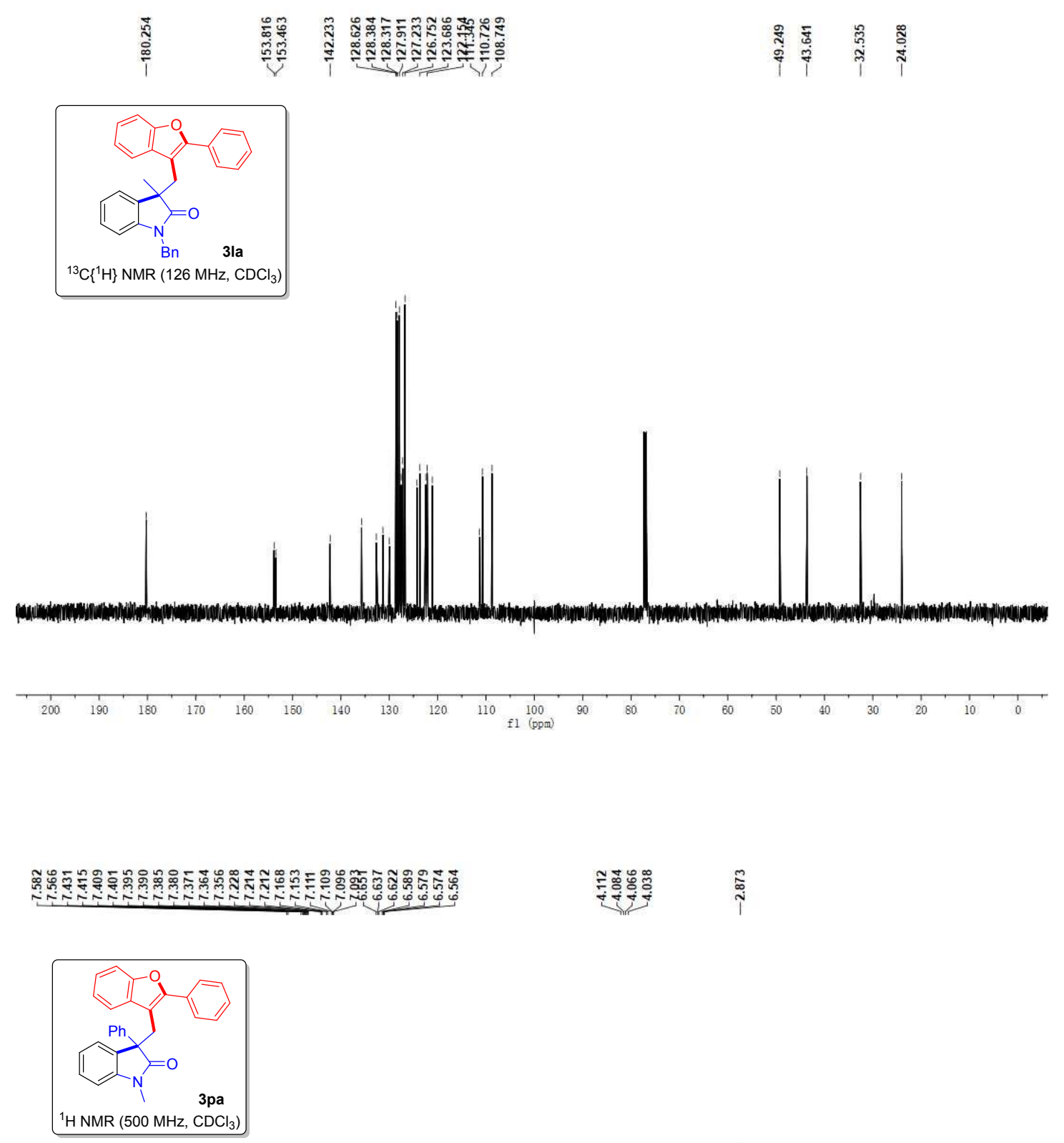

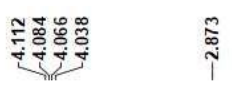

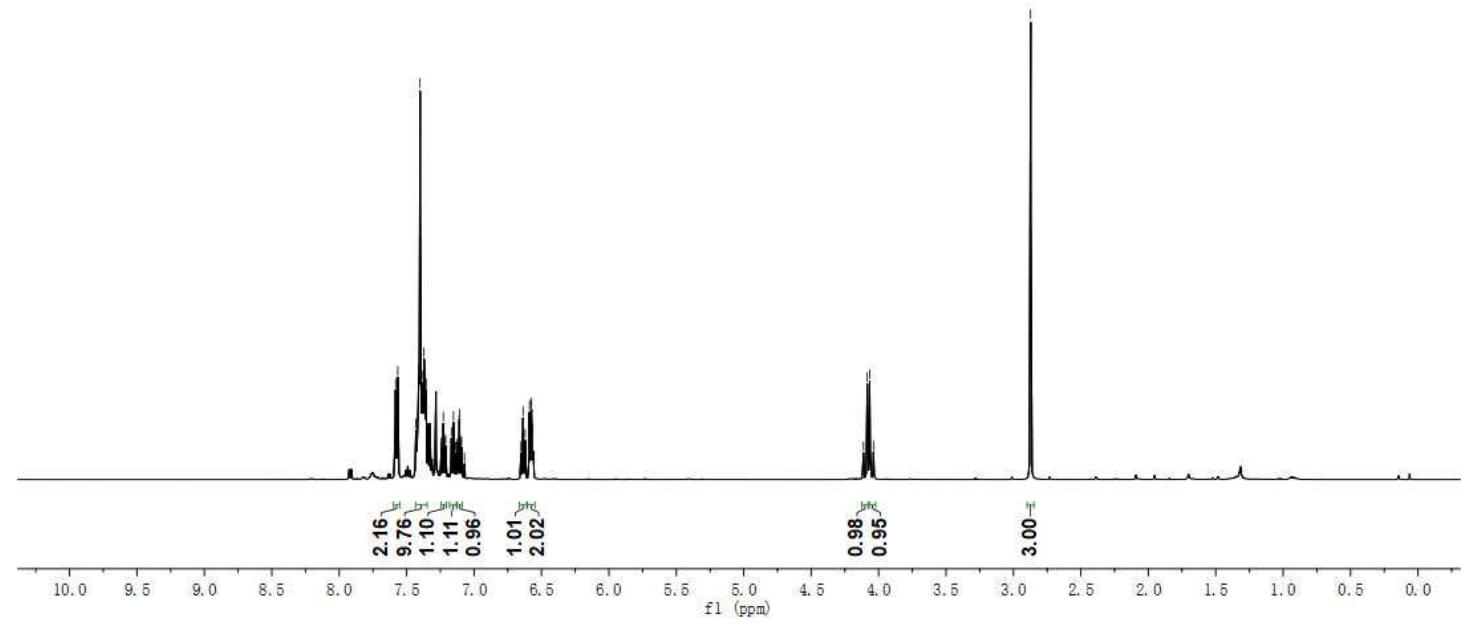



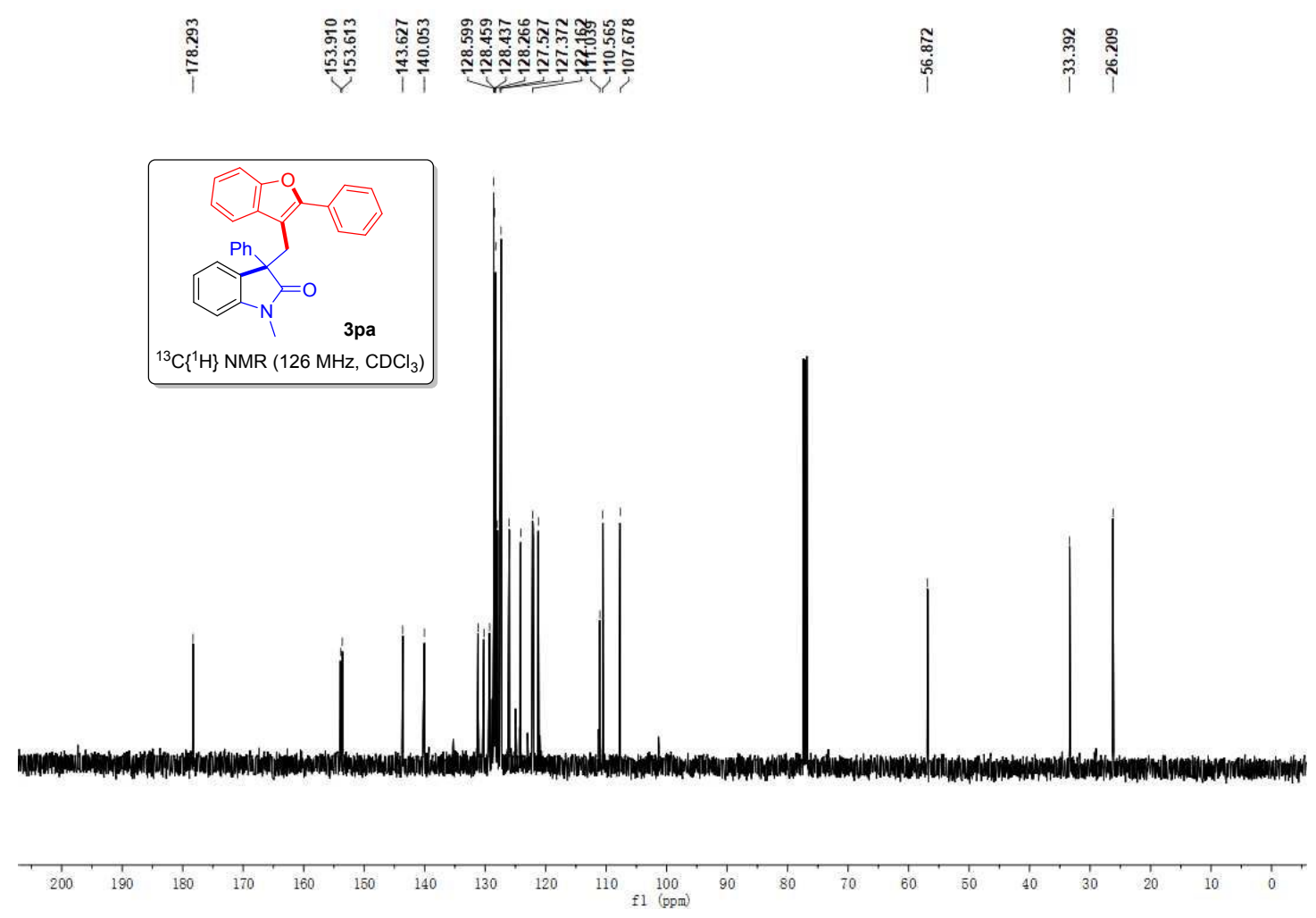

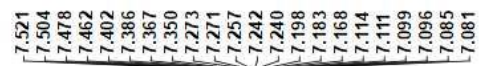

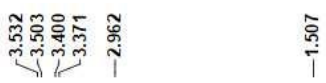
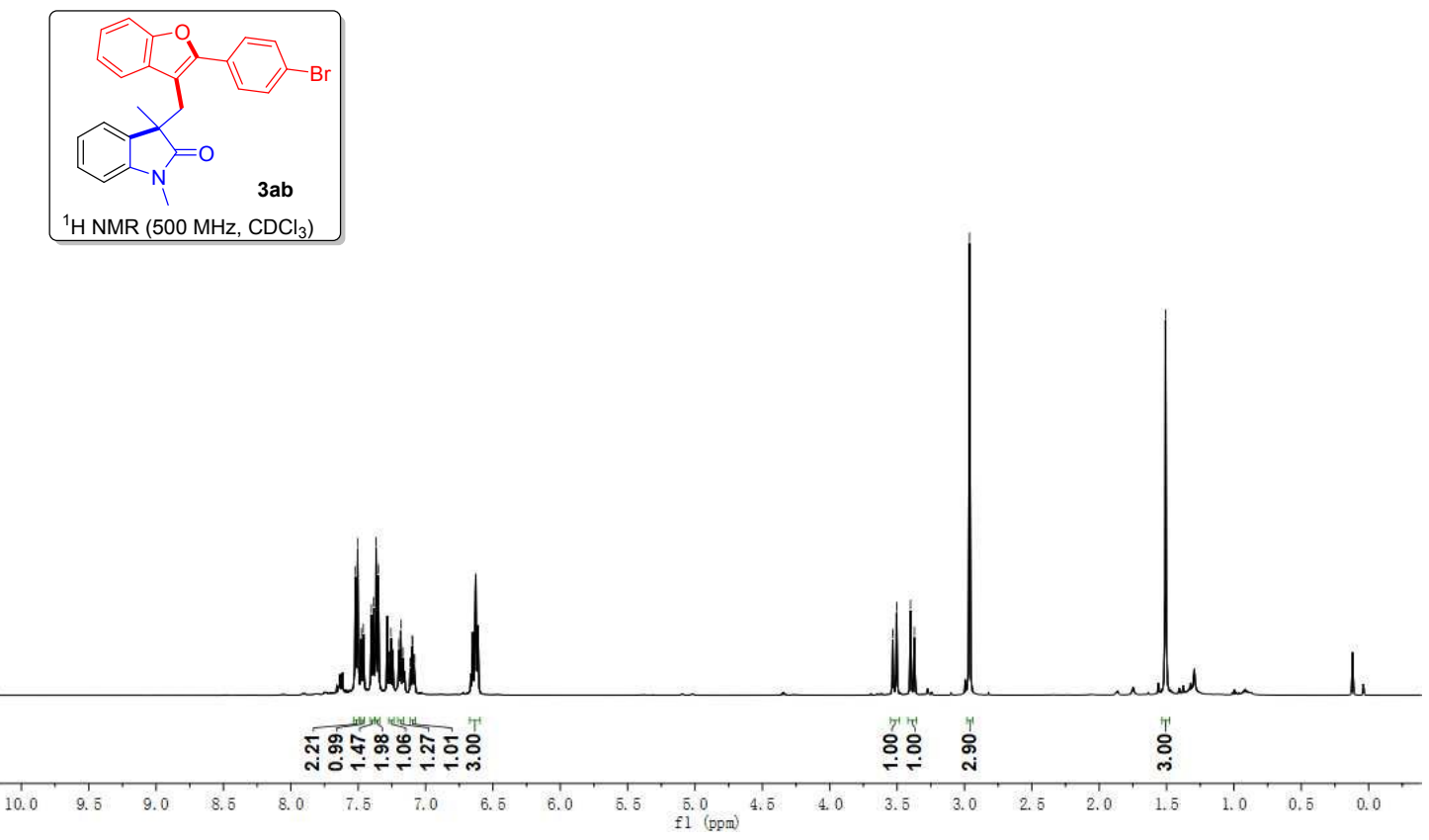


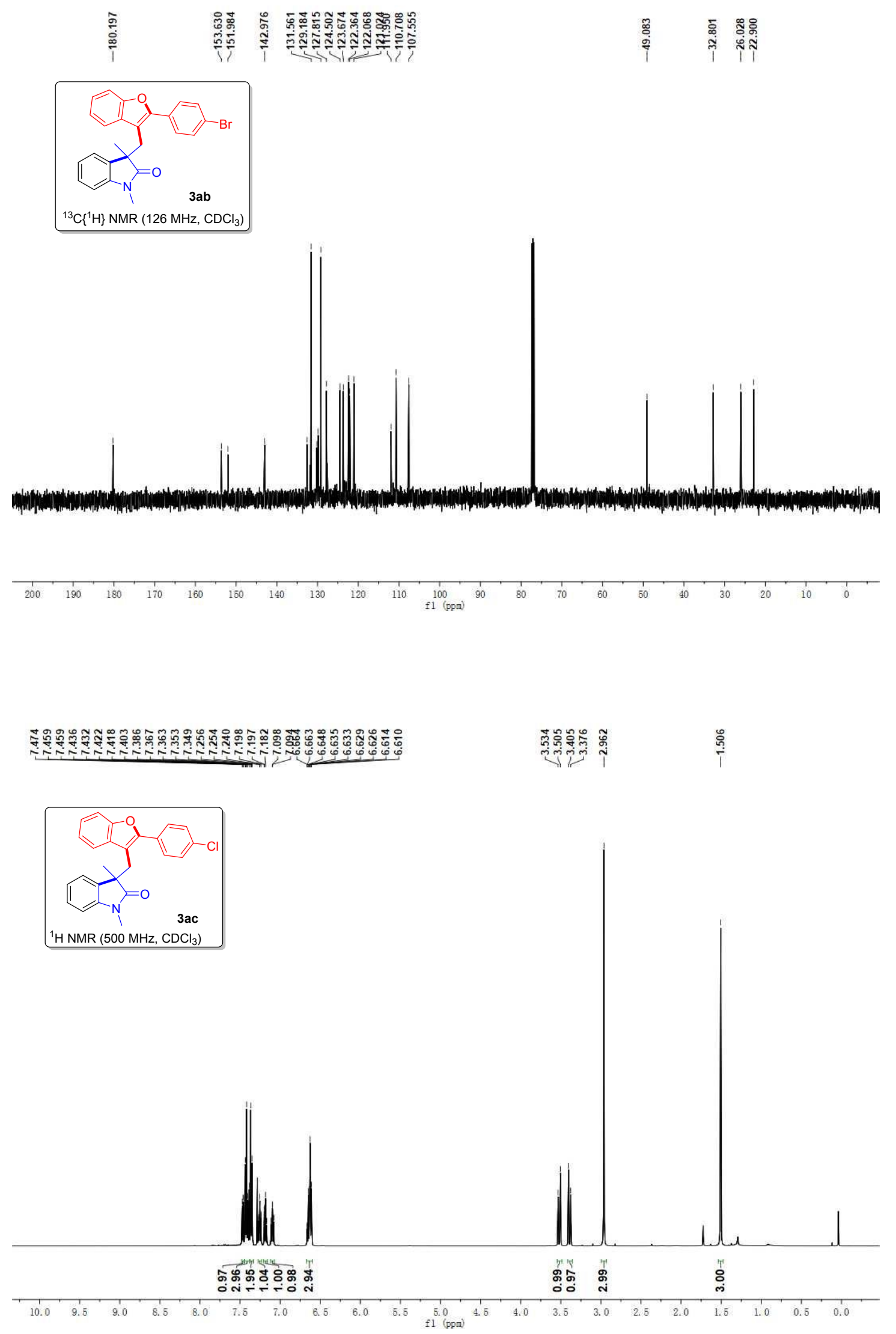



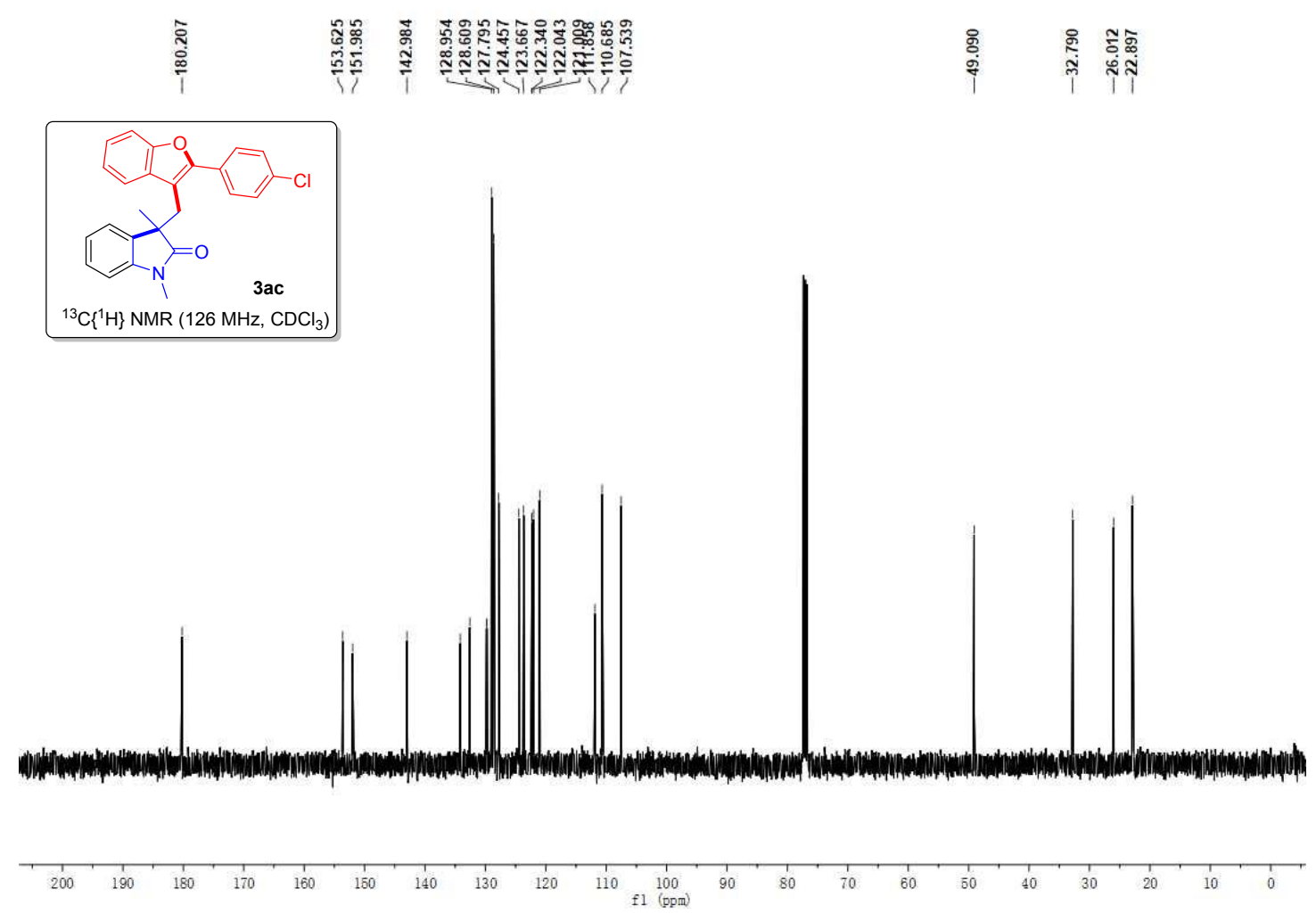

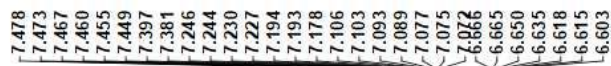

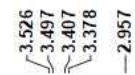

암

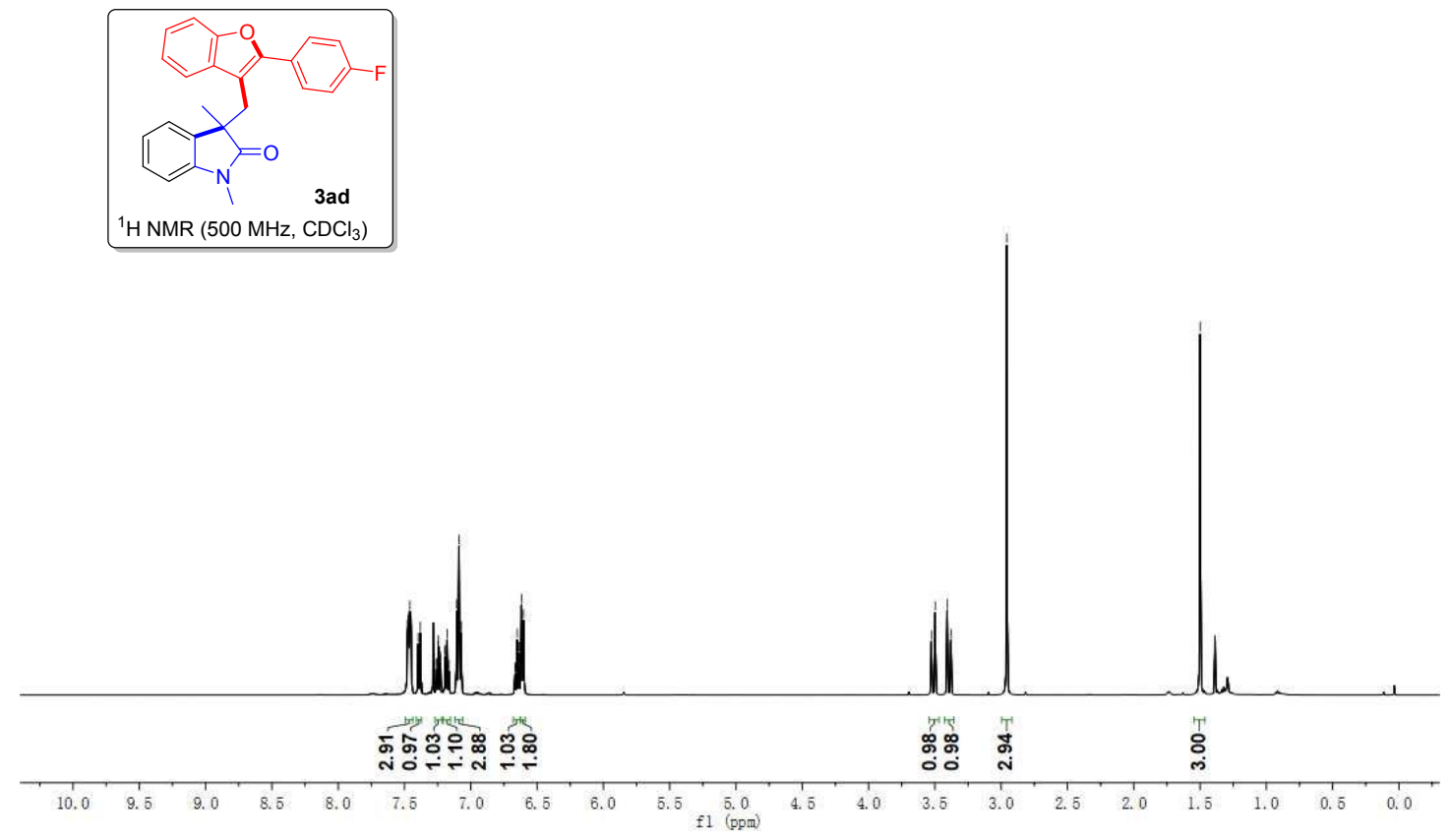




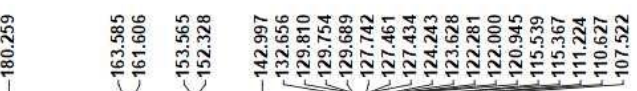

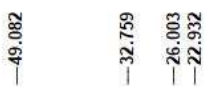

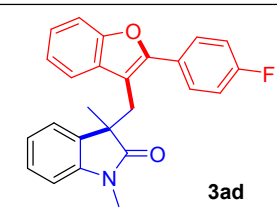

${ }^{13} \mathrm{C}\left\{{ }^{1} \mathrm{H}\right\}$ NMR $\left(126 \mathrm{MHz}, \mathrm{CDCl}_{3}\right)$
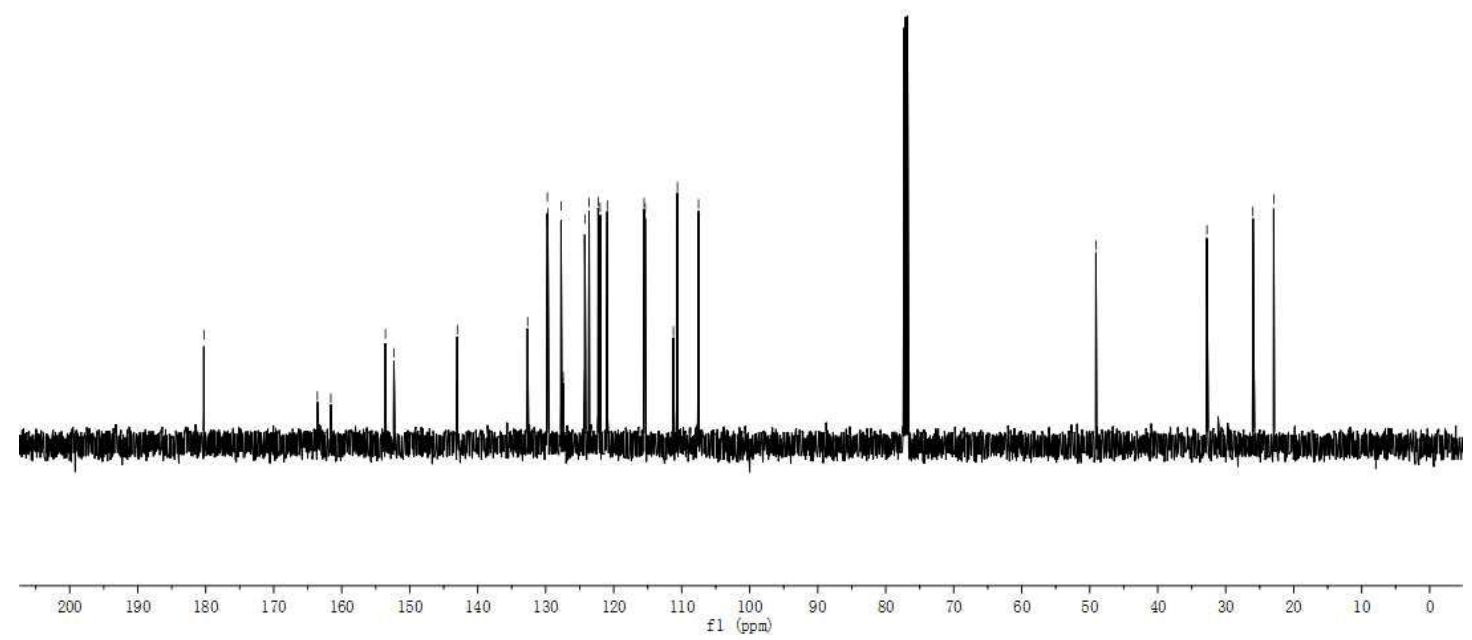

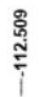
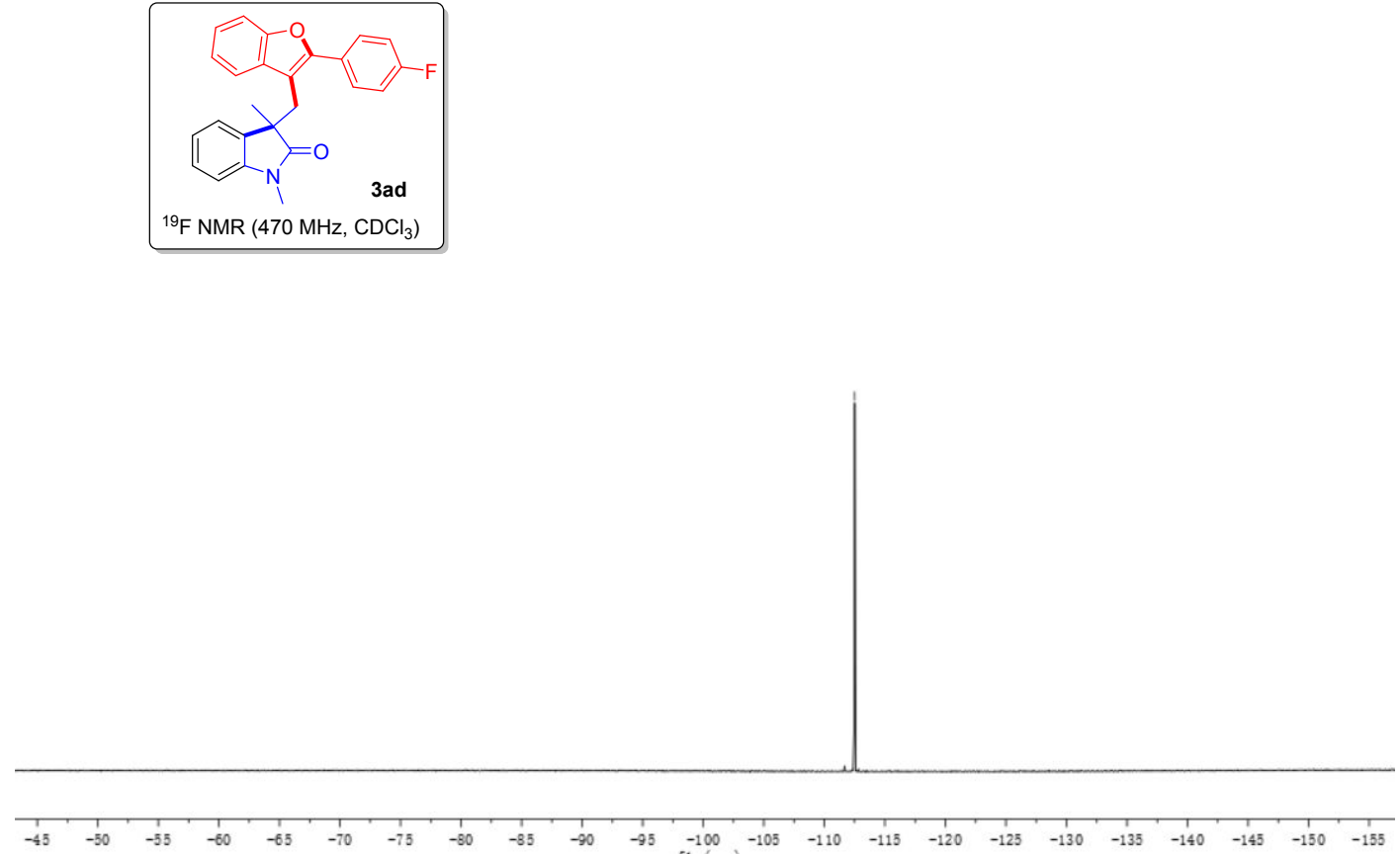


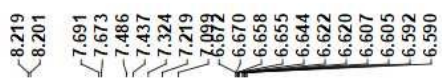
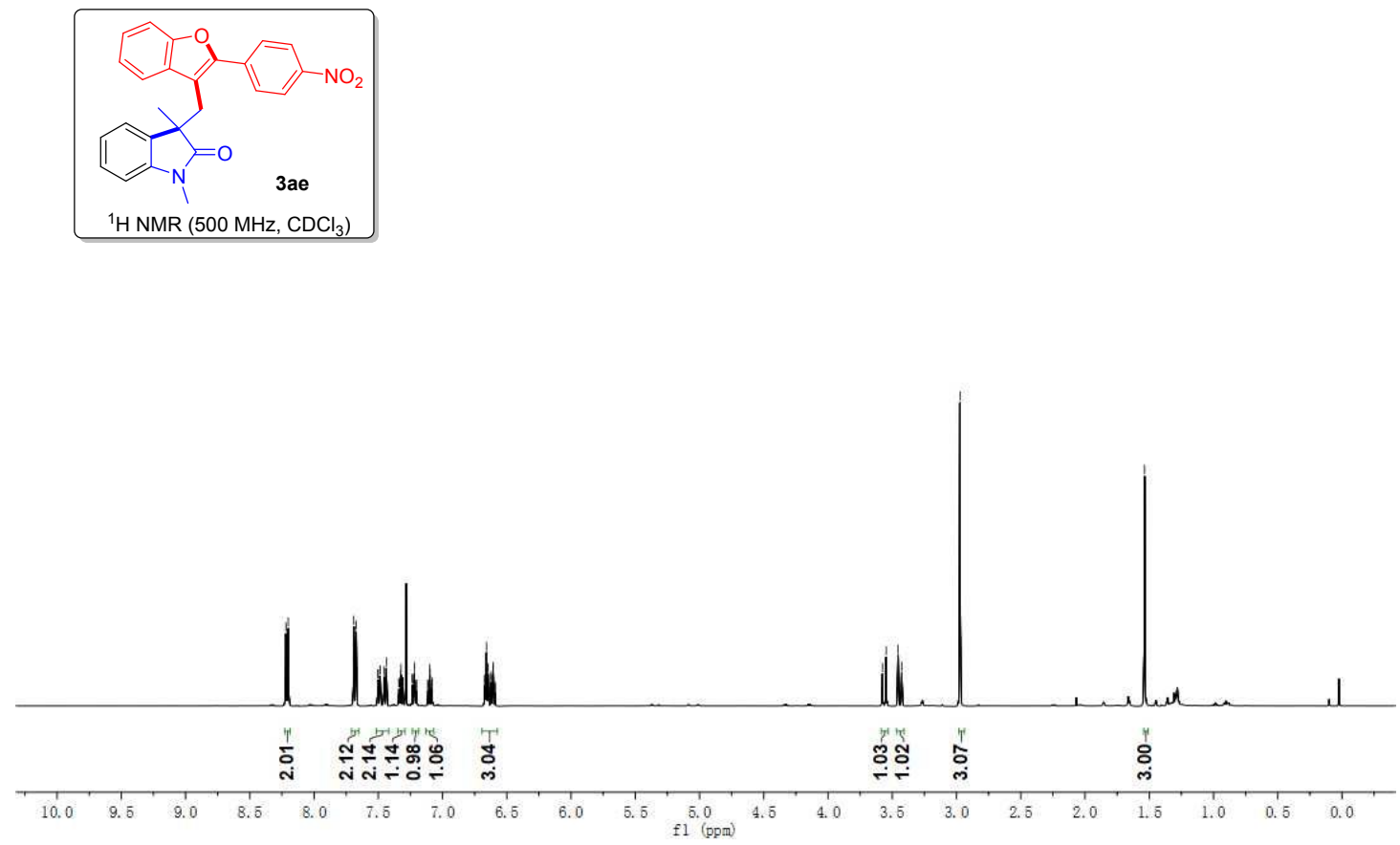

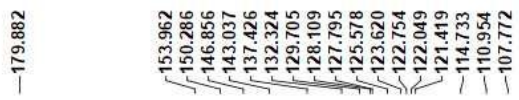

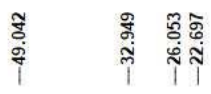

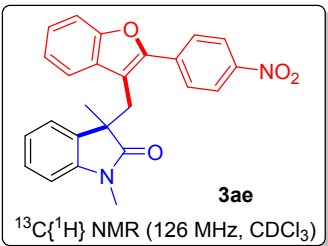

$\left.{ }^{13} \mathrm{C}^{1}{ }^{1} \mathrm{H}\right\} \mathrm{NMR}\left(126 \mathrm{MHz}, \mathrm{CDCl}_{3}\right)$
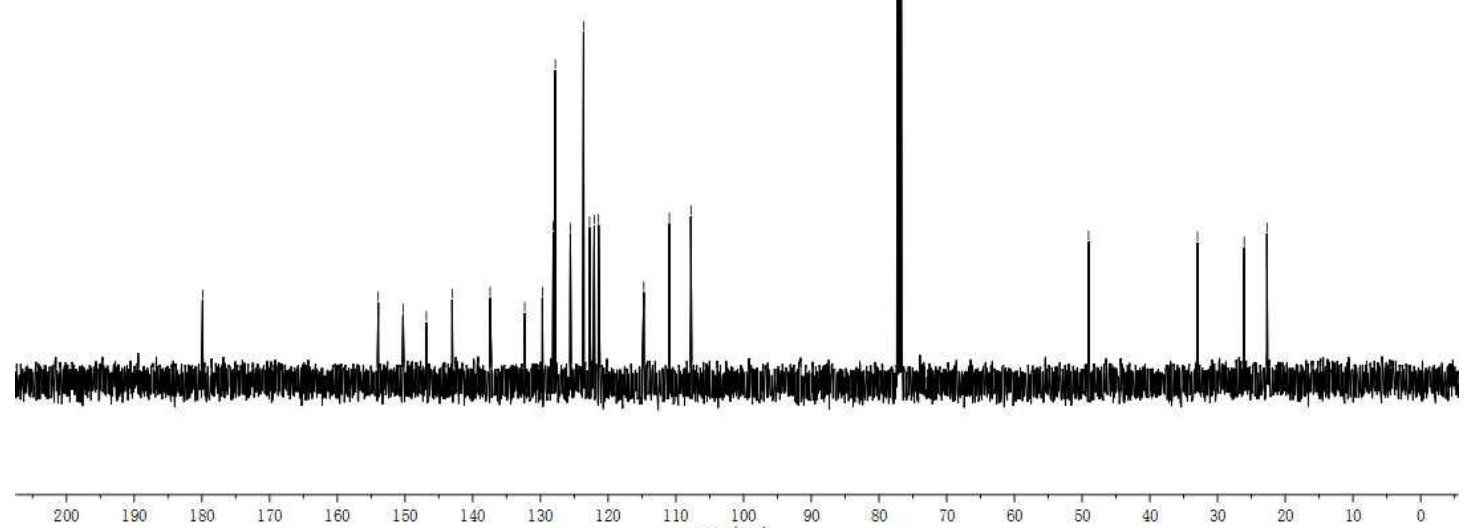

$110 \stackrel{100}{\mathrm{fl}} \stackrel{(\mathrm{ppm})}{\mathrm{g}}$ 

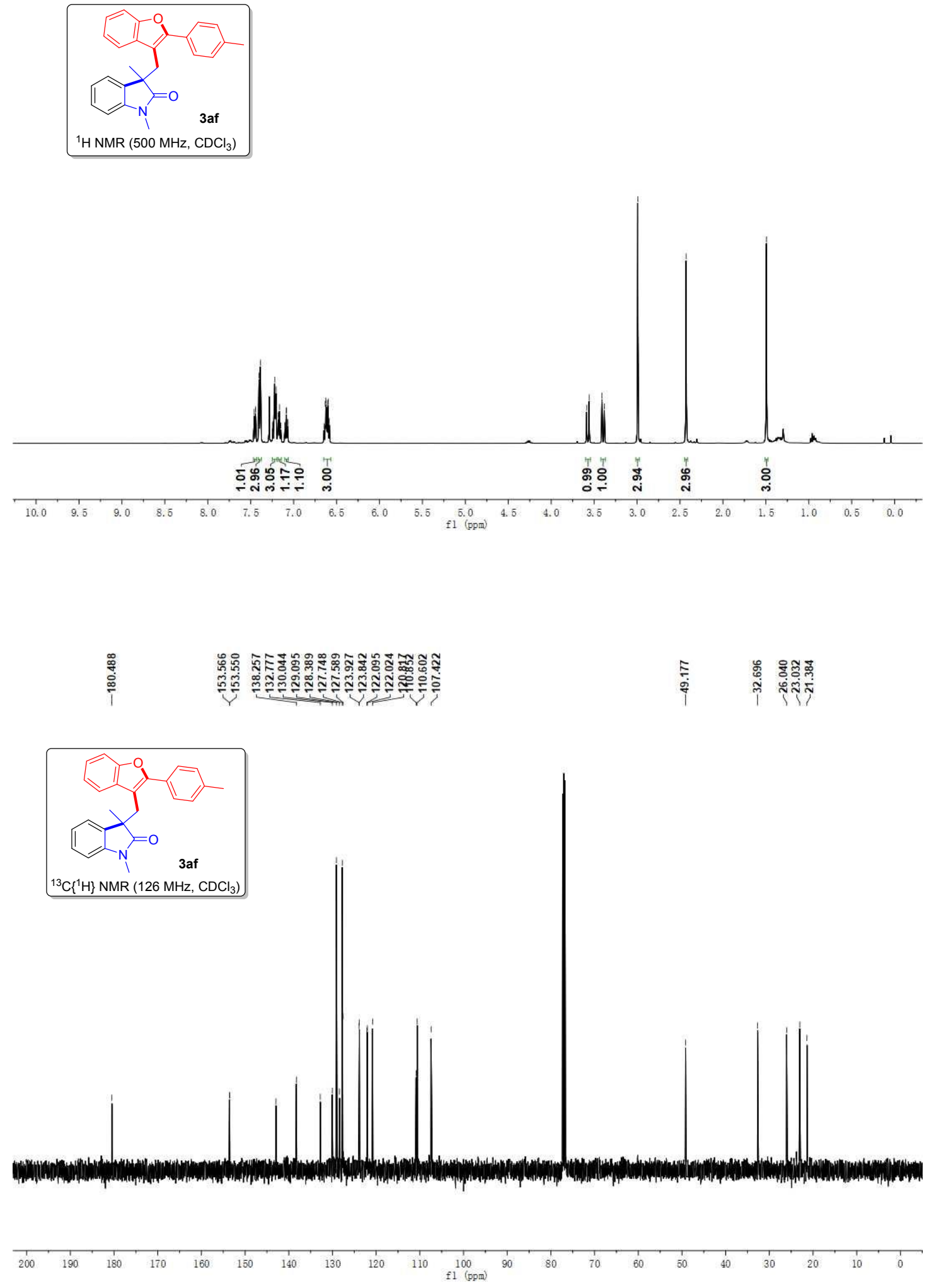

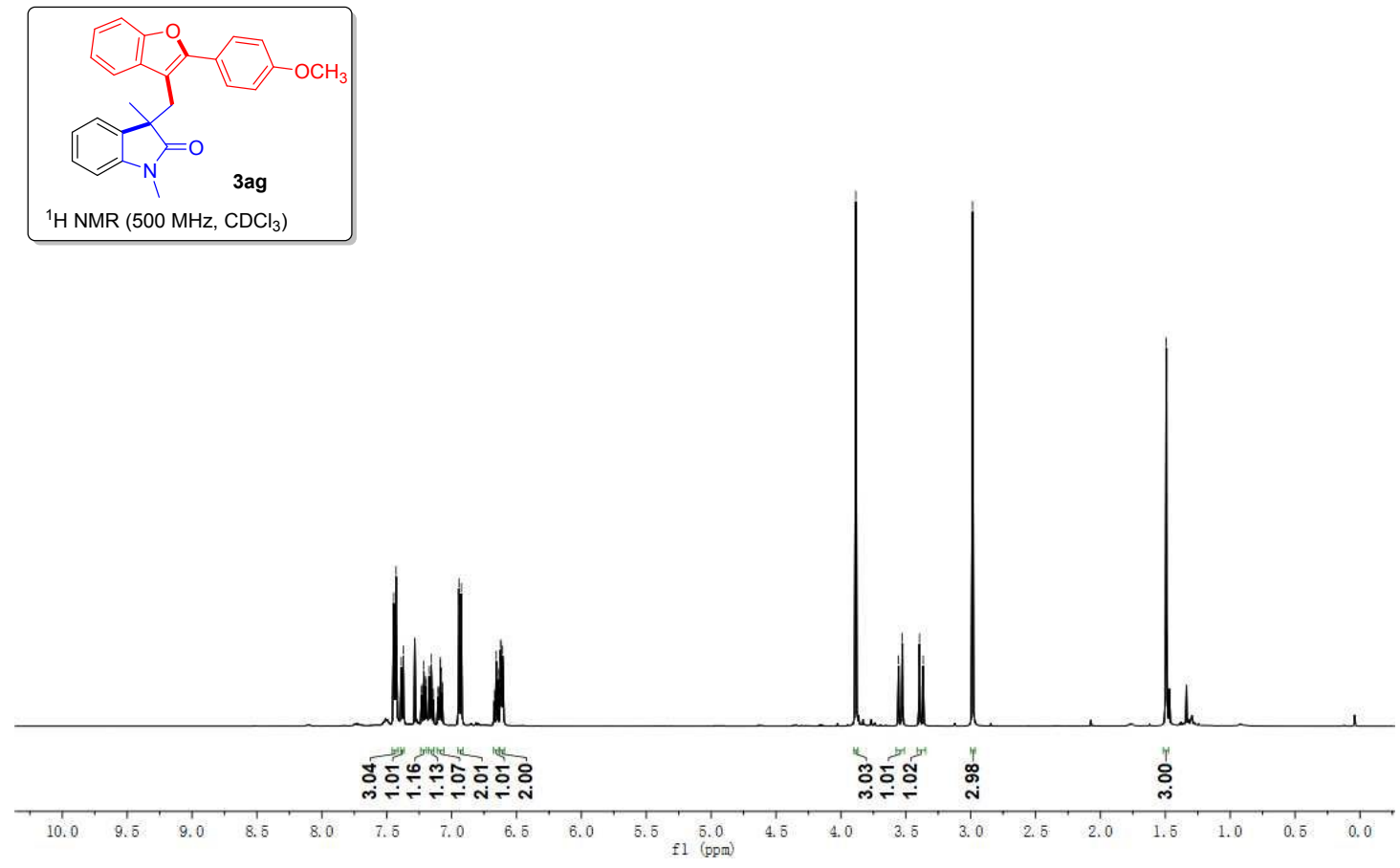

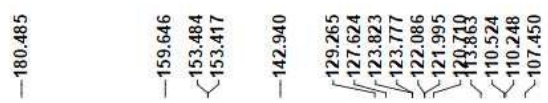

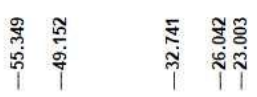
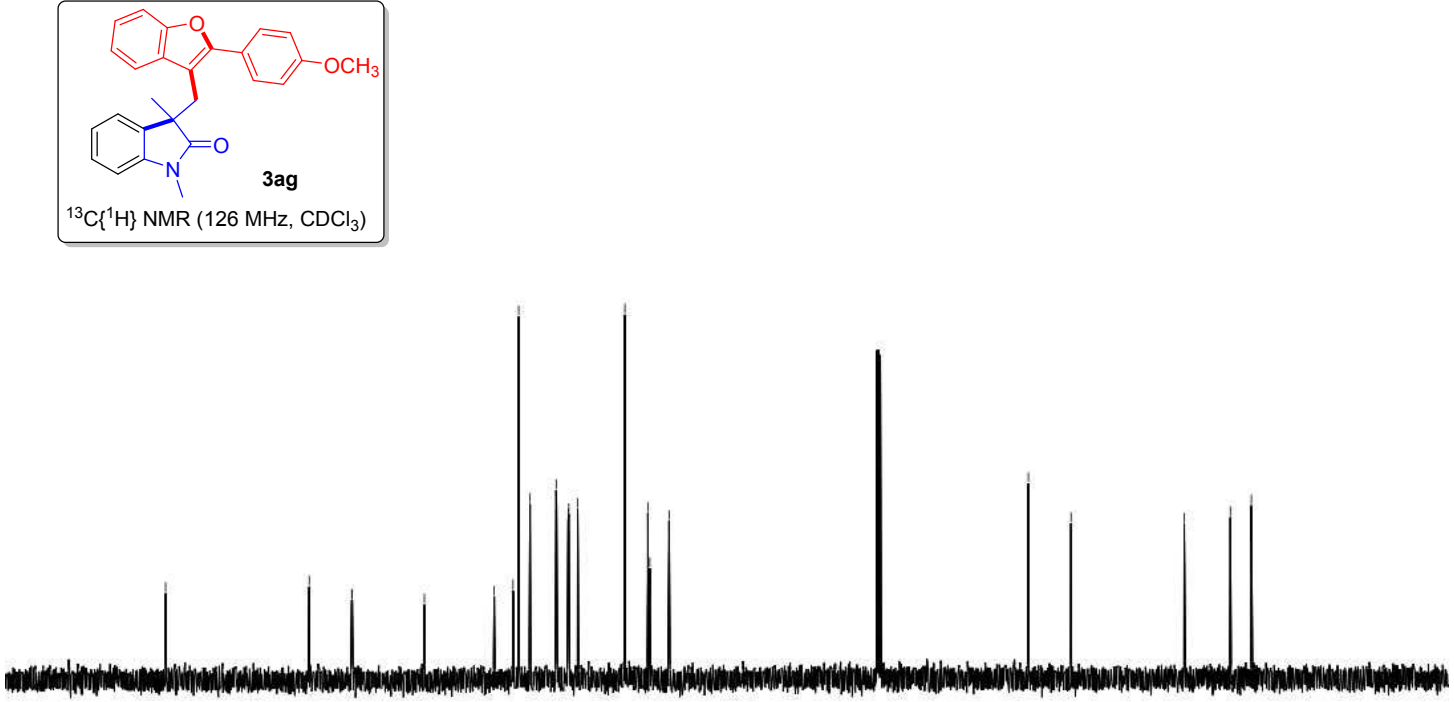

${ }_{200}^{1} \quad \frac{1}{190} \quad 118$

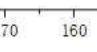

140

$\mathrm{fl}(\mathrm{ppp})$ 

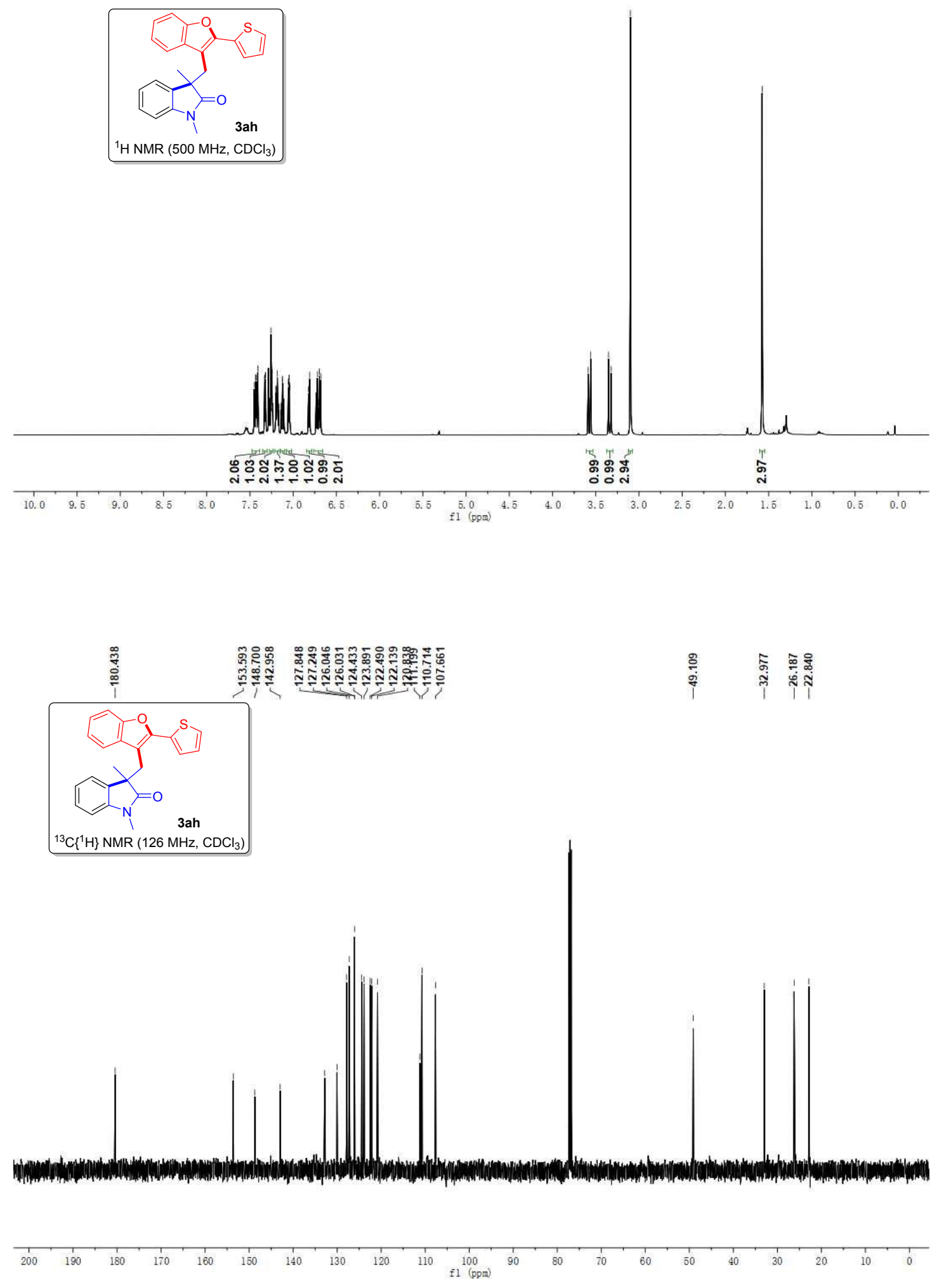

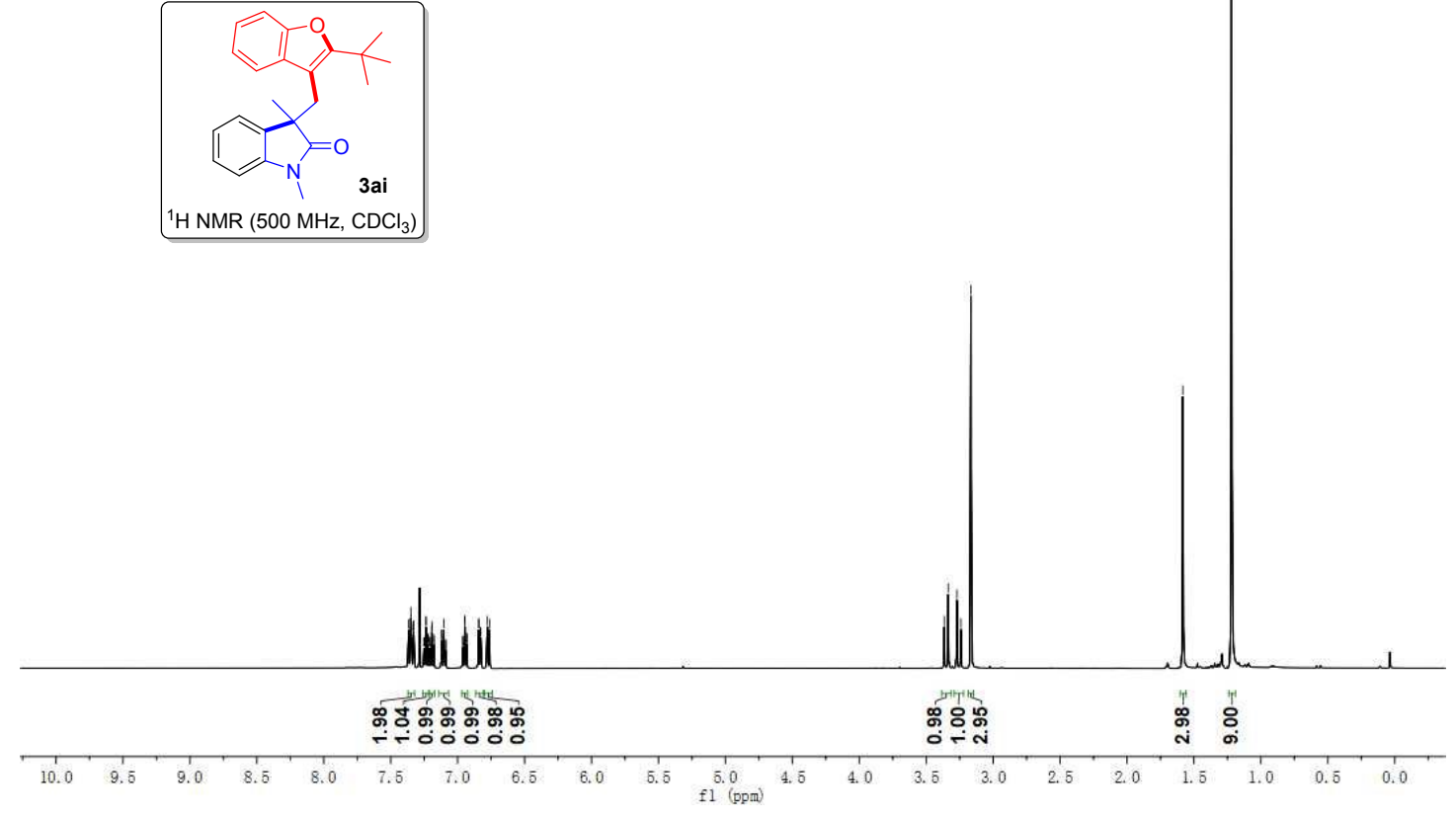

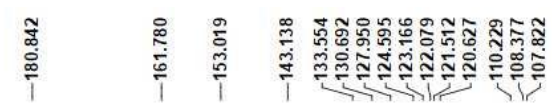

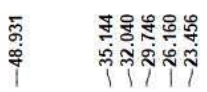

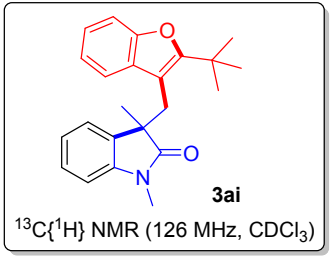

${ }^{3} \mathrm{C}\left\{{ }^{1} \mathrm{H}\right\}$ NMR $\left(126 \mathrm{MHz}, \mathrm{CDCl}_{3}\right)$
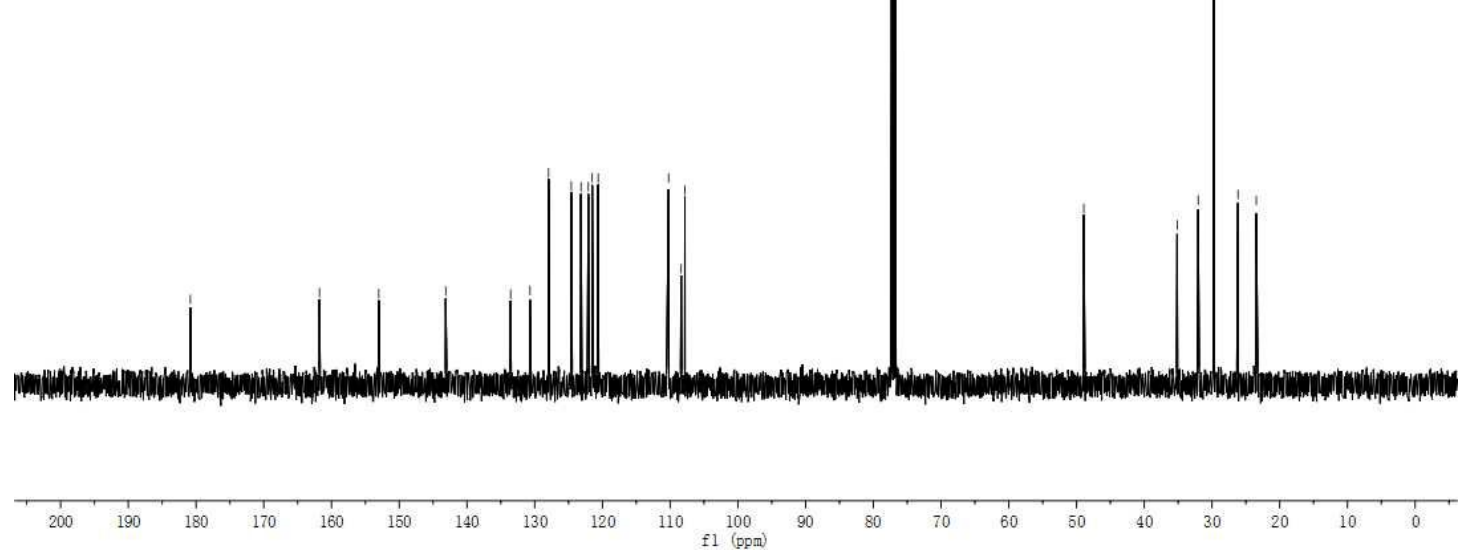


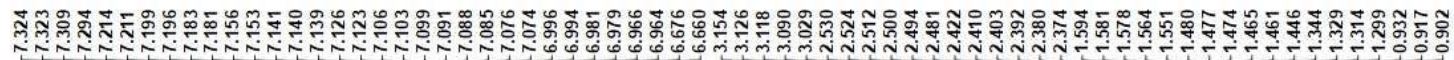
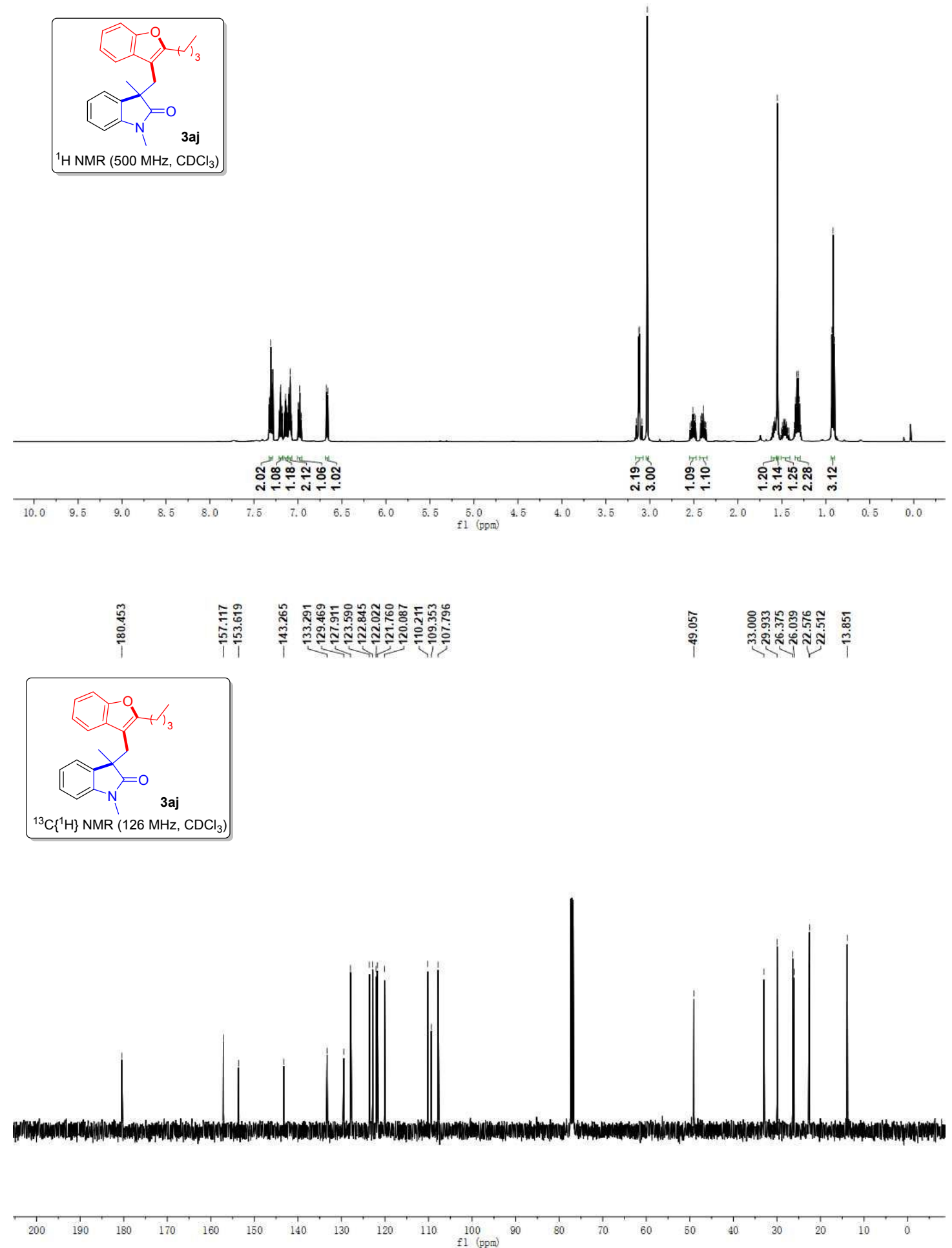


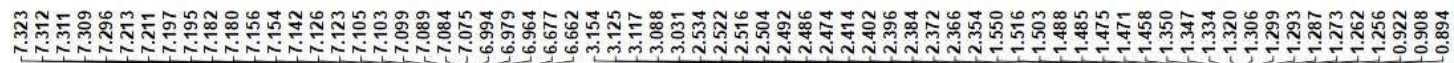

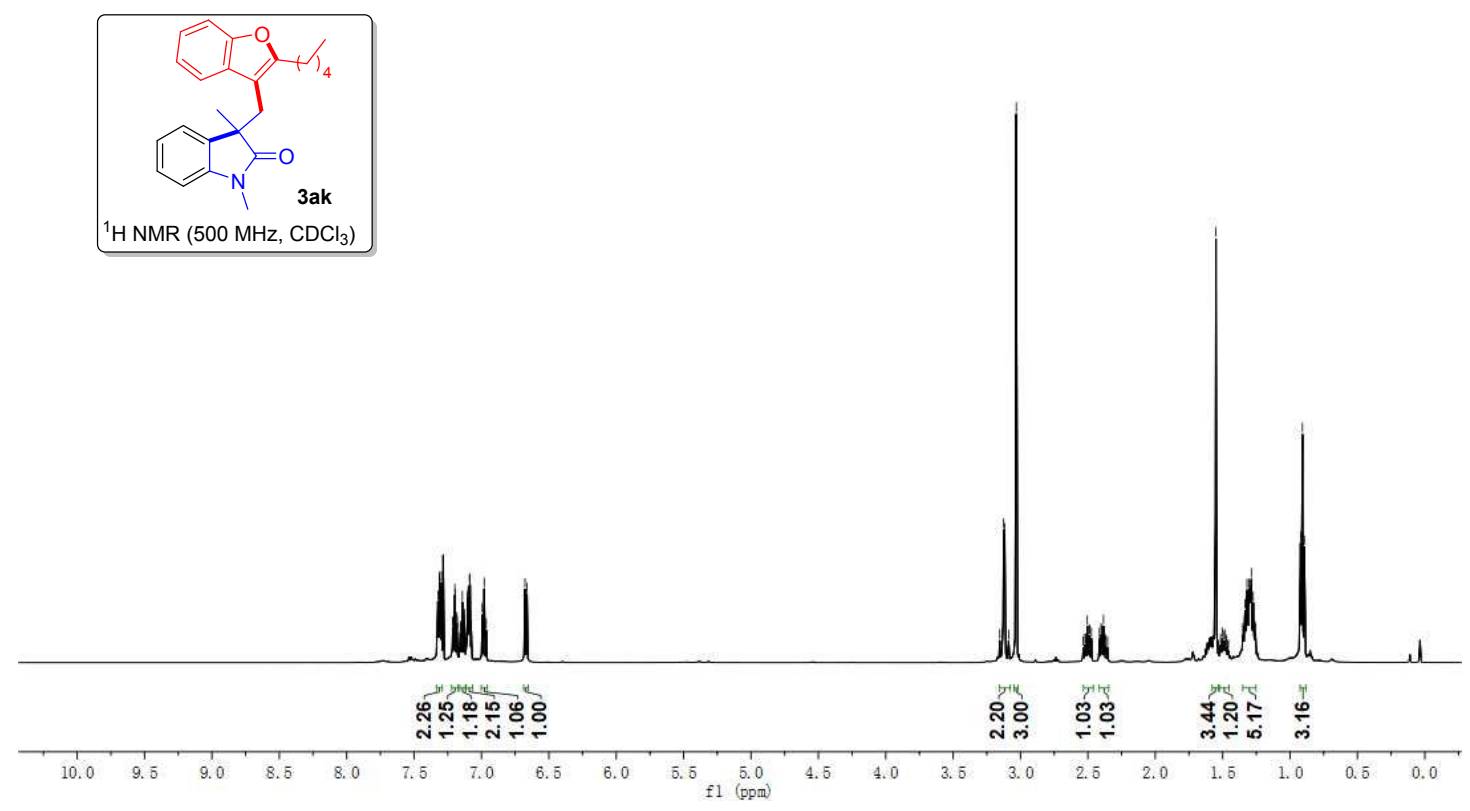

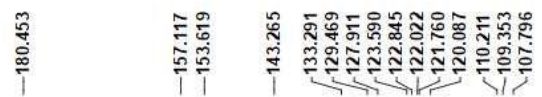

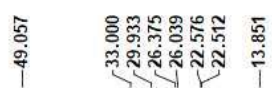
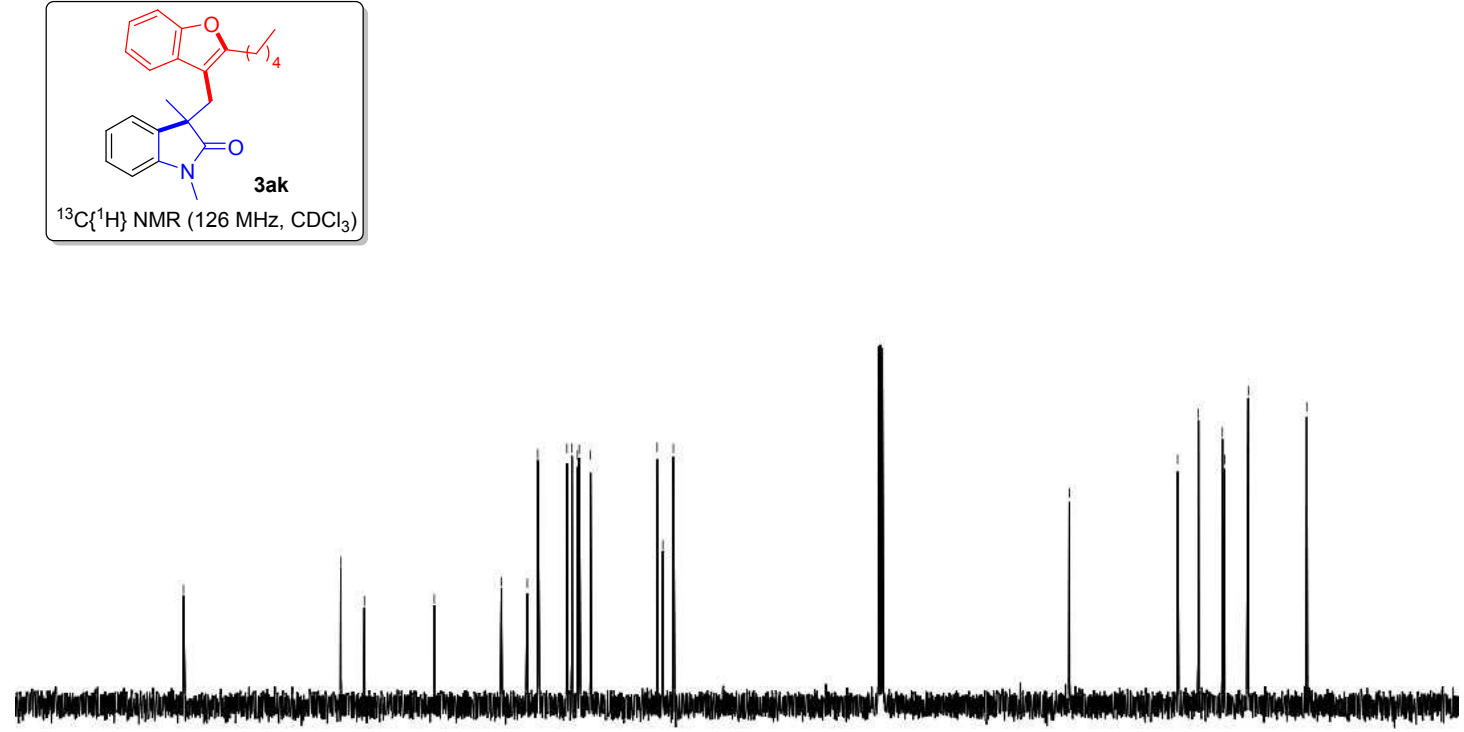

$f_{\mathrm{fl}}^{100}(\mathrm{ppm})$ 


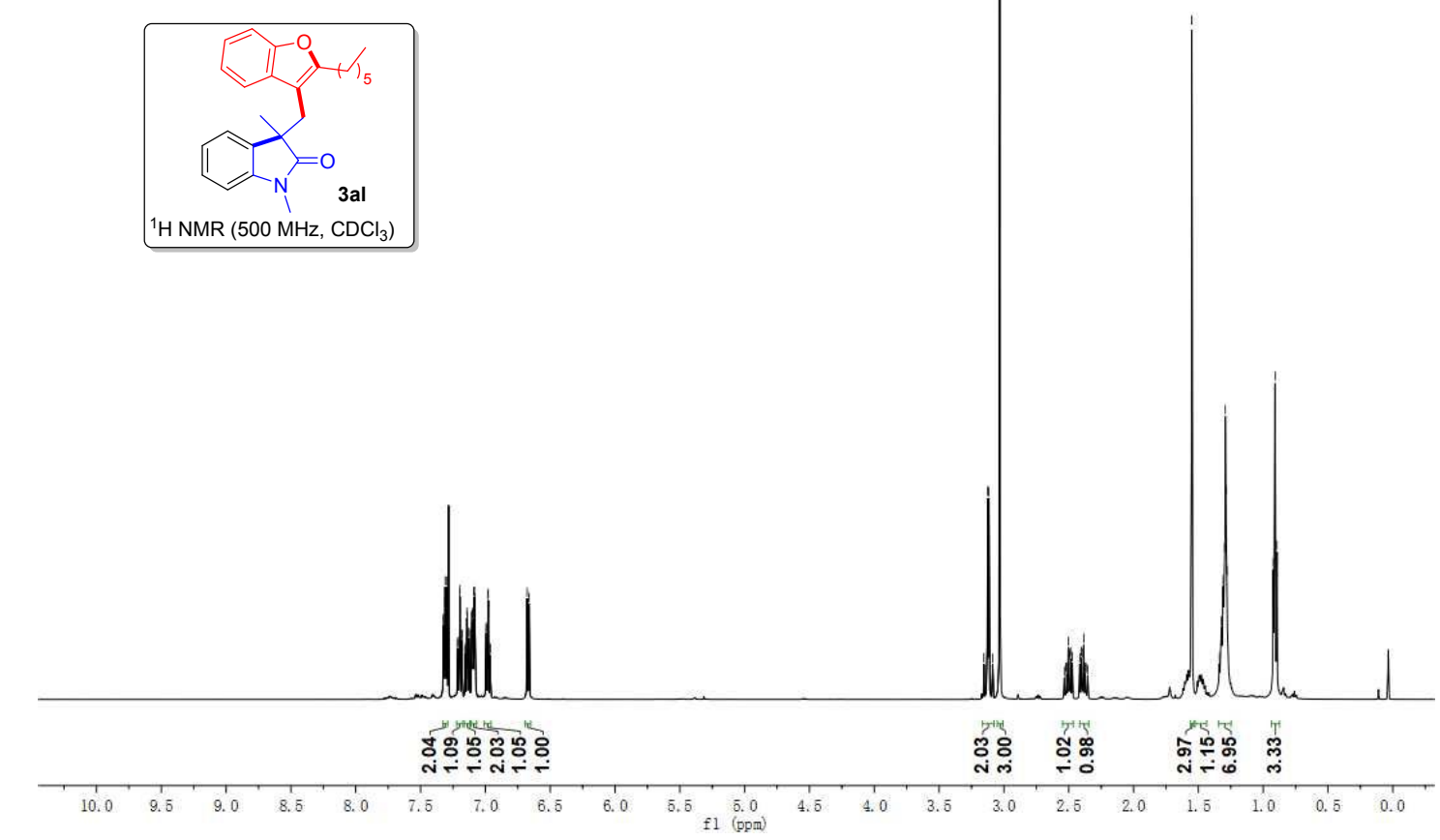

${ }^{1} \mathrm{H} \mathrm{NMR}\left(500 \mathrm{MHz}, \mathrm{CDCl}_{3}\right)$
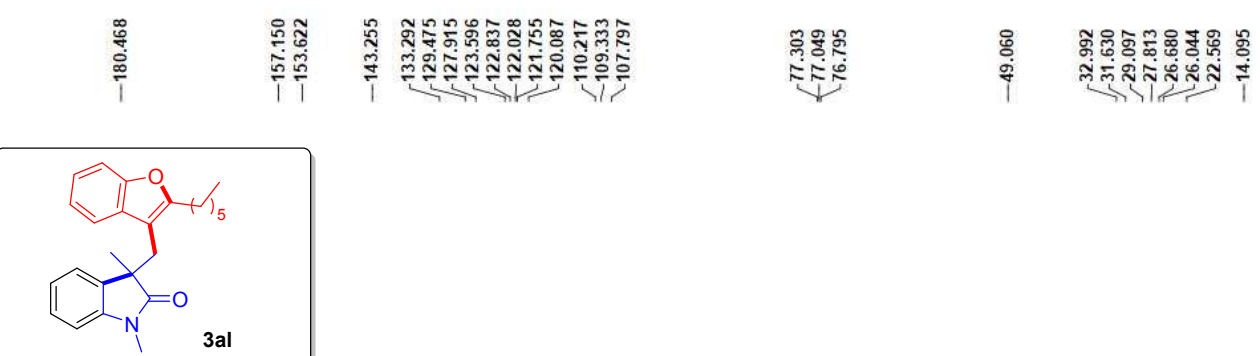

${ }^{13} \mathrm{C}\left\{{ }^{1} \mathrm{H}\right\} \mathrm{NMR}\left(126 \mathrm{MHz}, \mathrm{CDCl}_{3}\right)$

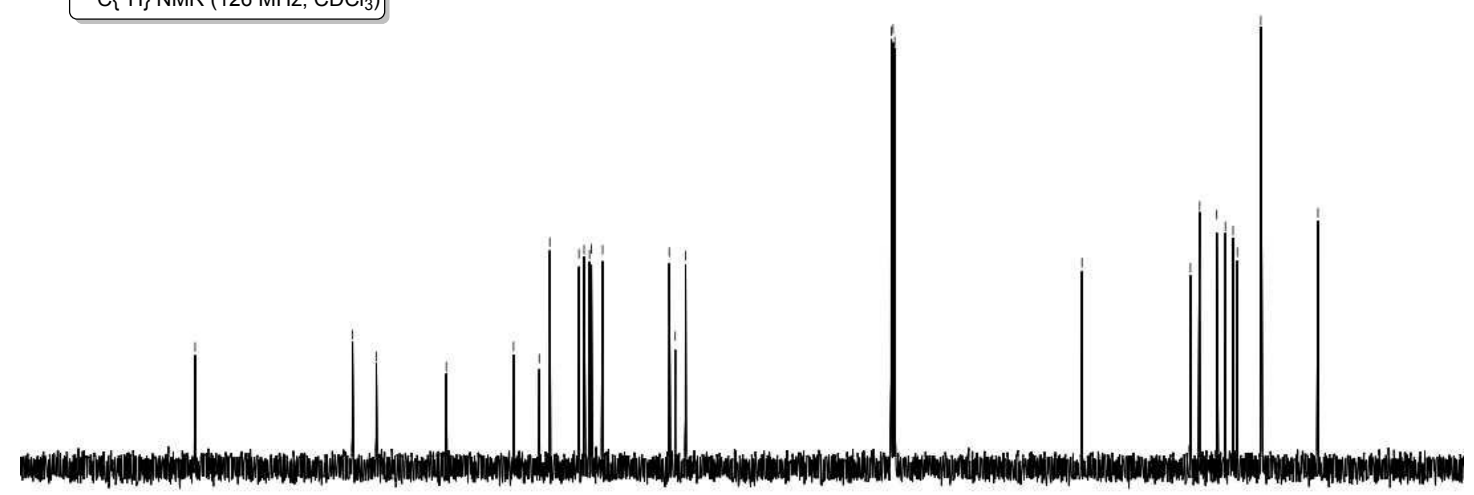



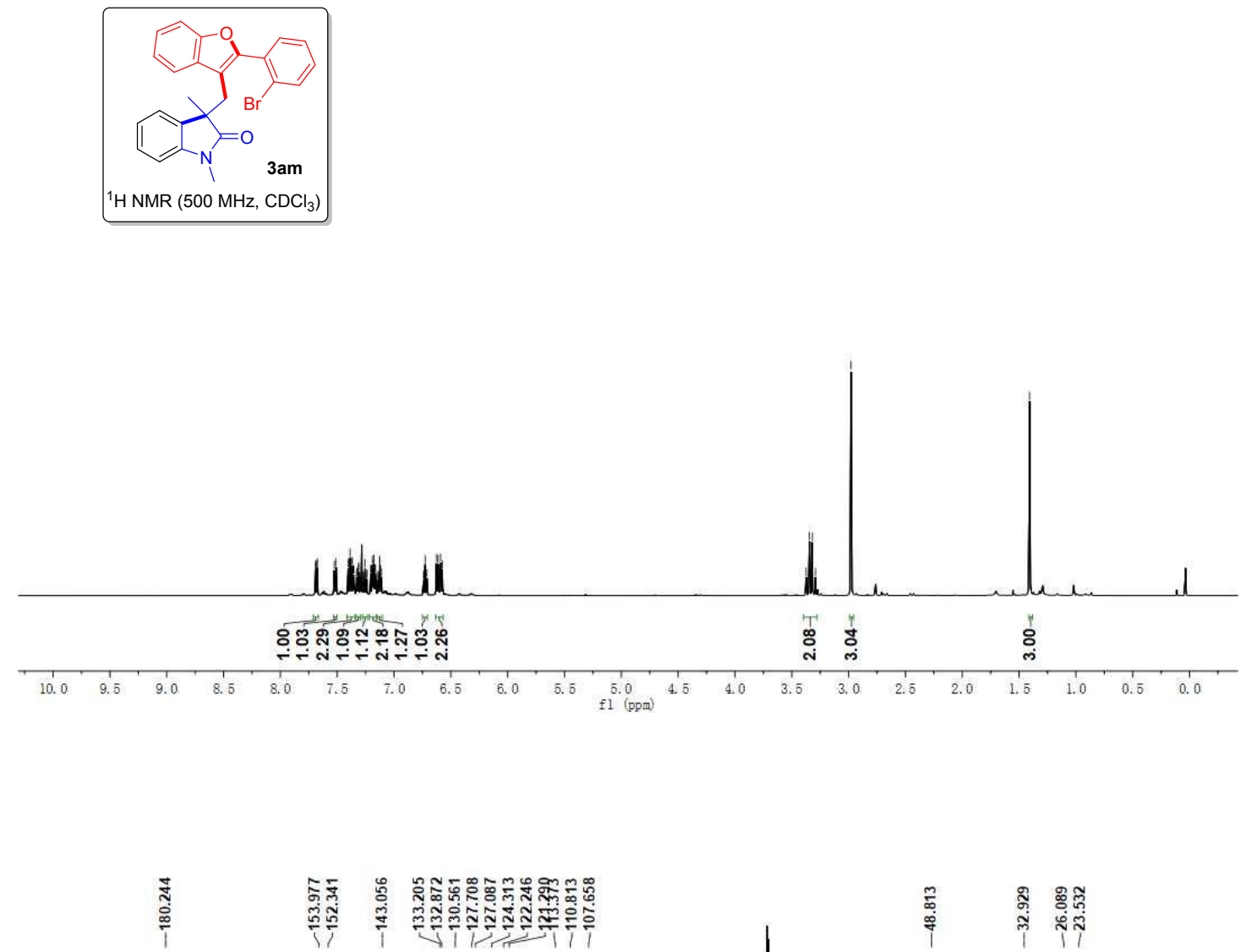

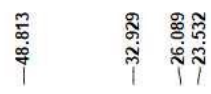
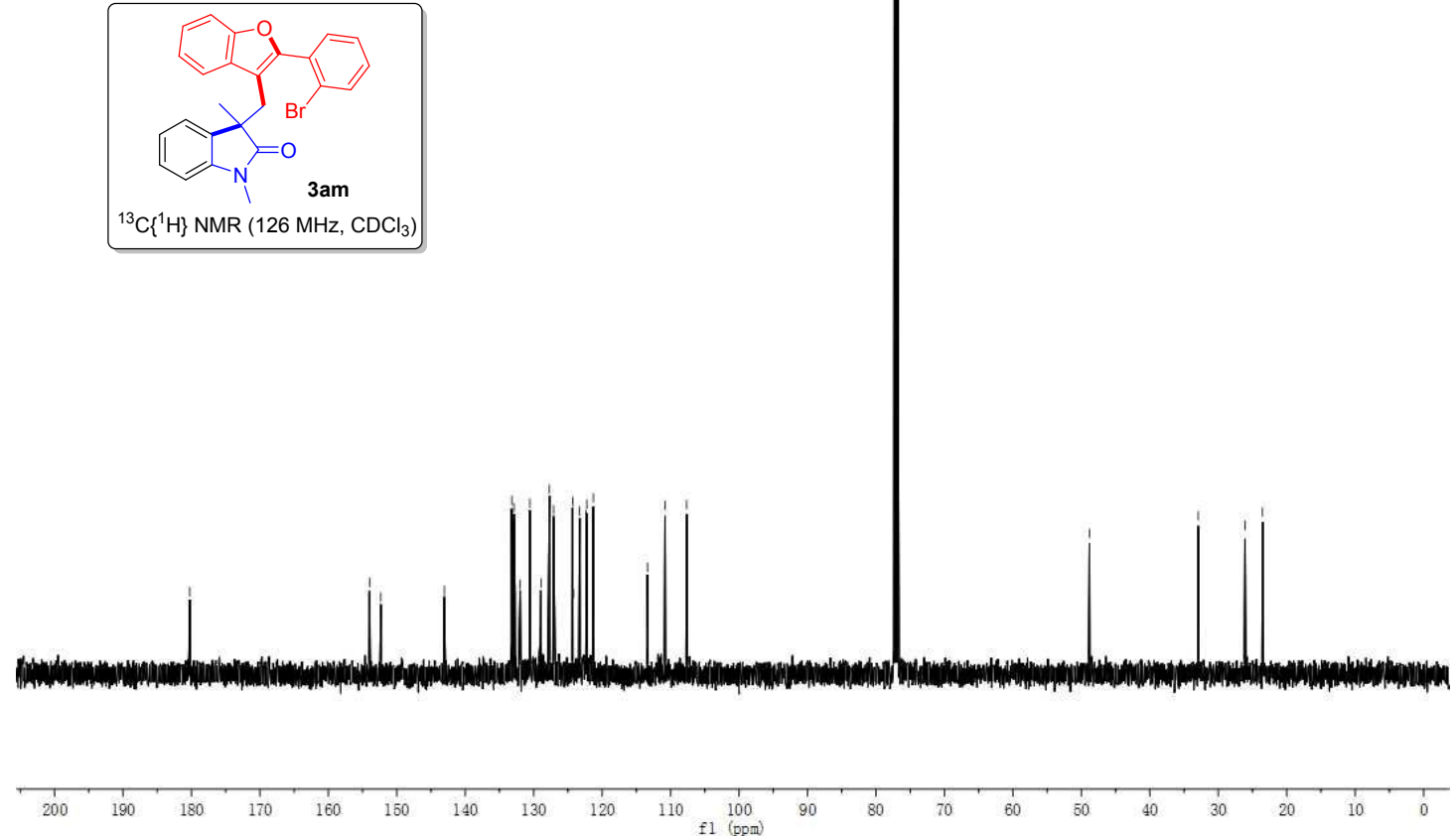

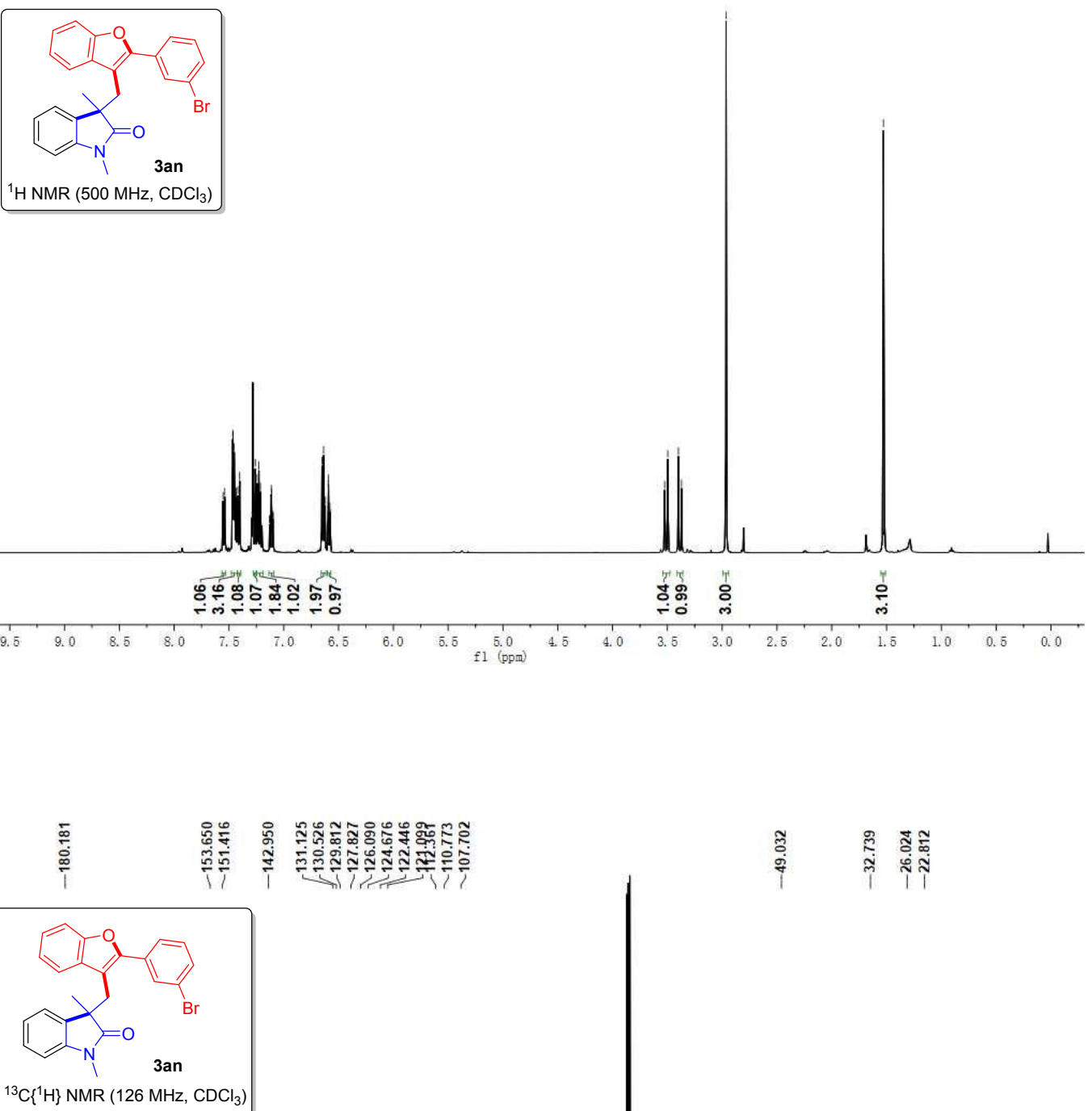

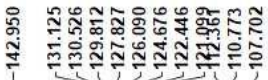

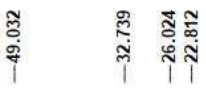

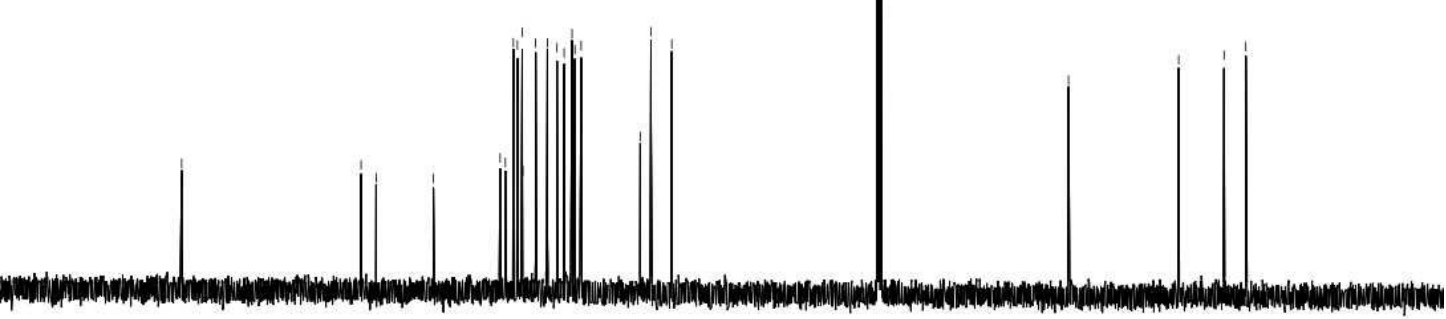




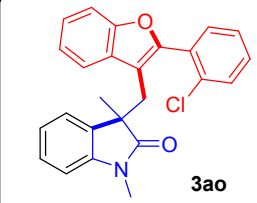

${ }^{1} \mathrm{H}$ NMR $\left(500 \mathrm{MHz}, \mathrm{CDCl}_{3}\right)$

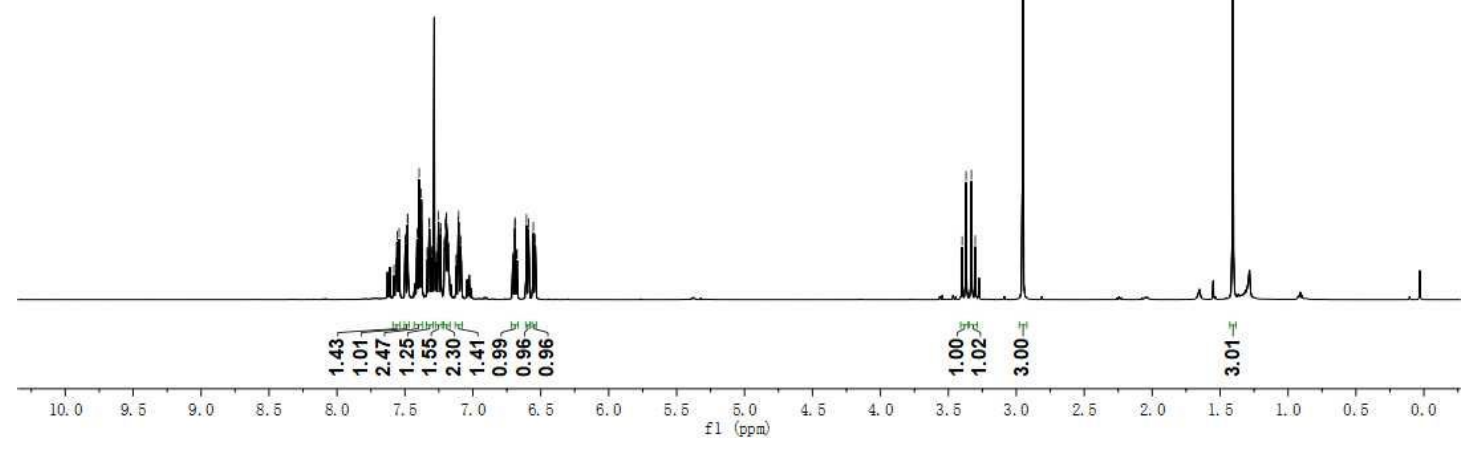

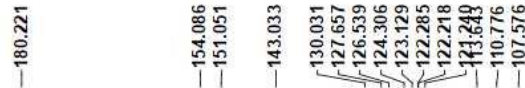

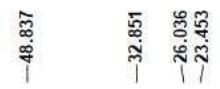

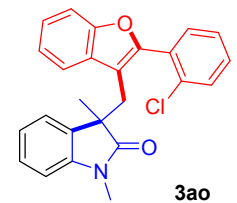

${ }^{13} \mathrm{C}\left\{{ }^{1} \mathrm{H}\right\} \mathrm{NMR}\left(126 \mathrm{MHz}, \mathrm{CDCl}_{3}\right)$
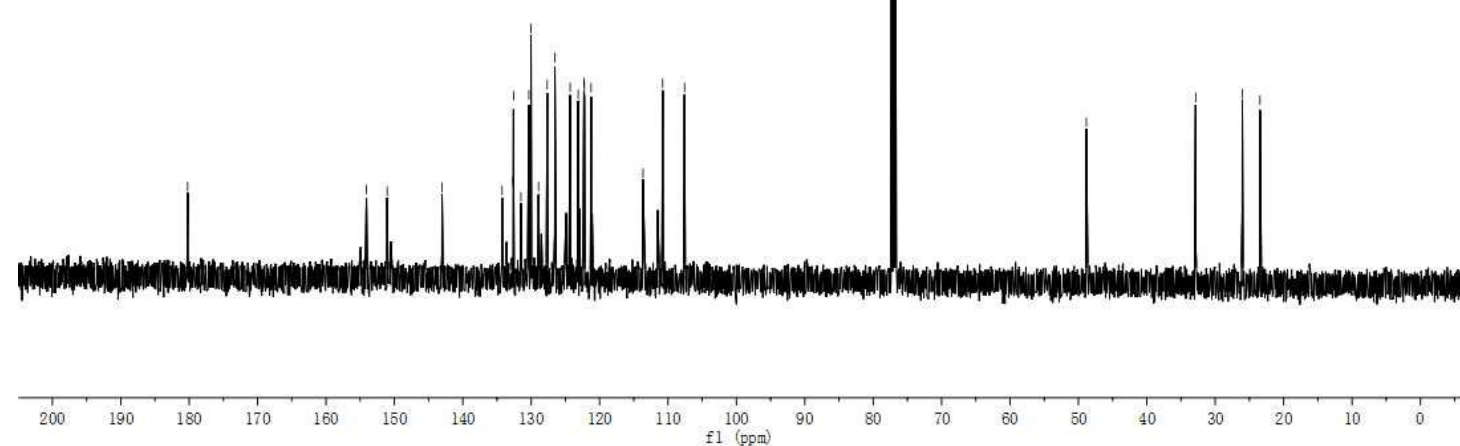


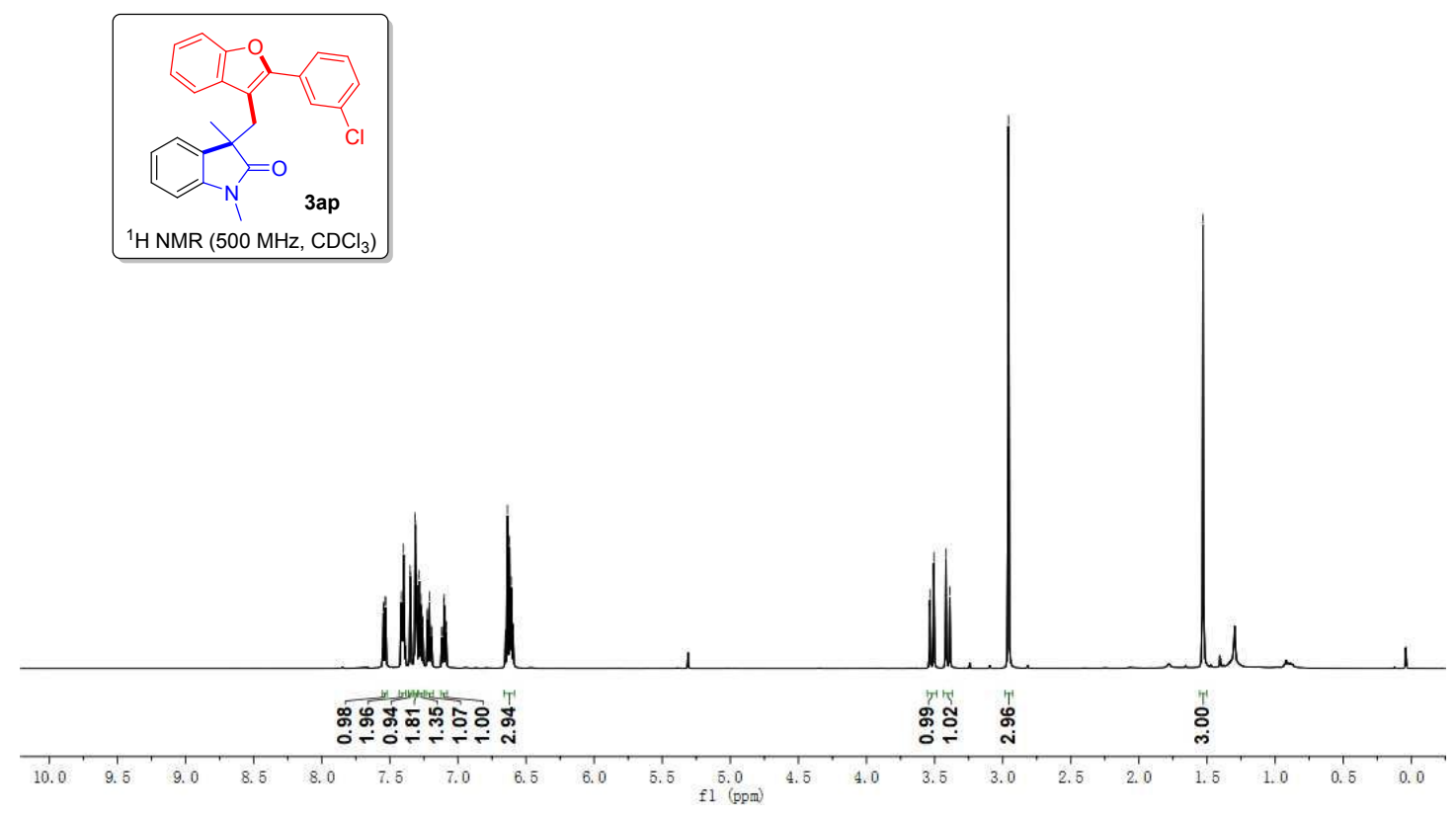

E

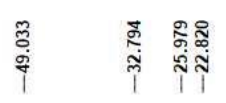

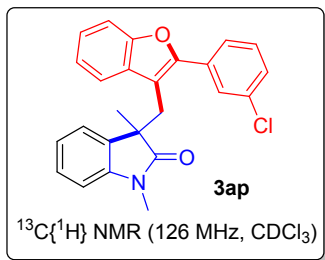

${ }^{13} \mathrm{C}\left\{{ }^{1} \mathrm{H}\right\} \mathrm{NMR}\left(126 \mathrm{MHz}, \mathrm{CDCl}_{3}\right)$
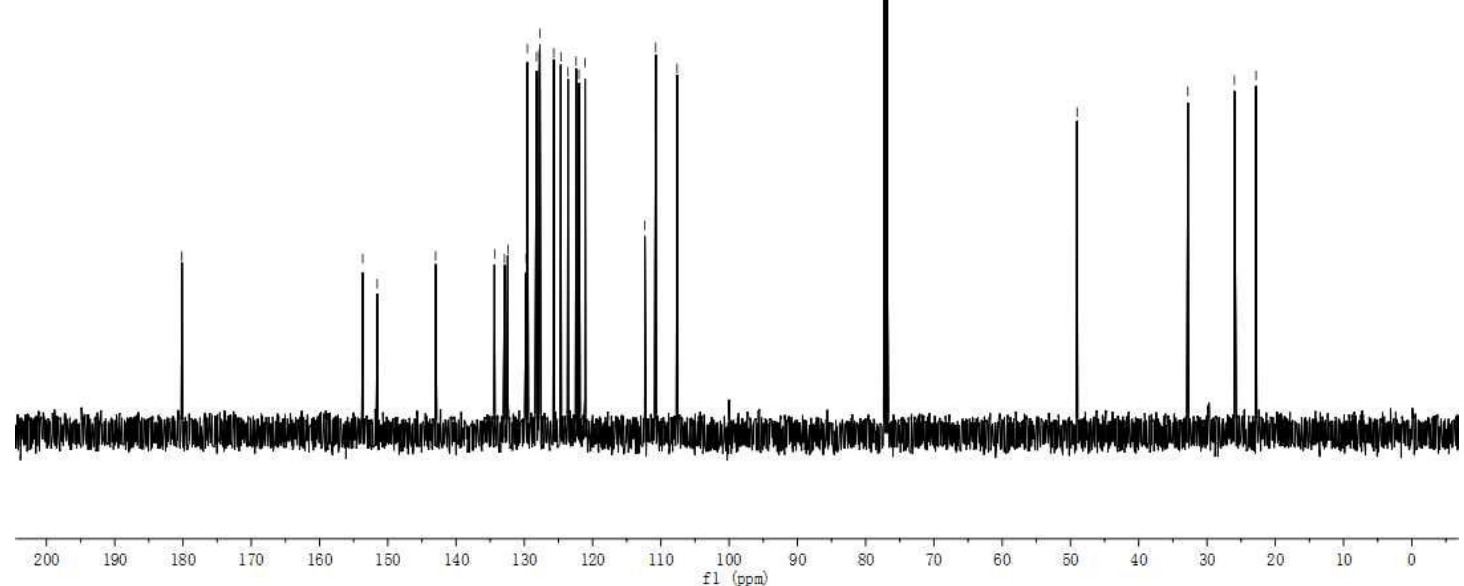

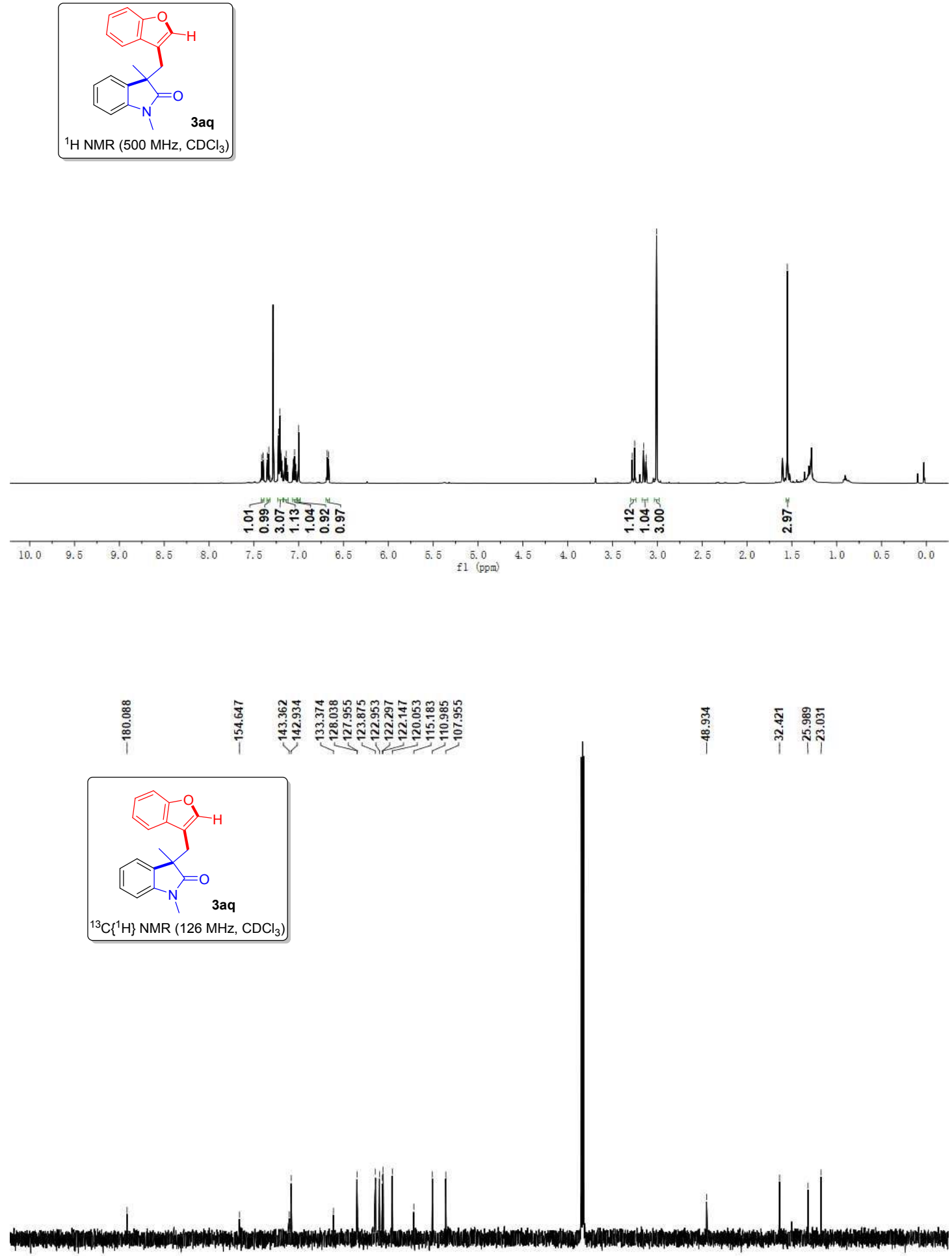

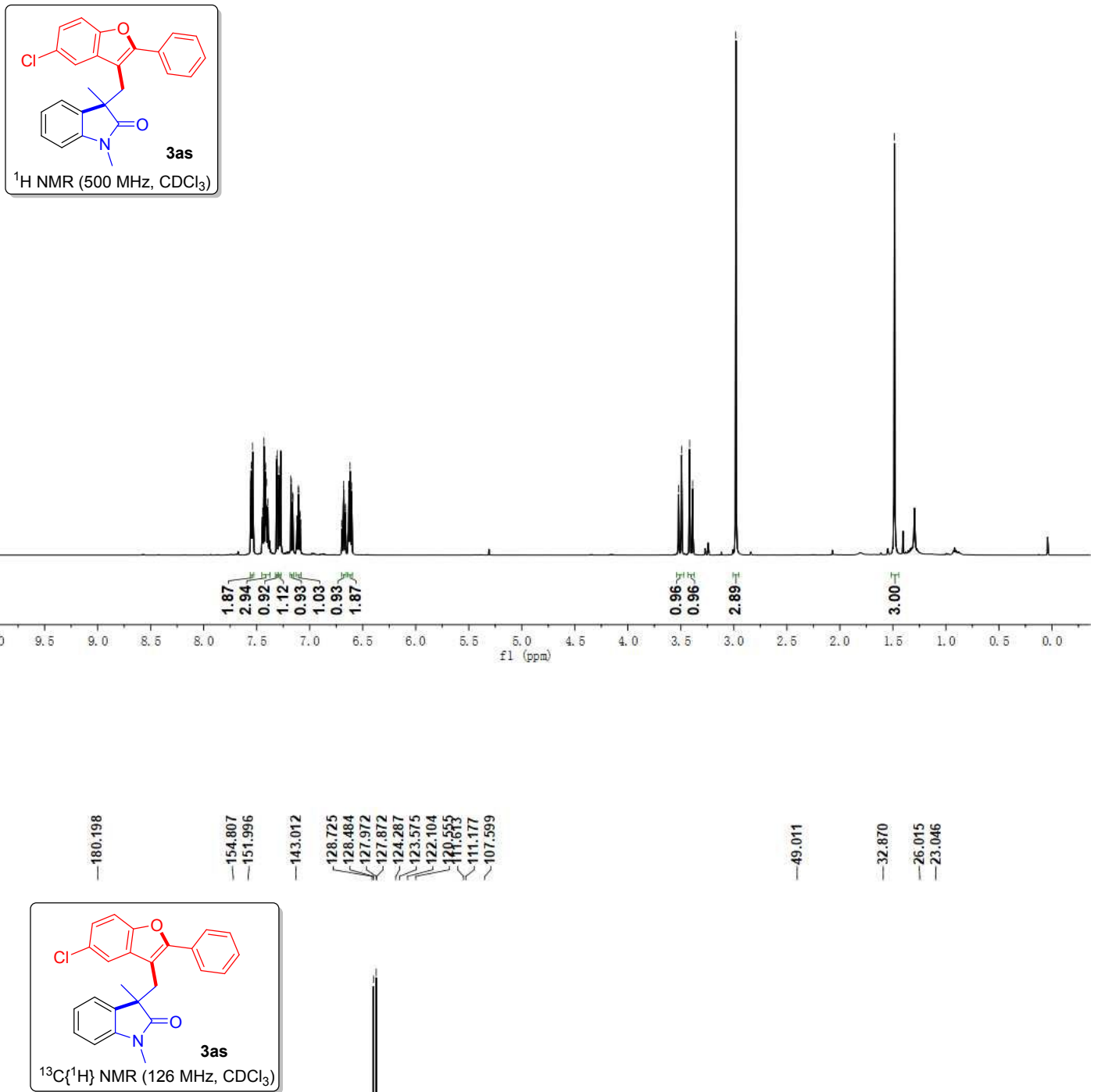

${ }^{13} \mathrm{C}\left\{{ }^{1} \mathrm{H}\right\}$ NMR $\left(126 \mathrm{MHz}, \mathrm{CDCl}_{3}\right)$
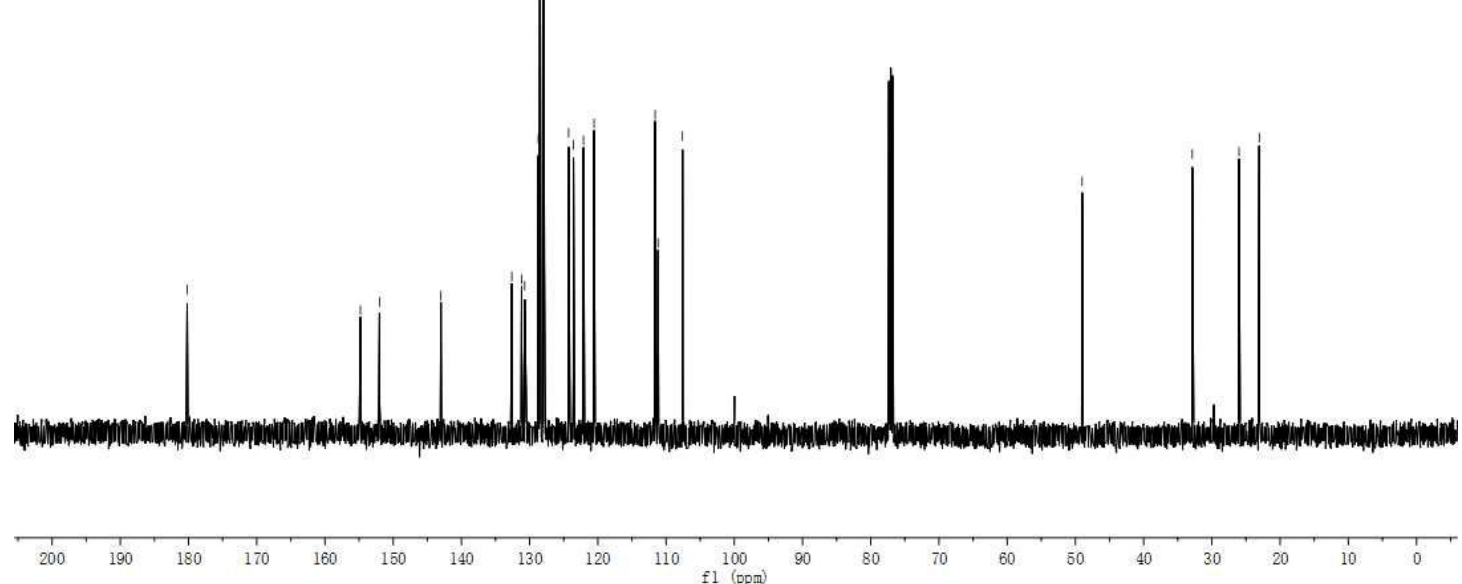

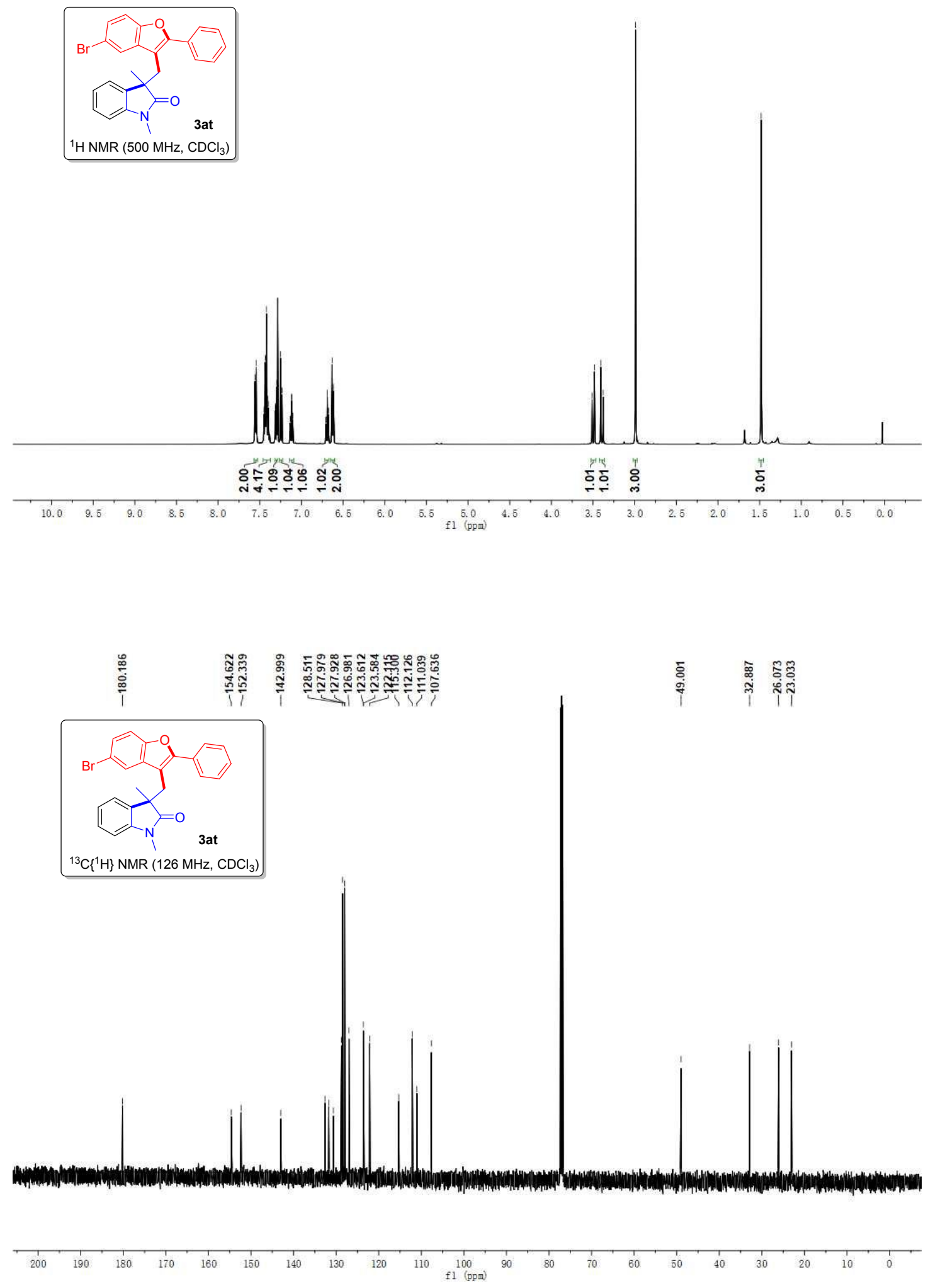

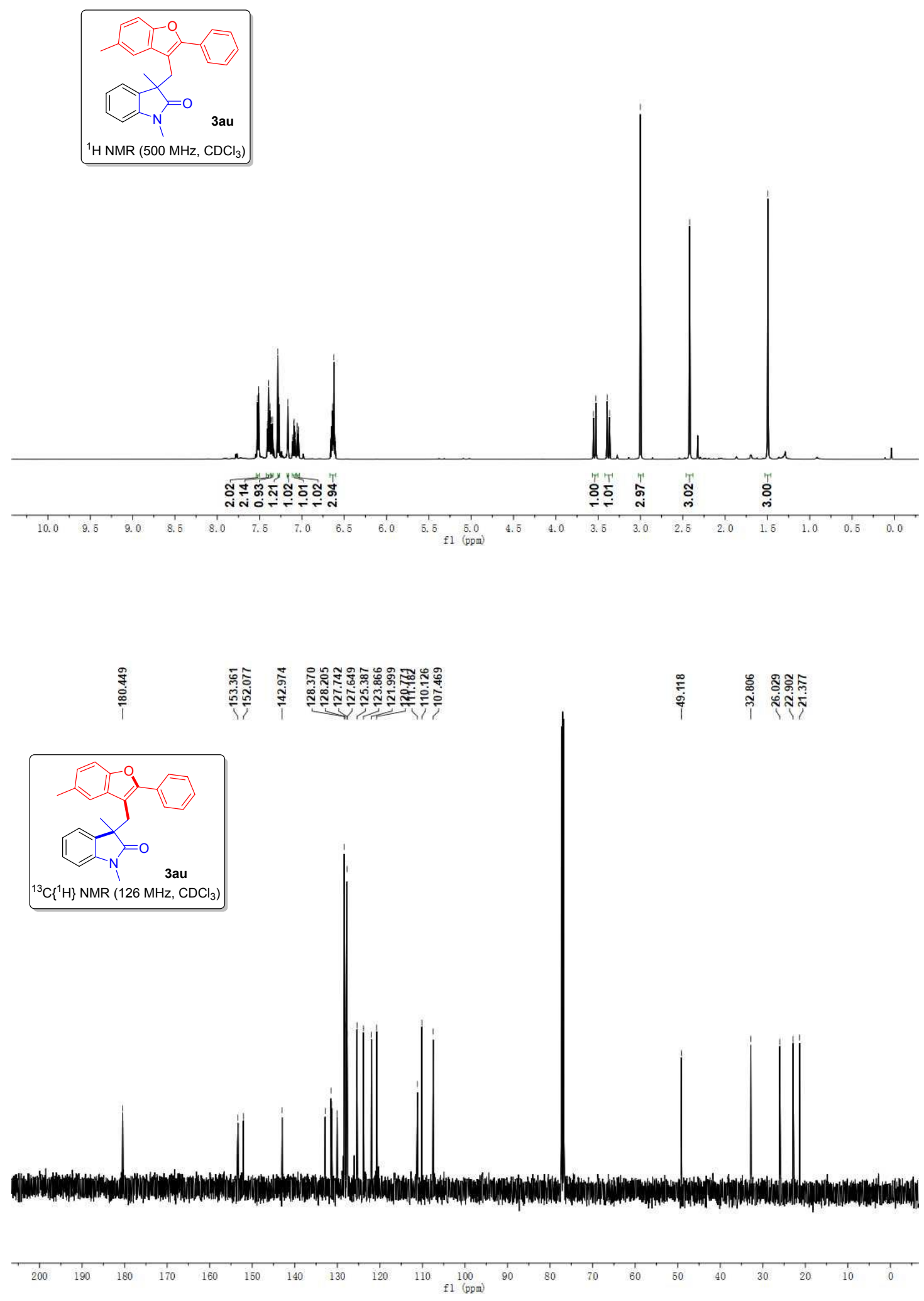

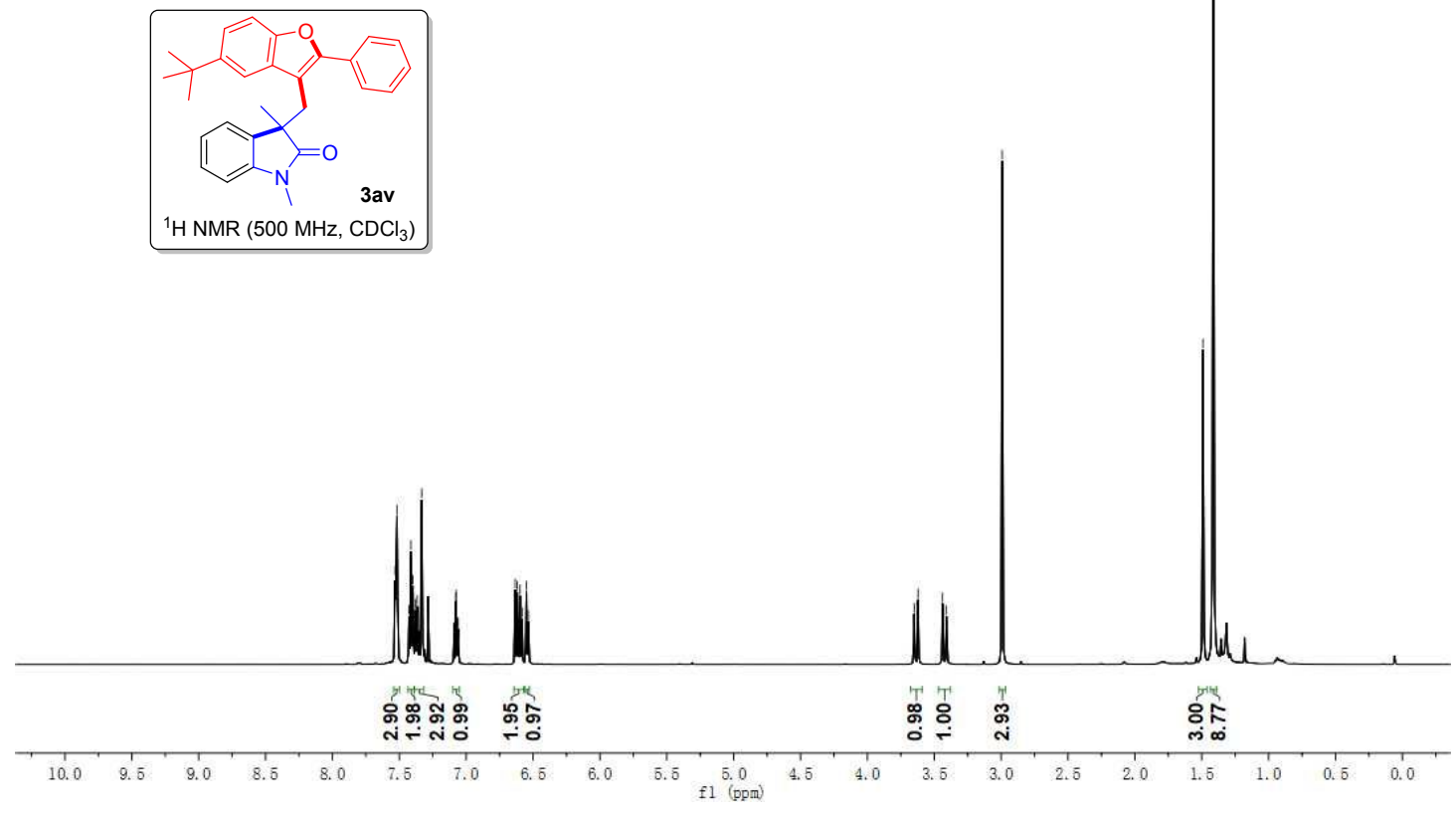

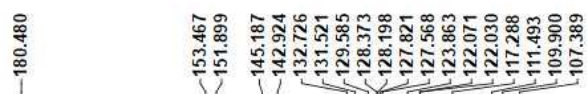

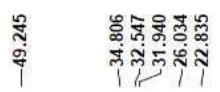

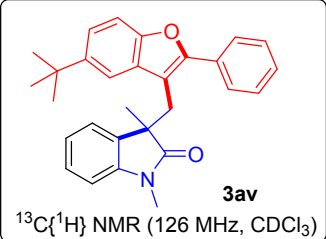

${ }^{13} \mathrm{C}\left\{{ }^{1} \mathrm{H}\right\}$ NMR $\left(126 \mathrm{MHz}, \mathrm{CDCl}_{3}\right)$

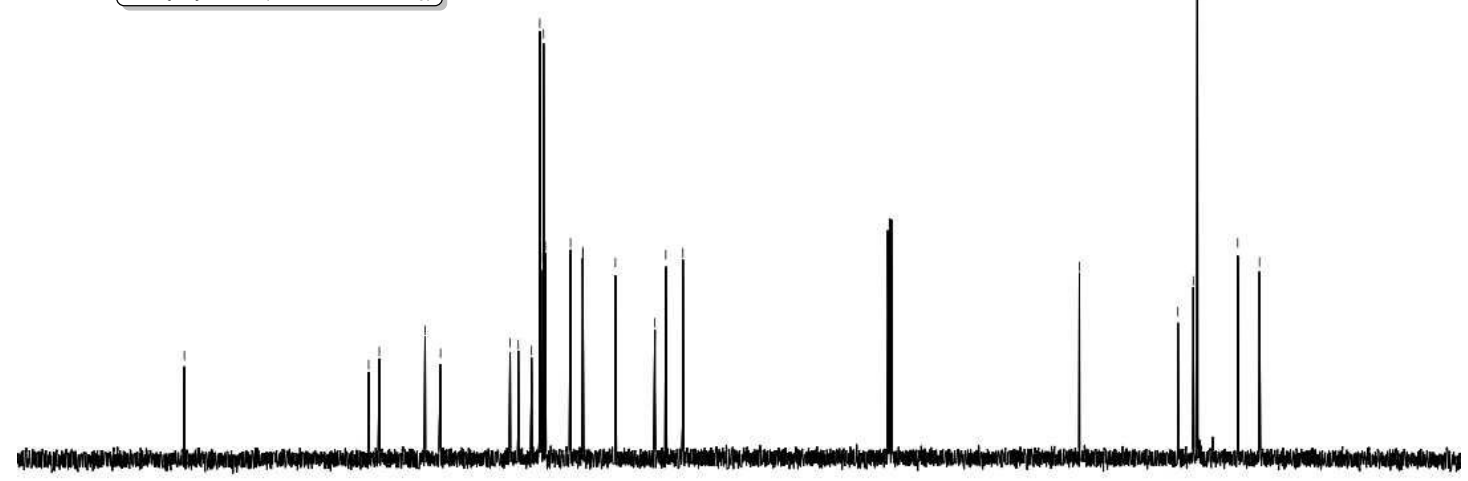

100
$f 1(\mathrm{ppm})$ 

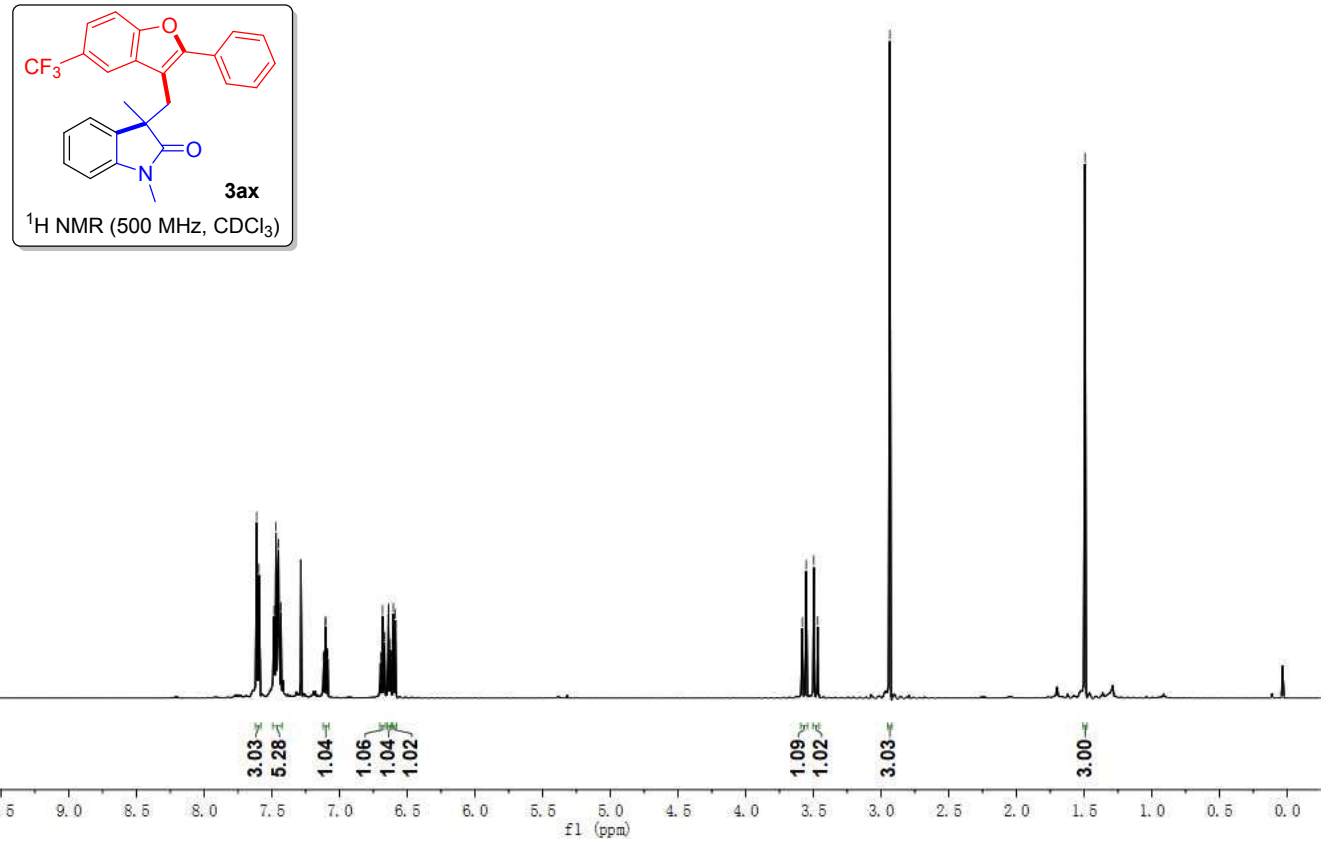

官

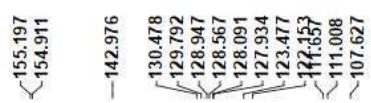

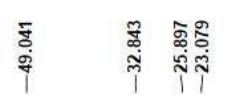

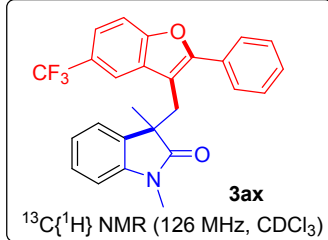

${ }^{13} \mathrm{C}\left\{{ }^{1} \mathrm{H}\right\} \mathrm{NMR}\left(126 \mathrm{MHz}, \mathrm{CDCl}_{3}\right)$
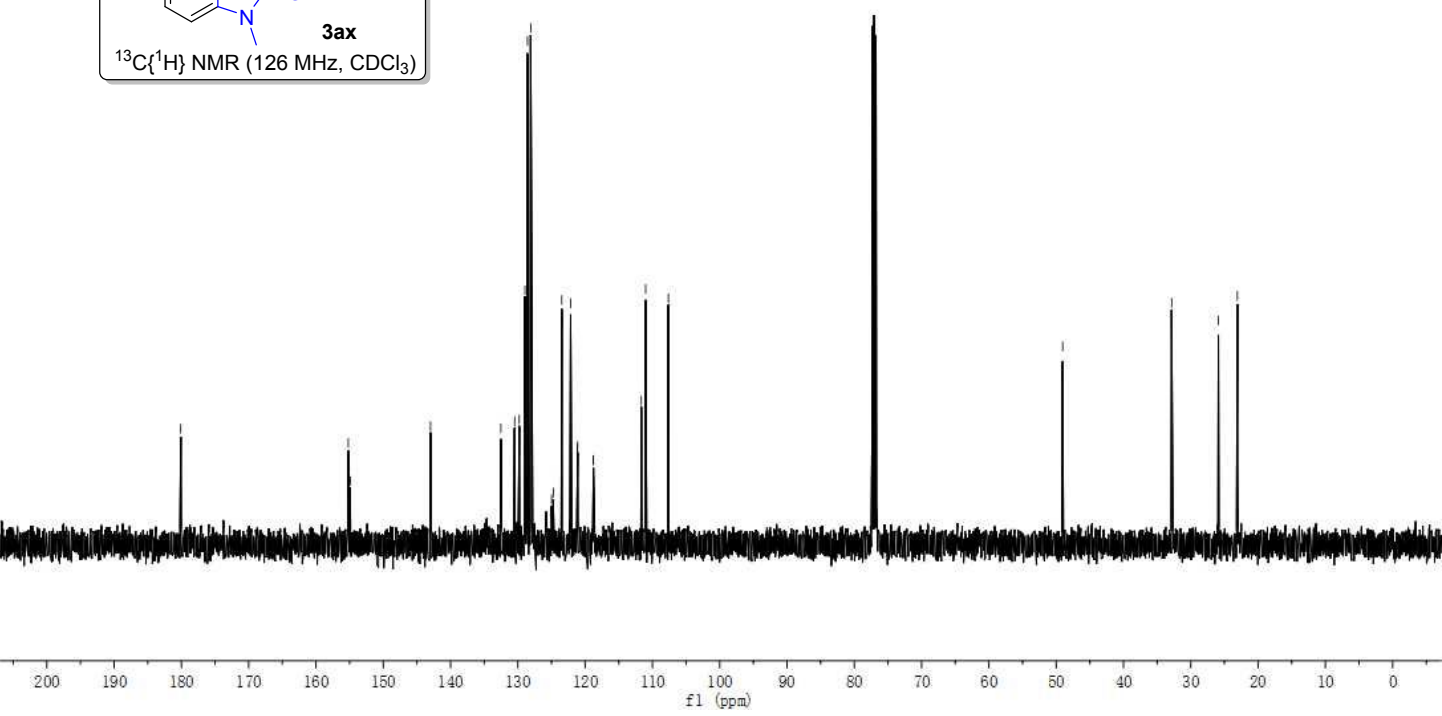


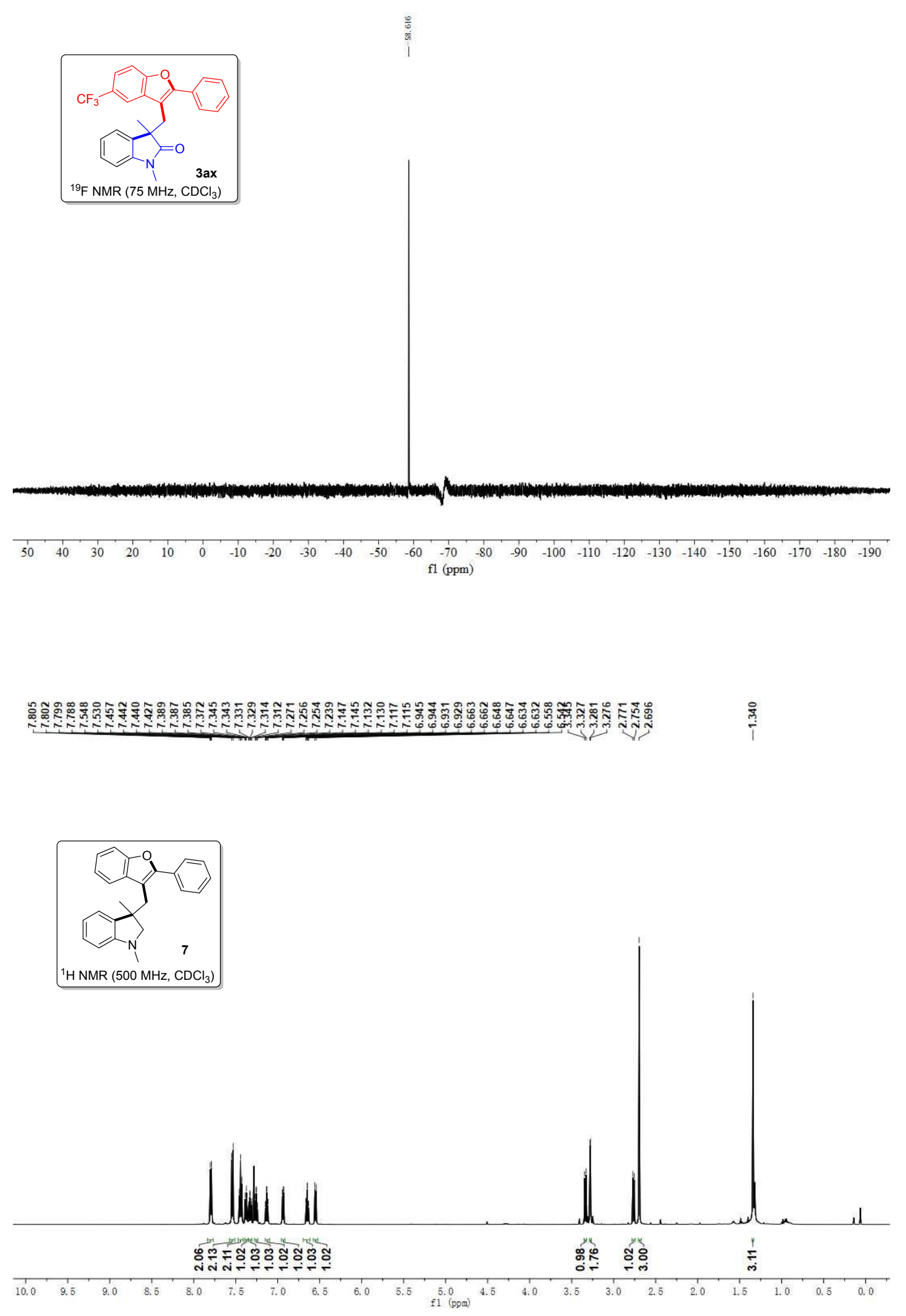



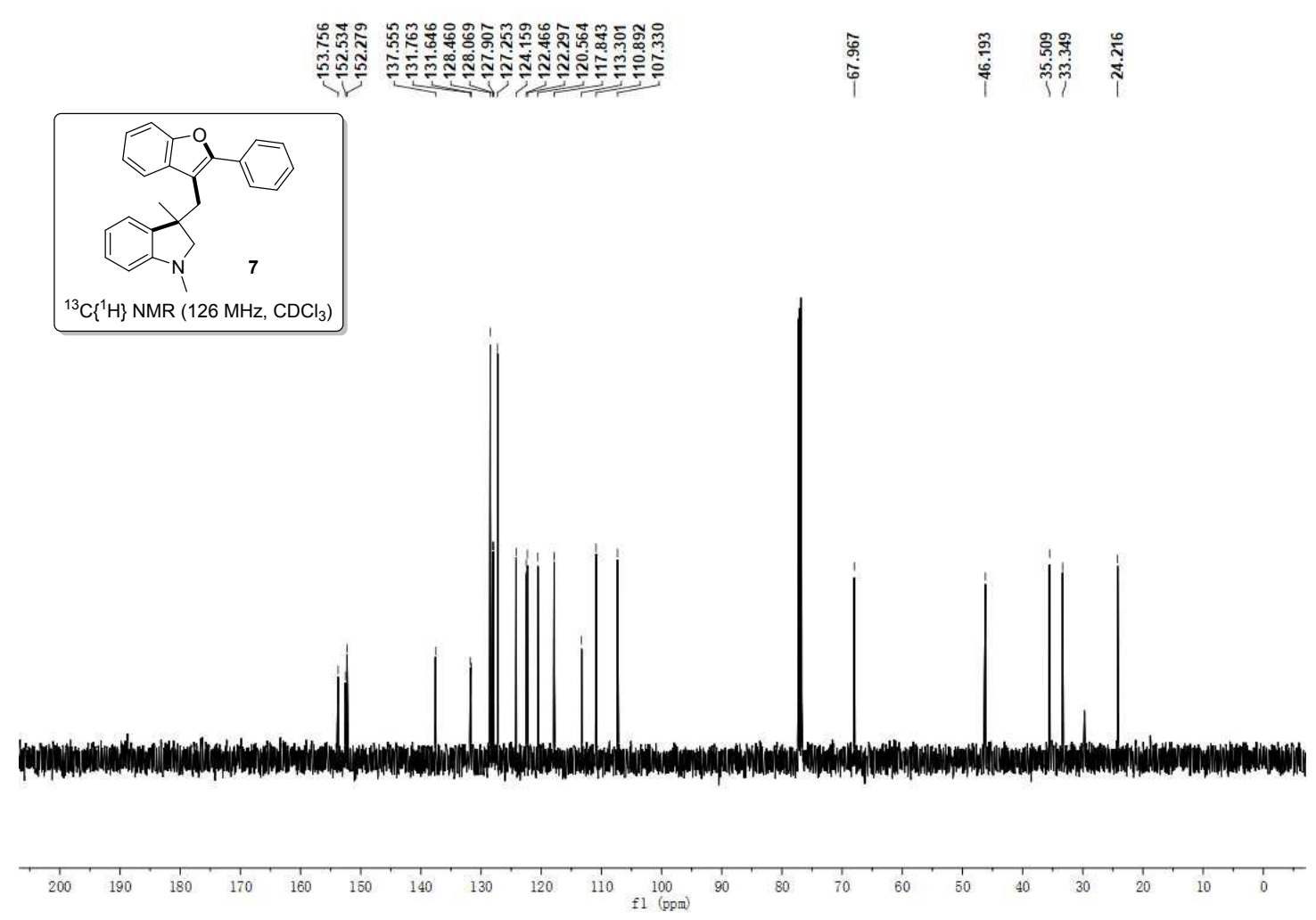